JOINT TRANSPORTATION RESEARCH PROGRAM

FHWA/IN/JTRP-2010/07

Final Report

GEOTECHNICAL DESIGN BASED ON CPT AND PMT

Daehyeon Kim

Youngjin Shin

Nayyar Siddiki

April 2010 


\section{TECHNICAL Summary}

INDOT Research

Technology Transfer and Project Implementation Information

TRB Subject Code:

Publication No.: FHWA/INDOT/JTRP-2010/07, SPR-3106

April 2010

Final Report

\section{MECHANISTIC DESIGN PROCEDURE FOR CRC COMPOSITE PAVEMENT}

\section{INTRODUCTION}

Several in-situ tests such as the Standard Penetration Test (SPT), the Cone Penetration Test (CPT, CPTU and SCPTU), the Flat Dilatometer Test (DMT), the Pressuremeter Test (PMT), and the Vane Shear Test (VST) have been widely used to obtain engineering parameters needed for geotechnical design. These in-situ tests are in some cases combined with laboratory tests (soil index tests, triaxial tests, unconfined compression tests, direct shear tests, and consolidation tests).

In particular, the CPT has recently gained much attention from many Departments of Transportation such as the Louisiana DOT, the Minnesota DOT and the California DOT (Caltrans) as these tests can effectively characterize the soil properties of large volumes of soils, thereby minimizing the need to perform a large number of timeconsuming laboratory tests. Use of in-situ testing offers not only time and cost savings, but also eliminates the concerns regarding sample disturbance resulting from soil sampling and storage.

The Standard Penetration Test (SPT) is still the most widely-used in-situ test. However, the SPT suffers from the following limitations: 1) the dependency of the SPT blow count $\mathrm{N}$ on the operator, 2) the lack of repeatability and accuracy, and 3) the lack of theoretical basis for interpretation. By contrast, the CPT provides fast and continuous soil profiling. Furthermore, the CPT is not operatordependent and has a strong theoretical basis for interpretation.

Due to its obvious advantages over other in-situ tests, the CPT has been increasingly used by many state Departments of
Transportation. This trend reflects the recognition that cost savings can be realized by improved geotechnical design practices with the use of results from more advanced in-situ tests. In order to further improve our geotechnical service, the Indiana Department of Transportation acquired CPT equipment in 2005. A thorough study on state-of-the-art practices regarding the use of these tests should be performed so that INDOT can benefit economically and technically from its investment in this advanced equipment.

There have been remarkable advancements in the interpretation of the CPT test. However, there are still considerable limitations for its use in routine geotechnical design and practice. This is because most empirical relationships between CPT results and soil properties have been developed for textbook soils (clean sand or pure clay). Also, some empirical correlations based on the CPT have been developed without due consideration of important factors such as the rate effect and the proper estimation of undrained shear strength. Therefore, all these factors should be considered in order to perform better and render more accurate geotechnical design.

The primary aim of this research project was to develop an empirical correlation between CPT results and clayey soils in Indiana. Attempts were made to evaluate the cone factor considering the plasticity index by performing the field cone penetration test and laboratory tests for clayey soils in Indiana. The rate effect of CPT was considered and the isotropic consolidated undrained compression test (CIUC) for shear strength assessment was used 


\section{FINDINGS}

The main objective of this research is to develop geotechnical design using CPT results, especially for clayey soils in Indiana. The detailed objectives of this project are: 1) to compile and summarize design methods available in the literature, facilitating the identification of methods that are suitable for soil types using CPT results; 2) to study the mechanical behavior of clayey soils commonly found in Indiana through a series of laboratory tests and in-situ tests; 3 ) to develop an empirically-based correlation between the engineering properties of clayey soils found in Indiana and CPT results.

The major findings of this project were: 1) the cone factor, which is vital to reliable estimation of undrained shear strength from cone resistance, is influenced by the following: soil type, penetration rate during CPT and test methods for undrained shear strength; 2) partial drainage may occur at the standard penetration rate during the CPT for most of the soils that are neither pure clay nor clean sand. It induces partial consolidation in front of the cone and increases cone resistance; 3 ) drainage conditions at a certain penetration rate during the CPT should be examined. If the drainage condition during the CPT is not an undrained one when developing relationships with undrained shear strength, the CPT should be performed again at a rate of penetration that is sufficiently high to ensure undrained penetration; 4) the undrained shear strength can vary with respect to test methods. Therefore, it is crucial to determine the proper evaluation method of undrained shear strength for the specific purpose of the project. In this research, the isotropic consolidated undrained compression test (CIUC) was used; 5) based on the field cone penetration test results, the empirical equation $N_{k}=0.285 I_{p}+7.636$ is suggested.

\section{IMPLEMENTATION}

The current research suggests an empirical equation to determine cone factor with respect to plasticity index for clayey soil in Indiana in order to correlate undrained shear strength and cone resistance using the CPT. It must be noted that the results are dependent on the quantity and quality of data used. Therefore, we recommend that future research should: 1) develop a general correlation by adding more data; 2) establish a CPT-based empirical equation for other soils in Indiana such as cohesionless soils.

\section{CONTACT}

\section{Tommy Nantung}

Research \& Development, INDOT

1205 Montgomery Street

West Lafayette, IN 47906

Phone: (765) 463-1521

Fax: (765) 497-1665

tnantung@indot.in.gov 
Final Report

FHWA/IN/JTRP-2010/07

\title{
GEOTECHNICAL DESIGN BASED ON CPT AND PMT
}

\author{
by
}

Dr. Daehyeon Kim, P.E.

Dr. Youngjin Shin

Nayyar Siddiki, P.E.

Joint Transportation Research Program

Project No. C-36-52X

File No. 06-20-23

SPR- 3106

\begin{abstract}
Conducted in Cooperation with the
Indiana Department of Transportation

and the U.S. Department of Transportation

Federal Highway Administration
\end{abstract}

The content of this report reflects the views of the authors who are responsible for the facts and the accuracy of the data presented herein. The contents do not necessarily reflect the official views or policies of the Indiana Department of Transportation or the Federal Highway Administration at the time of publication. This report does not constitute a standard, speculation or regulation.

School of Civil Engineering

Purdue University

April 2010 


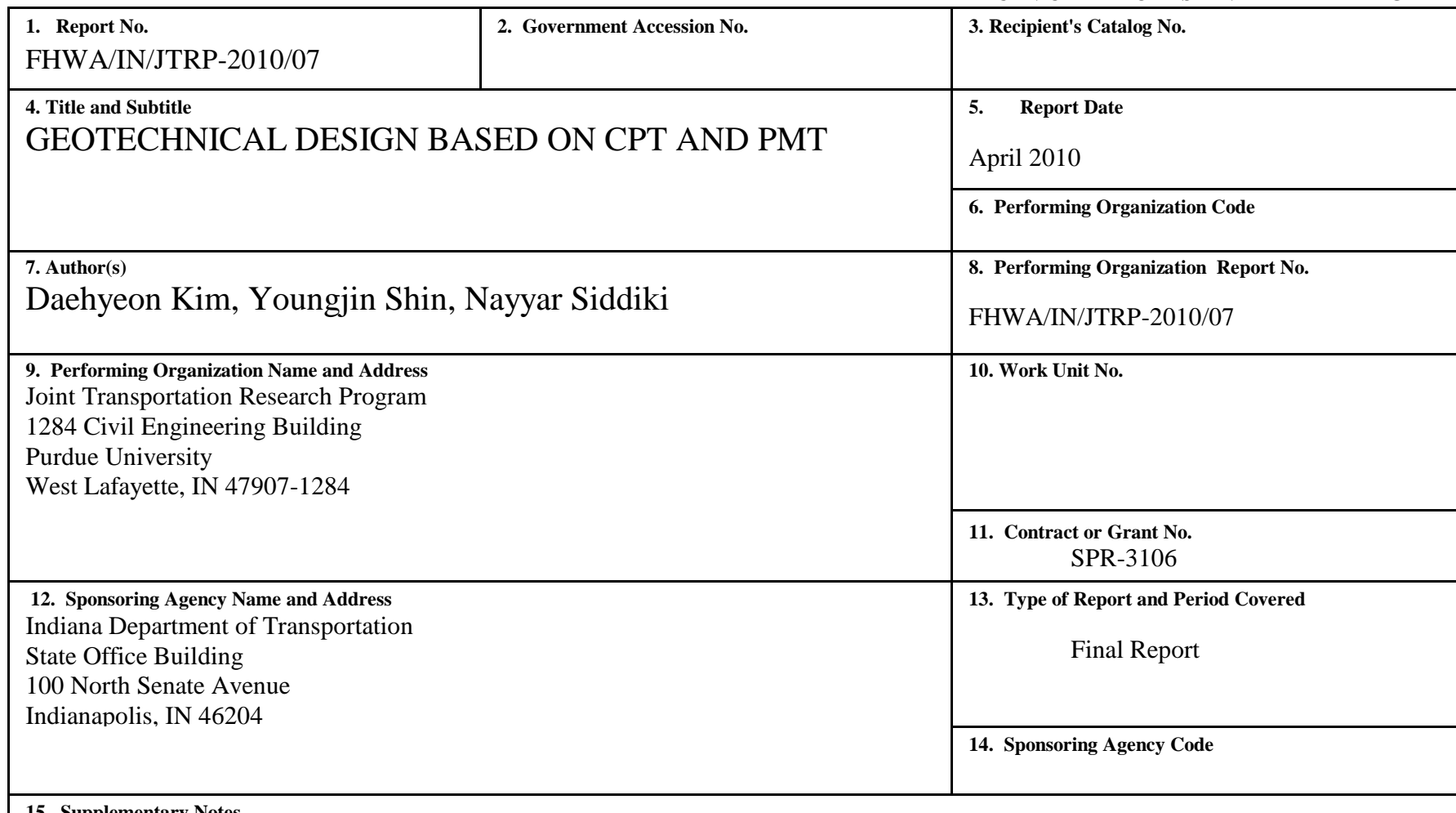

15. Supplementary Notes

Prepared in cooperation with the Indiana Department of Transportation and Federal Highway Administration.

16. Abstract

This research presents the correlation of undrained shear strength based on the cone resistance from the cone penetration test (CPT) for clayey soils in Indiana. It utilized the field cone penetration test program including the CPT, the index test, the one dimensional test and the triaxial test. The cone factor, which is essential to reliable estimation of undrained shear strength from cone resistance, has been evaluated considering the plasticity index of soils. The cone factor is influenced by the penetration rate during the CPT and test methods that are used for obtaining the undrained shear strength. The rate effect of the CPT has been examined to ensure undrained penetration, and the isotropic consolidated undrained compression test (CIUC) for shear strength assessment has been used to effectively reflect in-situ strength. Following the field cone penetration test program, clayey soils from 4 sites in Indiana have been investigated. Based on the results from the test program, the cone factor ranges from 8.0 at $I_{p}=7.9$ to 12.1 at $I_{p}=20.0$ for over-consolidated clays. This result parallels the increasing trend of the cone factor as the plasticity index increases, which was reported by Aas et al. (1986), while Lunne et al. (1976) and Baligh et al. (1980) showed decreasing trends. The equation $N_{k}=0.285 I_{p}+7.636$ is suggested for estimating the cone factor in geotechnical design.

\begin{tabular}{|l|l|l|l|l|}
\hline $\begin{array}{l}\text { 17. Key Words } \\
\text { Undrained shear strength, cone penetration test } \\
\text { (CPT), clayey soils in Indiana, cone factor, rate effect }\end{array}$ & $\begin{array}{l}\text { 18. Distribution Statement } \\
\text { No restrictions. This document is available to the public through the } \\
\text { National Technical Information Service, Springfield, VA 22161 }\end{array}$ \\
\hline $\begin{array}{l}\text { 19. Security Classif. (of this report) } \\
\text { Unclassified }\end{array}$ & $\begin{array}{l}\text { 20. Security Classif. (of this page) } \\
\text { Unclassified }\end{array}$ & $\begin{array}{c}\text { 21. No. of Pages } \\
91\end{array}$ \\
\hline
\end{tabular}




\section{ACKNOWLEDGEMENTS}

The authors deeply appreciate the opportunity to conduct this research under the auspices

of the Joint Transportation Research Program with support from the Indiana Department of Transportation and the Federal Highway Administration. They wish to recognize the active working relationship with the Study Advisory Committee members: Mir Zaheer and Keith Hoernschemeyer of the FHWA Indiana Division. The authors also convey special thanks to Travis Cole for performing CPT tests, to Bobby Daita from H.C. Nutting Company for providing Shelby tube samples, and to Steve Dick for all the help he extended in the laboratory. 


\section{TABLE OF CONTENTS}

Page

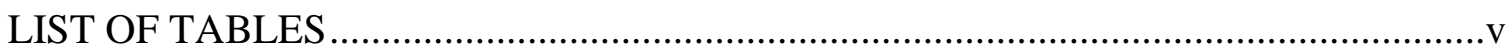

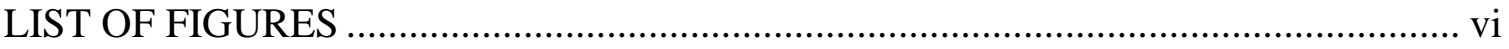

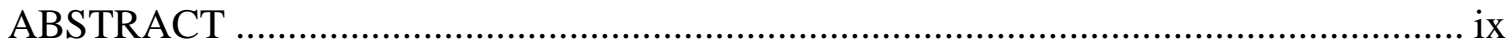

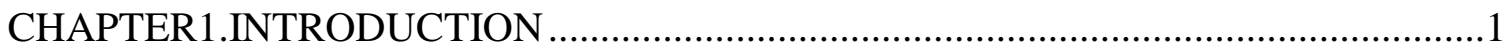

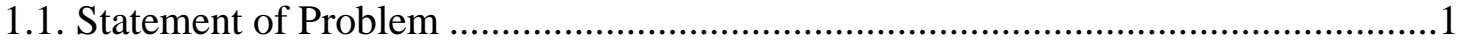

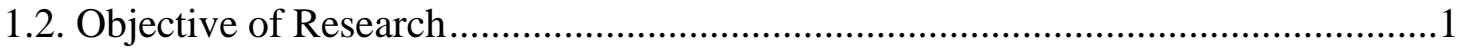

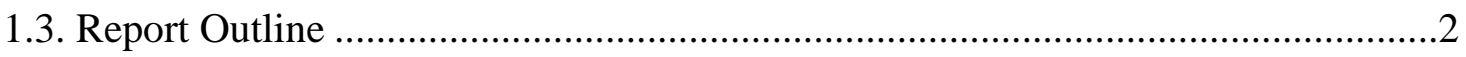

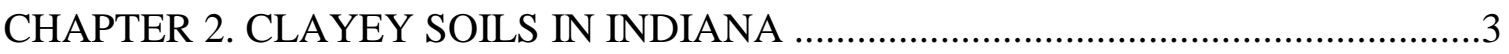

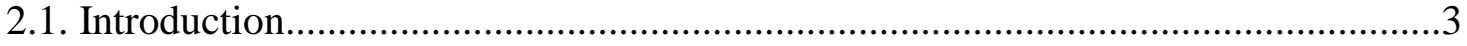

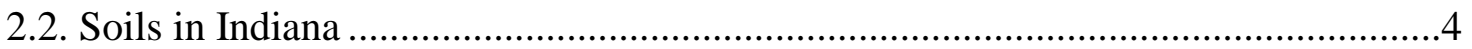

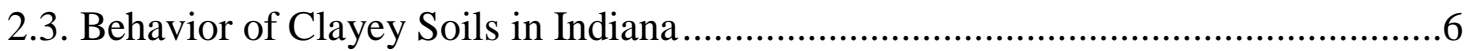

2.3.1. Literature Review on Clay Behavior ........................................................... 7

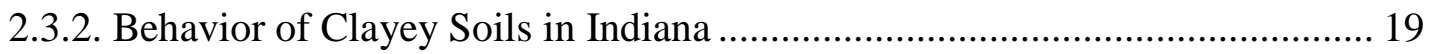

CHAPTER 3. PILE DESIGN BASED ON IN-SITU TEST .......................................25

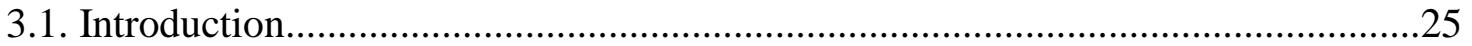

3.2. Direct Estimation of Pile Load Capacity Based on CPT ….................................27

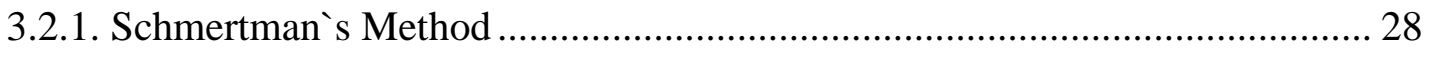

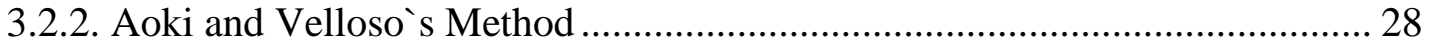

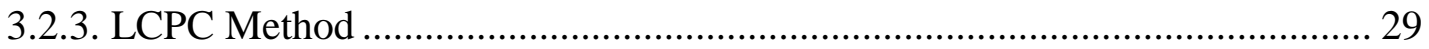

3.3. Indirect Estimation of Pile Load Capacity Based on Soil Property.......................30

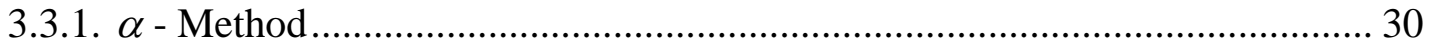


CHAPTER 4. FIELD CONE PENETRATION TEST AND LABORATORY TEST .....32

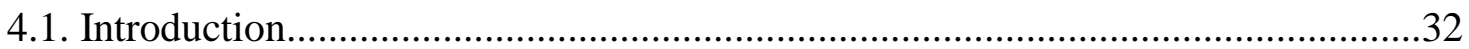

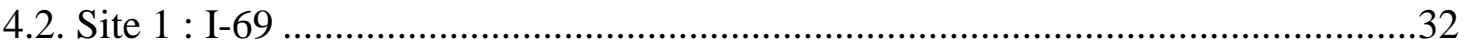

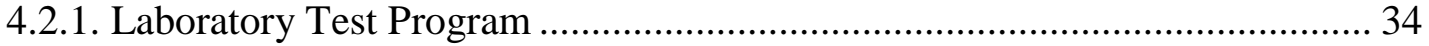

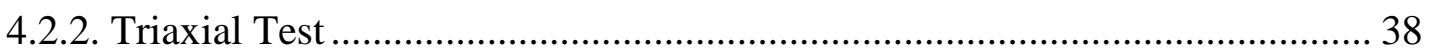

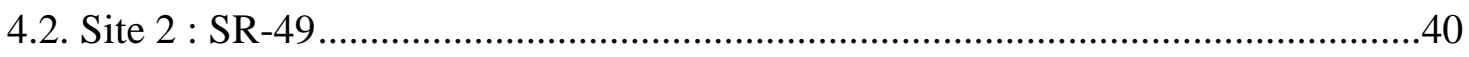

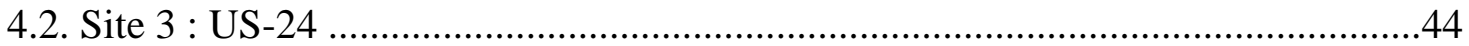

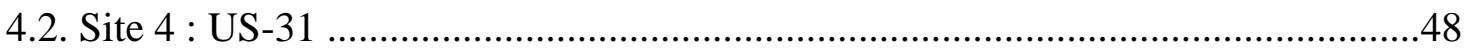

CHAPTER 5. SOIL PROPERTY ESTIMATION BASED ON CPT .............................55

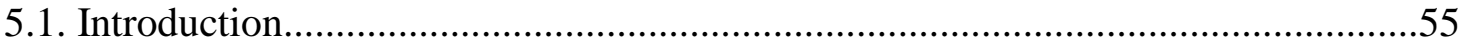

5.2. Correlation between Undrainded Shear Strength and Cone Resistance.................55

5.3. Influence of the Rate of Penetration on CPT ...................................................59

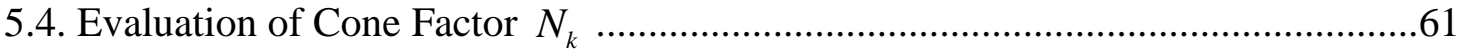

CHAPTER 6. CONCLUSIONS AND RECOMMENDATIONS ................................67

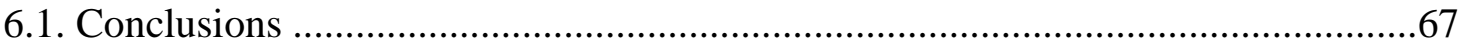

6.2. Recommendations and Future Research Needs..............................................67

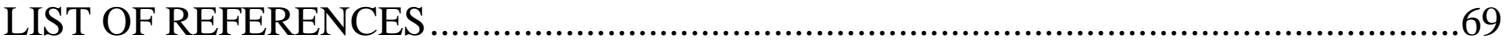




\section{LIST OF TABLES}

Table

Table 1 Summary of laboratory index testing for I-69 ............................................ 35

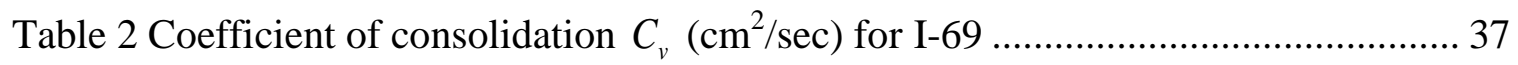

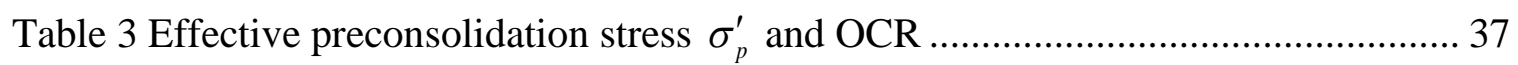

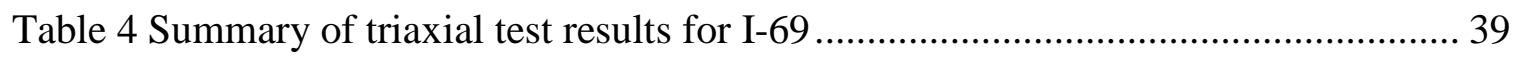

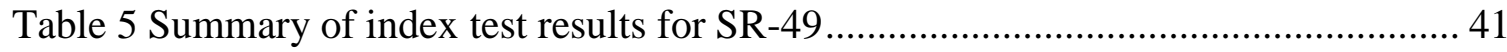

Table 6 Coefficient of consolidation $C_{v}\left(\mathrm{~cm}^{2} / \mathrm{sec}\right)$ for TB-9 for SR-49................41

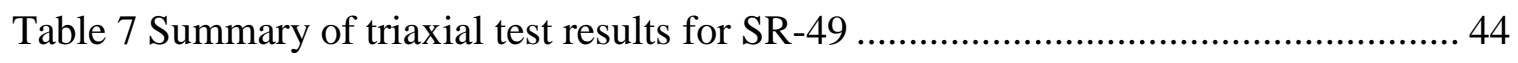

Table 8 Summary of laboratory index testing for US-24I ....................................... 46

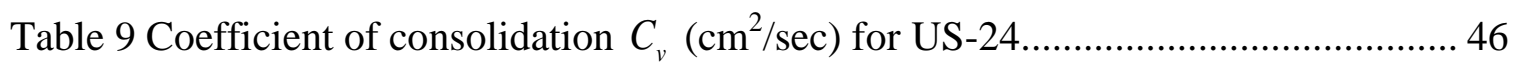

Table 10 Effective preconsolidation stress $\sigma_{p}^{\prime}$ and OCR for US-24........................... 47

Table 11 Summary of triaxial test results for US-24 ............................................ 48

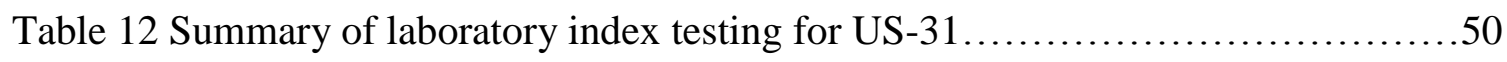

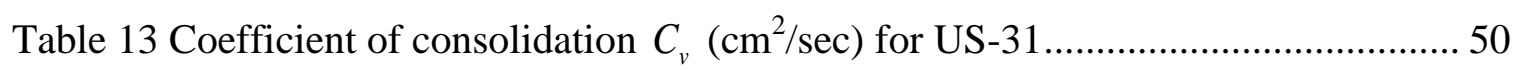

Table 14 Effective preconsolidation stress $\sigma_{p}^{\prime}$ and OCR for US-31 $\ldots \ldots \ldots \ldots \ldots \ldots \ldots . \ldots \ldots$

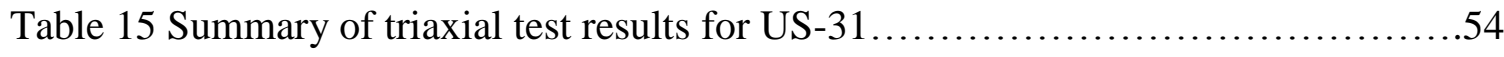

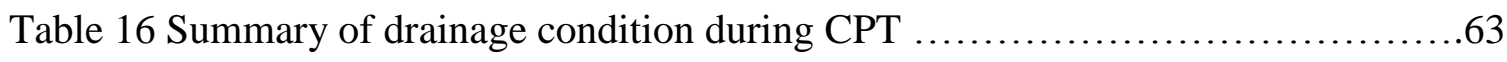

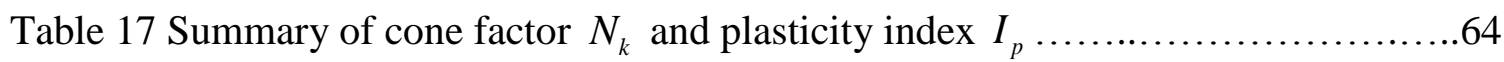




\section{LIST OF FIGURES}

Figure

Page

Figure 1 Major soil formations in the State of Indiana (West, 1995) 5

Figure 2 A consolidated undrained test on a normally consolidated clay sample (Bishop

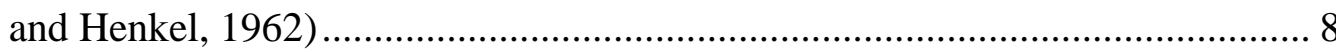

Figure 3 Mohr envelopes for consolidated undrained test on a normally consolidated clay sample (Bishop and Henkel, 1962)

Figure 4 A consolidated undrained test on a heavily over-consolidated clay sample (Bishop and Henkel, 1962) 9

Figure 5 Mohr envelopes for consolidated undrained test on a heavily over-consolidated clay sample (Bishop and Henkel, 1962) 10

Figure 6 The effect of over-consolidation on the value of pore pressure parameter A at the failure: (a) Weald clay (b) London clay (Bishop and Henkel, 1962) ....... 11

Figure 7 Undrained stress-strain behavior of reconstituted Pietrafitta clay (Burland et al, 1996) 13

Figure 8 Undrained stress-strain behavior of reconstituted Corinth marl (Burland et al, 1996).

Figure 9 Behavior of reconstituted Boston blue clay in undrained triaxial compression (Santagata, 1994) 16

Figure 10 One dimensional compression curves for various reconstituted clays (Burland, 1990). 17

Figure 11 Influence of (a) mixing moisture contents; (b) load increment duration on compression curves for reconstituted clays (Leonards and Ramiah, 1959).... 18

Figure 12 Typical one dimensional compression curves for Boston blue clay (Ladd et al., 1999) 19

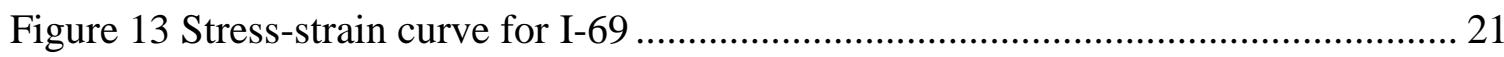

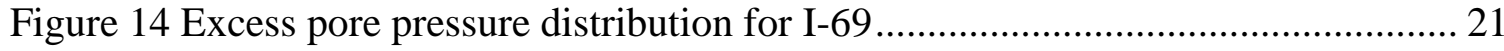




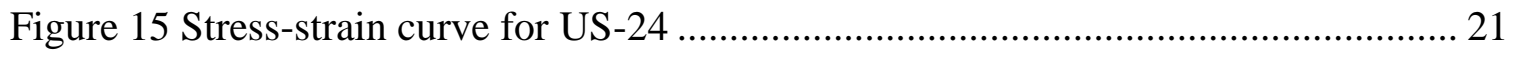

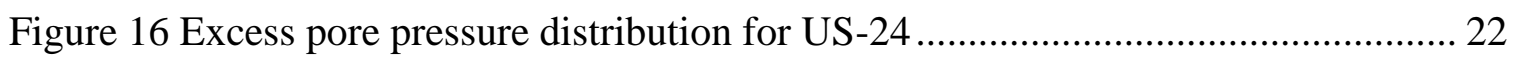

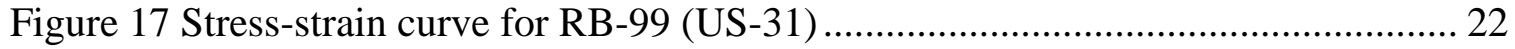

Figure 18 Excess pore pressure distribution for RB-99 (US-31) ................................. 23

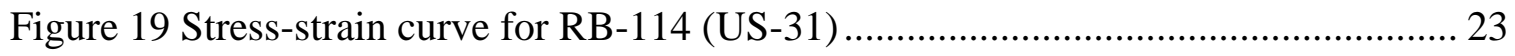

Figure 20 Excess pore pressure distribution for RB-114 (US-31) ............................... 23

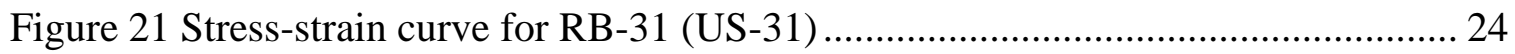

Figure 22 Excess pore pressure distribution for RB-31 (US-31) ................................ 24

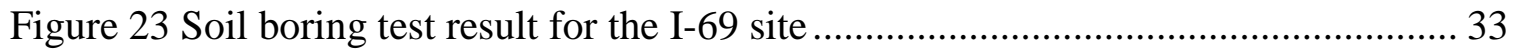

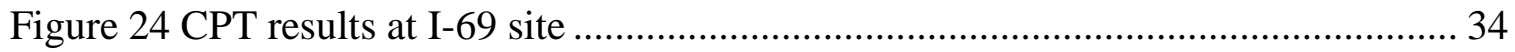

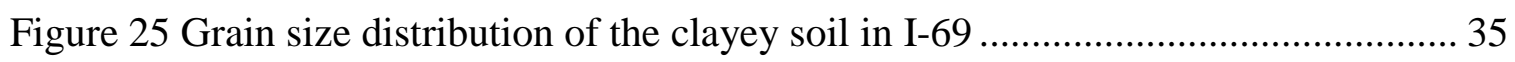

Figure 26 Geocomp automated consolidation testing apparatus .................................. 36

Figure 27 Specimen displacements versus square root of time (48 kPa) for I-69 ........... 37

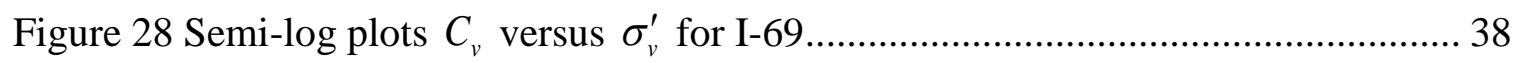

Figure 29 Semi-log plots of settlement versus vertical stress for I-69 …...................... 38

Figure 30 Geocomp automated static triaxial testing apparatus ................................... 39

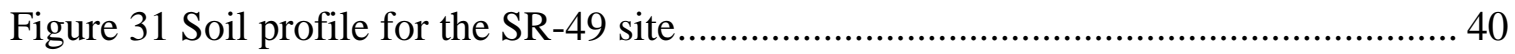

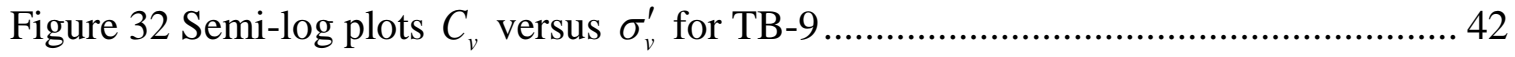

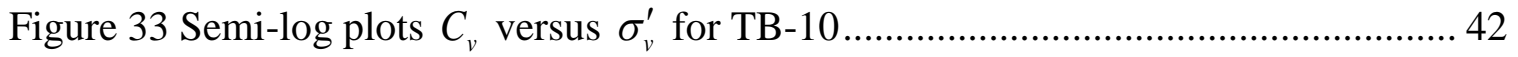

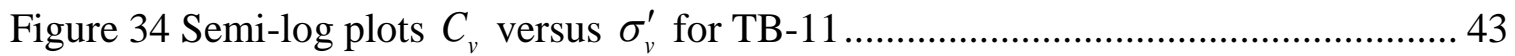

Figure 35 Semi-log plots $C_{v}$ versus $\sigma_{v}^{\prime}$ for TB-14

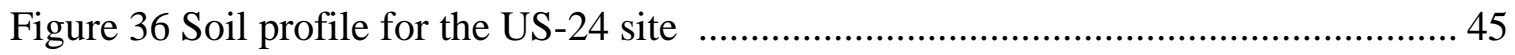

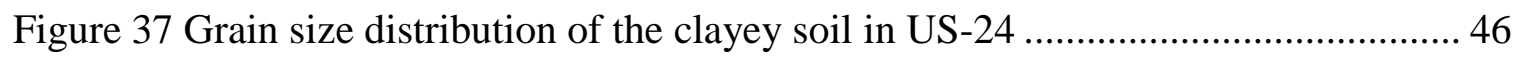

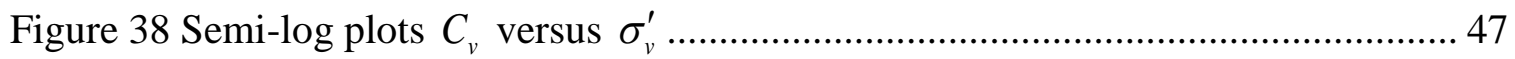

Figure 39 Semi-log plots of settlement versus vertical stress for US-24 ....................... 47

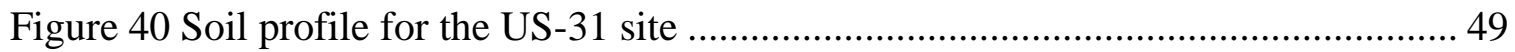

Figure 41 Semi-log plots $C_{v}$ versus $\sigma_{v}^{\prime}$ for RB-99 ............................................. 51 
Figure

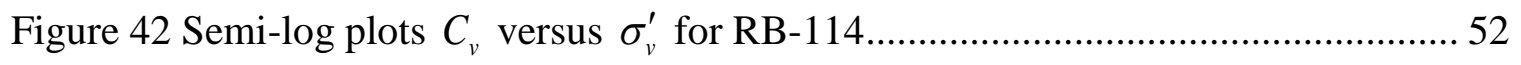

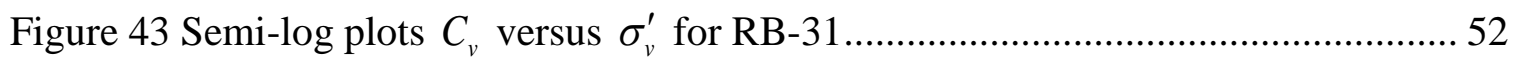

Figure 44 Semi-log plots of settlement versus vertical stress for RB-99 …................... 53

Figure 45 Semi-log plots of settlement versus vertical stress for RB-114 ..................... 53

Figure 46 Semi-log plots of settlement versus vertical stress for RB-31 ...................... 54

Figure 47 The cone factor $N_{k}$ values for clayey soils in England (Nash and Duffin, 1982)

Figure 48 The cone factor $N_{k}$ values for clayey soils in England (O`riordan et al., 1982)

Figure 49 Correlations between cone factor $N_{k}$ and plasticity index (Lunne et al., 1976)

Figure 50 Correlations between cone factor $N_{k}$ and plasticity index $I_{p}$ (Baligh et al.,1980)

Figure 51 Correlations between cone factor $N_{k}$ and plasticity index (Aas et al., 1986) .. 59

Figure 52 Effect of penetration rate on normalized cone resistance and pore pressure

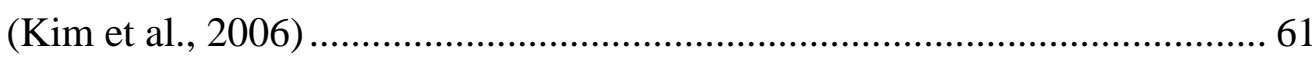

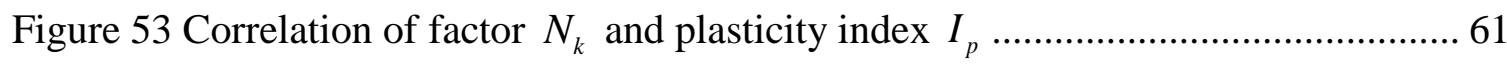




\begin{abstract}
Kim, Daehyeon, Shin, Youngjin, and Siddiki, Nayyar. "Geotechnical Design Based on CPT and PMT" Final Report FHWA/IN/JTRP-2009/XX, SPR 3106, Joint Transportation Research Program, Purdue University, September 2008

Keywords: undrained shear strength, cone penetration test (CPT), clayey soils in Indiana, cone factor, rate effect

This research presents the correlation of undrained shear strength based on the cone resistance from the cone penetration test (CPT) for clayey soils in Indiana. It utilized the field cone penetration test program including the CPT, the index test, the one dimensional test and the triaxial test. The cone factor, which is essential to reliable estimation of undrained shear strength from cone resistance, has been evaluated considering the plasticity index of soils. The cone factor is influenced by the penetration rate during the $\mathrm{CPT}$ and test methods that are used for obtaining the undrained shear strength. The rate effect of the CPT has been examined to ensure undrained penetration, and the isotropic consolidated undrained compression test (CIUC) for shear strength assessment has been used to effectively reflect in-situ strength. Following the field cone penetration test program, clayey soils from 4 sites in Indiana have been investigated. Based on the results from the test program, the cone factor ranges from 8.0 at $I_{p}=7.9$ to 12.1 at $I_{p}=20.0$ for over-consolidated (OC) clays. This result parallels the increasing trend of the cone factor as the plasticity index increases, which was reported by Aas et al. (1986), while Lunne et al. (1976) and Baligh et al. (1980) showed decreasing trends. The equation $N_{k}=0.285 I_{p}+7.636$ is suggested for estimating the cone factor in geotechnical design.
\end{abstract}




\section{CHAPTER1 INTRODUCTION}

\subsection{Statement of Problem}

Currently, the cone penetration test (CPT) is considered one of the most useful in-situ tests and is widely used in onshore and offshore soil investigations. The CPT measures the cone resistance, the sleeve friction resistance, and the pore pressure. These measurements can be effectively used for the following applications: 1) to classify soil identification, 2) to directly estimate pile capacity from the CPT and 3) to evaluate soil properties through an appropriate correlation, especially the undrained shear strength. Thus, the CPT can be used for a wide range of geotechnical engineering applications.

There have been remarkable advancements in the interpretation of the CPT test. However, there are still considerable limitations for its use in routine geotechnical design and practice. This is because most empirical relationships between the CPT results and soil properties have been developed for textbook soils (clean sand or pure clay). Also, some empirical correlations based on CPT have been developed without consideration of important factors such as the rate effect and the proper estimation of undrained shear strength. It is necessary to take all these factors into consideration in order to obtain more accurate geotechnical design.

\subsection{Objective of Research}

The main objective of this research is to develop geotechnical design using CPT results, especially for clayey soils in Indiana. The detailed objectives of this project are:

1) To compile and summarize design methods available in the literature for CPT to identify methods that are suitable for soil types;

2) To study the mechanical behavior of clayey soils commonly found in Indiana through a series of laboratory tests and in-situ tests;

3) To develop an empirically-based correlation between the engineering properties of clayey soils found in Indiana and CPT results. 
In order to accomplish these goals, we performed the field cone penetration test program including the $\mathrm{CPT}$, the index test, the one dimensional test and the triaxial test. In accordance with the test results, we suggest a rational correlation between undrained shear strength and cone resistance for clayey soil in Indiana to enable better and more exact geotechnical design. Clayey soils from 4 sites have been investigated considering the following: the rate effect of the CPT and the use of the isotropic consolidated undrained compression test (CIUC) for shear strength assessment.

\subsection{Report Outline}

The report is organized into six chapters:

Chapter 1 provides an introduction.

Chapter 2 presents a comprehensive literature review of non-textbook soil, soils in Indiana, and the behavior of clay. The behavior of clayey soils in Indiana has been investigated through laboratory tests.

Chapter 3 reviews pile design method based on cone penetration tests (CPT), including direct and indirect estimation.

Chapter 4 describes the field cone penetration program performed for clayey soils in Indiana. Techniques for tests and test procedures are described. The test results are also summarized.

Chapter 5 deals with correlations between undrained shear strength and cone resistance and discusses the influence of the rate effect during the CPT. The cone factor considering plasticity index for clayey soils in Indiana is suggested.

Chapter 6 consists of a summary, conclusions, and recommendations for further research. 


\section{CHAPTER 2 CLAYEY SOILS IN INDIANA}

\section{$\underline{2.1 \text { Introduction }}$}

Soil mechanics has been primarily developed for two specific types of soils, namely, clean sands and pure clays. Textbook soil mechanics, or the mechanics of clean sands and pure clays, has therefore been studied extensively to date. Although there are some similarities, pure clays and clean sands are distinct materials in several aspects. Each geomaterial exhibits its own extreme behavior. Pure clay is very resistant to permeation. Therefore, loading or unloading clay soils induces pore pressures. They dissipate after a certain amount of time, which is completely dependent on their compressibility. The behavior of clay soils is close to that of clay in an undrained condition in the short term, but conversely is similar to the behavior of drained clay in the long term. The amount of pore pressure dissipation determines whether the condition is classified as undrained or drained. By contrast, clean sand is very permeable. Thus, a drained loading condition prevails in most cases even though the rates of loading are higher than the dissipation of pore water pressure; for example, earthquakes can produce undrained behavior. In addition to their natural differences, there is another reason soil mechanics focuses mainly on clean sands and pure clays. As mentioned earlier, sands are very permeable materials while clays allow very little permeation. This feature has been useful in laboratory tests designed to apply entirely opposite drainage conditions to soil samples: a drained condition in sand and an undrained condition in clay, respectively. Studies about these two situations are vast and widely available in textbooks.

Unfortunately, many naturally-formed deposits of geomaterials are neither clean sands nor pure clays. These kinds of soils are non-textbook soils. It is obvious that the behaviors of non-textbook soils differ from those of clean sands or pure clays due to their

compositions. Moreover, loading rates for such soils may be neither drained nor 
undrained depending on their loading rates and dissipation rates. This means that geotechnical design using parameters obtained from either drained or undrained tests may lead to problems such as conservative or unsafe design for foundations, retaining structures and slopes. The geotechnical design based on non-textbook soil should consider its drainage condition at loading for economic and effective design. In this research, clayey soils in Indiana have been used. Its drainage condition would be examined in advance to know whether two extreme drainages could be applied. The intrinsic characteristics of Indiana soil and its mechanical behavior are reviewed in the following chapters.

\section{$\underline{2.2 \text { Soils in Indiana }}$}

The geology of Indiana is both complex and diverse. According to Zevgolis (2005), its geologic history includes periods of deposition and subsequent erosion, subsidence and faulting, and submersion by epi-continental seas with subsequent deposition of thousands of feet of material to form sedimentary rocks. All of these events took place prior to the start of the Quaternary Period, which began about two million years ago. The bedrock that was created over time is buried in most of the northern part of the state by more recent, unconsolidated Quaternary deposits. Most of the present land surface in Indiana was developed during the Quaternary Period, which includes the Pleistocene (Glacial) and Holocene (Recent) Epochs.

Indiana is located toward the eastern edge of the great interior plains of North America. These plains extend from the Appalachian Mountains in the east to the Rocky Mountains in the west. This area has been highly glaciated and its terrain is mainly flat. Thus, glaciation and its effects have played a major role in the formation of the local soils, especially in the northern and central parts (Zevgolis, 2005). The other controlling factor in the formation of soils is the resistance of bedrock to erosion in southern Indiana. 


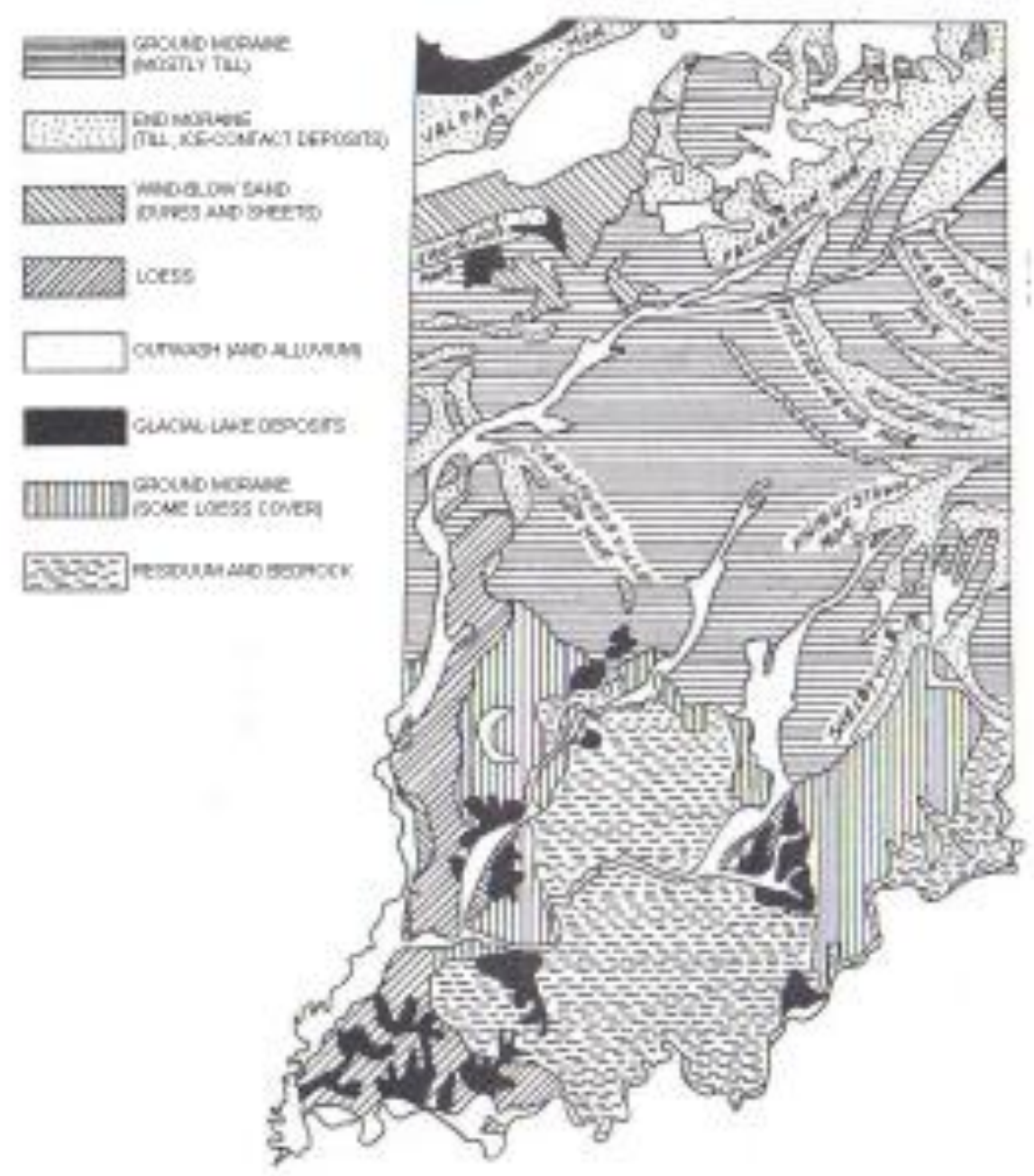

Figure 1 Major soil formations in the State of Indiana (Zevgolis, 2005)

Figure 1 shows the distribution of the major soil formations across the state. The material that is found in northern and central Indiana is a glaciated deposit. The northern part of Indiana is a deposit of the Wisconsin glaciation. The central part is an extensive plain of deposits left by the glaciers of the Illinoian period. In both cases, the bedrock is buried beneath the glacial deposits. The difference between the two zones is that the northern one has some small parts with non-glacial sediments, such as dunes, and stream or lake deposits.

The soil formation that is most widely encountered in northern and central Indiana is till, i.e. a sand-clay or silty-clay material. The way till is generally formed is as follows: 
The debris transported by a glacier is eventually deposited after the ice has melted and it is then called drift. The deposition takes place either on site, in which case we refer to it as unstratified drift, or after the debris is being carried away by the meltwater, in which case we refer to it as stratified drift. The unstratified drift consists of till, which in turn consists of a rather random mixture of materials ranging in size from clay to large boulders. It is composed mostly of silt and clay with occasional pebbles. Till is deposited by the receding glacier to yield landforms collectively known as moraines. Much of northern and central Indiana is known as the Tipton Till Plain, made up of ground moraines and end moraines (Zevgolis, 2005).

In short, most of Indiana's soils are non-textbook soils, which have different characteristics than either clean sands or pure clays. This research therefore focuses on suggesting CPT-based design methods suitable for Indiana clayey soils.

\section{$\underline{2.3 \text { Behavior of Clayey Soils in Indiana }}$}

In order to obtain a clear picture of the behavior of clayey soils encountered in Indiana, laboratory tests have been performed. The index properties of natural clayey soils can vary widely over the area where they are collected. Therefore, every time a new source of material is obtained, a series of index property tests should be carried out. Grain size distribution, Atterberg limits, and specific gravity tests have been conducted. Compression curves and compressibility parameters have been obtained from the Oedometer test.

Undrained behavior of clayey soils is investigated through a consolidated undrained test $(\mathrm{CU})$. There are several available laboratory test methods for undrained shear strength including: the direct simple shear test (DSS), the isotropic consolidated undrained test (CIU), the $K_{0}$ consolidated undrained test $\left(\mathrm{CK}_{\mathrm{o}} \mathrm{AU}\right)$ and the unconsolidated undrained test (UU). The method of determining undrained shear strength can significantly influence the results. This indicates that the value of undrained shear strength is not fixed. Therefore, it is crucial to determine the proper evaluation method of undrained shear strength for the specific purpose of the project. 
In this research, the isotropic consolidated undrained compression test (CIUC) was chosen in order to effectively simulate in-situ conditions and estimate undrained shear strength. In an unconsolidated undrained test (UU), a specimen is not consolidated to an in-situ mean effective stress. For this reason, the test is likely to underestimate undrained shear strength. According to Jardine et al. (2005), $K_{0}$ consolidated undrained tests (CAU) on high quality samples provide a more representative estimate of in-situ shear strength under triaxial compression conditions, but obtaining an accurate in-situ $K_{0}$ evaluation with laboratory tests is challenging. Therefore, the isotropic consolidated undrained test (CIU) was used in this research to estimate the undrained shear strength of the clay. The isotropic consolidated undrained test (CIU) tends to slightly overestimate undrained shear strength when compared to the $K_{0}$ consolidated undrained test (CAU) if $K_{0}$ is smaller than unity, which is due to the isotropic consolidation before shearing.

When the shear strength mobilized in the field is determined from laboratory tests, several factors should be considered: mode of shear, shearing time to failure, progressive failure, and soil disturbance. Analysis of these factors will allow for the correction of the laboratory test shear strength before use for field undrained failures (Jardine et al., 2005 and Mesri and Huvaj, 2007).

\subsubsection{Literature Review on Clay Behavior}

\section{Undrained Shear Strength Behavior of Clay Soils}

Figure 2, developed by Bishop and Henkel (1962), illustrates typical behaviors as shown in consolidated undrained tests $(\mathrm{CU})$ on reconstituted normally consolidated clays (NC). Mohr circles with different consolidation pressures are shown in Figure 3 in terms of total and effective stresses. Volume change is prevented during shearing so that positive pore pressure develops. Regarding over-consolidated clays (OC), Figure 4 shows typical results: a decrease in pore pressure has occurred until failure is reached. The magnitude of pore pressure induced in the case of over-consolidated clays (OC) greatly depends on the degree of the over-consolidation ratio (OCR). Mohr circles of overconsolidated clays (OC) may have a cohesion intercept in both total and effective stresses 
as shown in Figure 5. For over-consolidated clays (OC), excess pore pressures start to develop as positive, approach zero and then, for samples with an over-consolidation ratio (OCR) greater than about 6, become negative (Salgado, 2006). Bishop and Henkel (1962) showed the effects of over-consolidation ratio (OCR) on the pore pressure changes during shear with $A_{f}$ parameter in Figure 6 for samples of both Weald Clay and London Clay. $A_{f}$ stands for the ratio of pore pressure development to deviatoric stress at failure. $A_{f}$ decreases as the over-consolidation ratio (OCR) increases, and becomes negative when the over-consolidation ratio (OCR) is greater than approximately 4 .
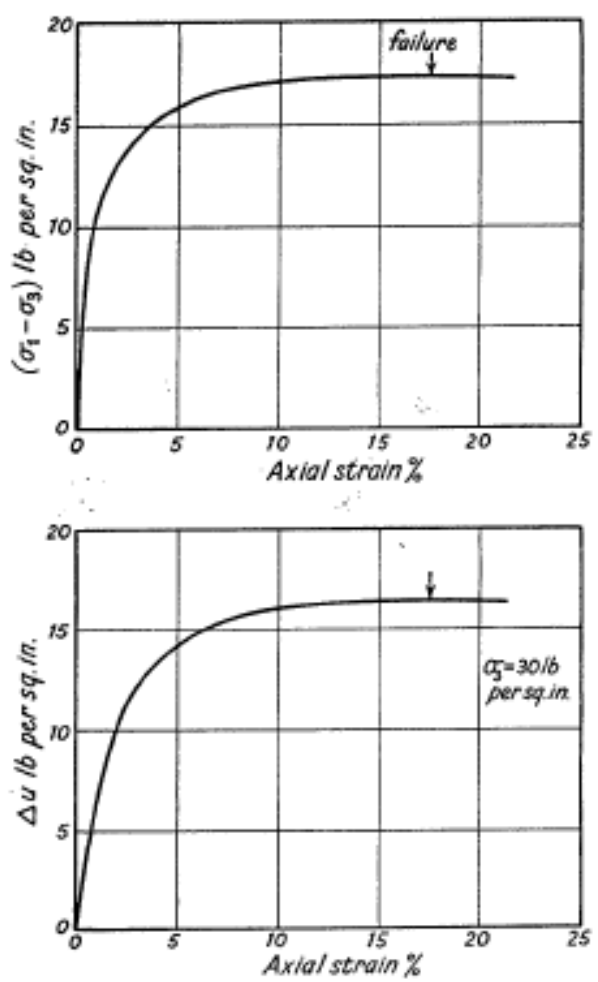

Figure 2 A consolidated undrained test on a normally consolidated clay sample (Bishop and Henkel, 1962) 

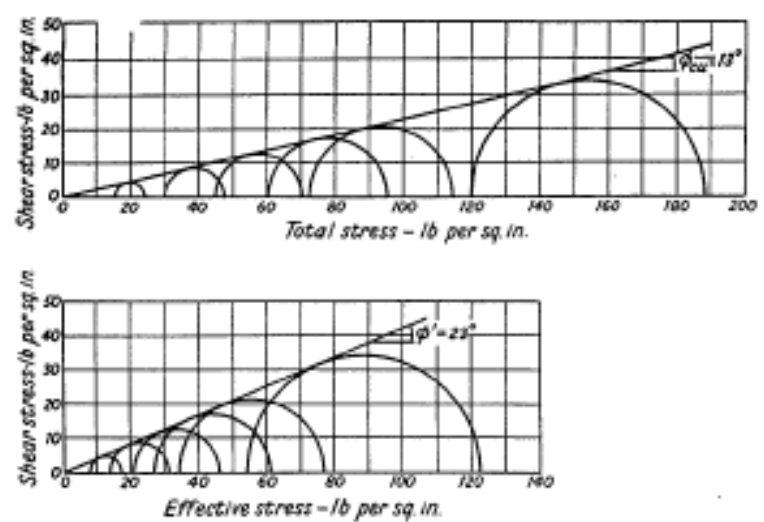

Figure 3 Mohr envelopes for consolidated undrained test on a normally consolidated clay sample (Bishop and Henkel, 1962)
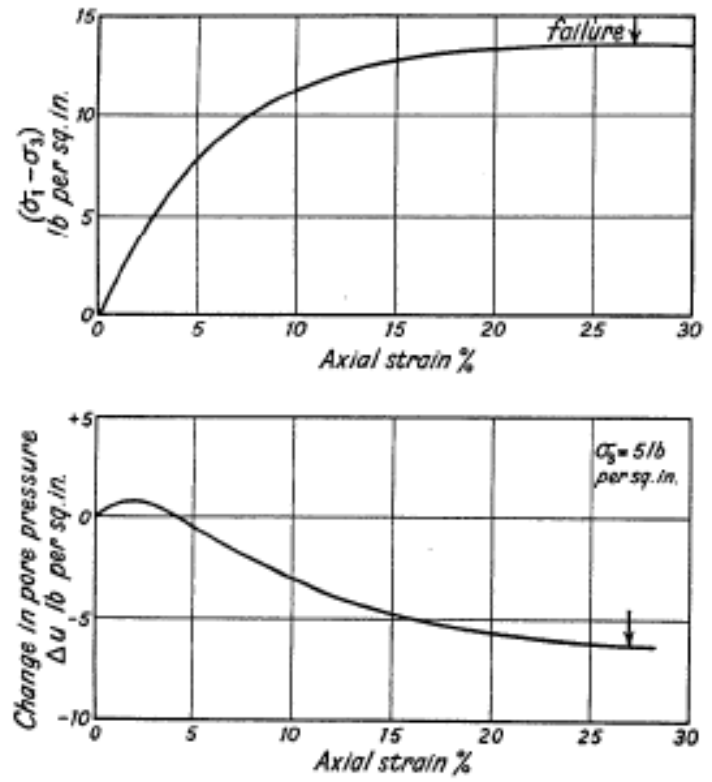

Figure 4 A consolidated undrained test on a heavily over-consolidated clay sample (Bishop and Henkel, 1962) 

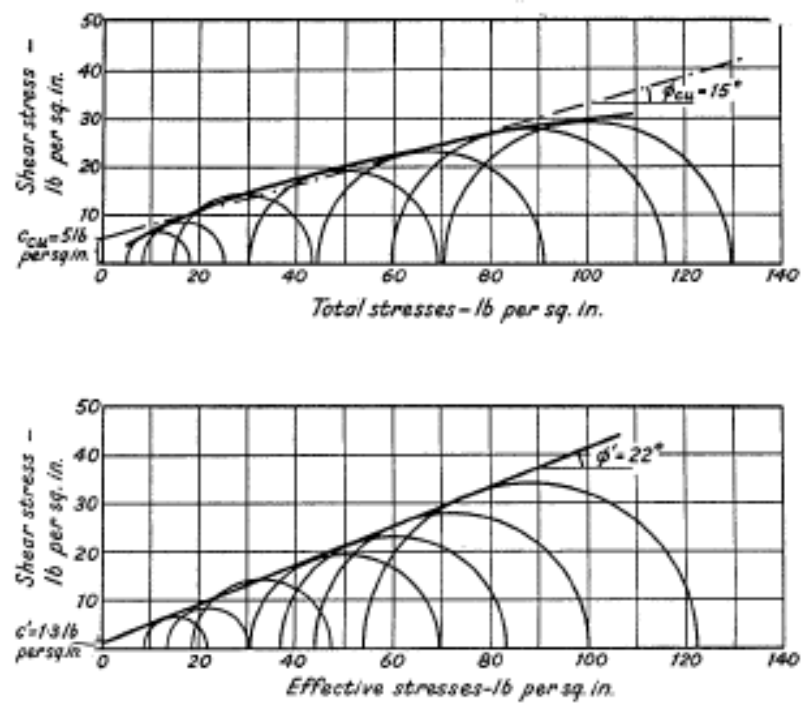

Figure 5 Mohr envelopes for consolidated undrained test on a heavily over-consolidated clay sample (Bishop and Henkel, 1962) 

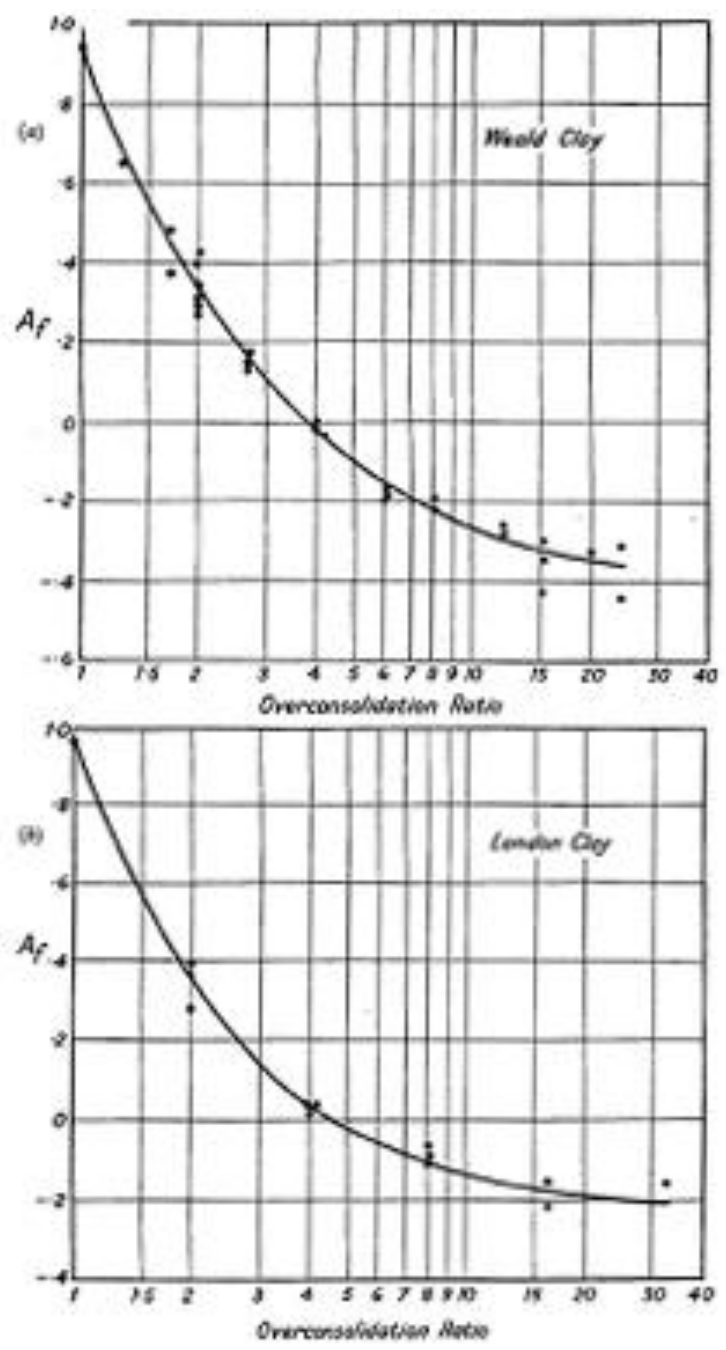

Figure 6 The effect of over-consolidation on the value of pore pressure parameter A at the failure: (a) Weald clay (b) London clay (Bishop and Henkel, 1962)

Atkinson and Bransby (1978) collected isotropic consolidated undrained test results for reconstituted Weald clay from Bishop and Henkel (1962) and drew the typical $p^{\prime}: q^{\prime}$ and $v: p^{\prime}$ diagrams for normally consolidated clays (NC) and over-consolidated clays (OC). Positive pore pressure develops during shearing because there is no volume change within soil samples for normally consolidated clays (NC) and it decreases the mean effective stress $p^{\prime}$. Therefore, the effective stress path moves left compared to the total stress path and the volume during shearing is consistent with volume after consolidation. A soil sample was prepared similarly to previous tests except for the over- 
consolidation ratio (OCR), which was isotropically consolidated to $827 \mathrm{kN} / \mathrm{m}^{2}$ and unloaded to $34.5 \mathrm{kN} / \mathrm{m}^{2}$. This means that its over-consolidation ratio (OCR) is 24 . Shearing with no volume change creates negative pore pressure development for overconsolidated clays (OC). The effective stress path moves right compared to the total stress path opposite the normally consolidated clays (NC) and the volume of the soil sample is constant.

In a 1990 Rankine lecture, Burland (1990) argued that the compressibility and strength properties of reconstituted clay provide a useful frame for understanding and interpreting the properties of natural clay. Triaxial tests were conducted on four stiff clays (Pietrafitta clay, Todi clay, Vallericca clay and Corinth marl) and compared with the corresponding results for reconstituted clays. Burland et al. (1996) concluded that the strength reduction after the peak is primarily due to breakage of interparticle bonds, but some particle orientation also takes place at higher confining stresses for both the normally consolidated (NC) and the over-consolidated (OC) clays. Figure 7 shows the isotropic consolidated undrained test (CIU) stress-strain relationships for normally and over-consolidated reconstituted Pietrafitta clay. All the over-consolidated samples were unloaded from a previous value of $p^{\prime}=2000 \mathrm{kPa}$. With regard to the normally consolidated (NC) samples, the undrained stress-strain and pore pressure-strain relationships show flat peaks and at axial strains about $15 \%$ the strengths reduce rapidly. It is evident that soil samples with higher mean effective stresses show greater undrained shear strengths, and more pore pressure develops. With regard to the over-consolidated (OC) samples, undrained stress-strain curves show rapid post-peak reductions in strength. The behavior of the over-consolidated (OC) samples is dilatant and it is inclined to grow more dilatant with higher over-consolidation ratios (OCR). Figure 8 shows isotropic consolidated undrained test (CIU) stress-strain curves for normally consolidated and over-consolidated reconstituted Corinth marl. The undrained over-consolidated samples were unloaded from $p^{\prime}=2000 \mathrm{kPa}$. For the normally consolidated (NC) and the overconsolidated (OC) samples, the undrained stress-strain curves are smoother compared to Pietrafitta clay even though the trend of the behavior is similar. 

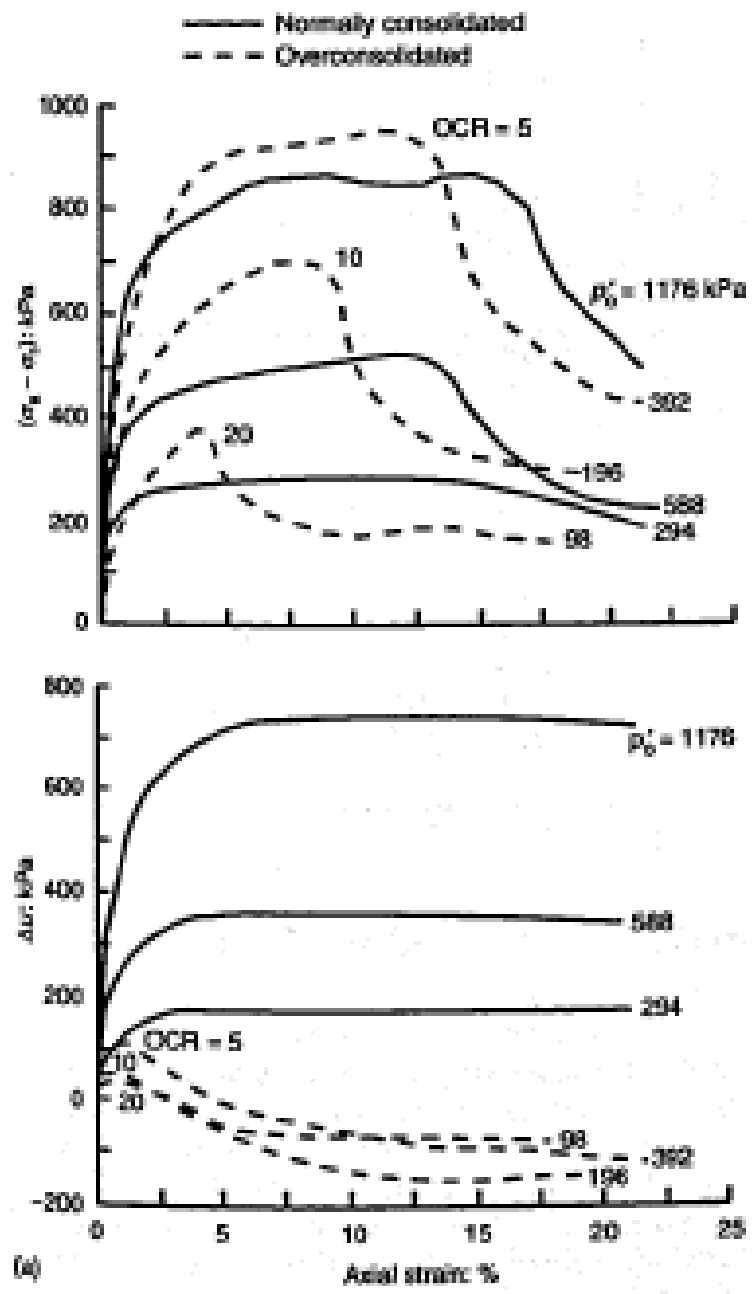

Figure 7 Undrained stress-strain behavior of reconstituted Pietrafitta clay (Burland et al, 1996) 

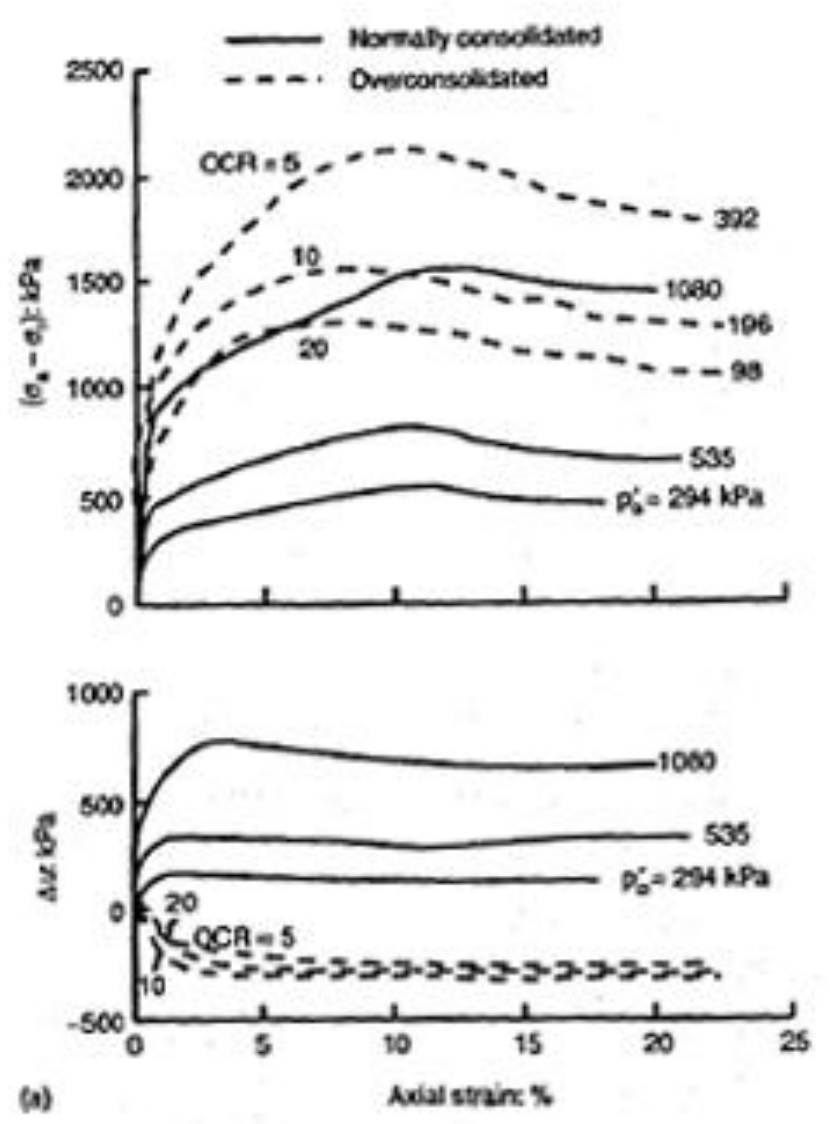

Figure 8 Undrained stress-strain behavior of reconstituted Corinth marl (Burland et al, 1996)

The behavior of another representative clay soil, Boston blue clay, was reviewed. Undrained strength behavior for Boston blue clay has been studied by many researchers. Figure 9 shows the typical triaxial compression behavior of reconstituted Boston blue clay at OCR of 1, 2, 4, and 8, as illustrated by Santagata (1994). It presents the effective stress paths normalized to the maximum vertical consolidation stress $\sigma_{v m}^{\prime}$, the stress strain curves and normalized excess pore pressures during shearing. Normally consolidated clay (NC) shows a peak at small strains followed by development of large positive pore pressures that cause a significant decrease in $p^{\prime}$ and significant post-peak softening, while over-consolidated clay (OC) shows a decrease in the peak value of 
strength, in strain softening and in the development of excess negative pore pressure (Santagata, 1994).

The undrained stress-strain lines of over-consolidated (OC) samples of Boston blue clay present flat peaks while those of Pietrafitta clay and Corinth marl have rapid peaks due to dilatancy. However, Corinth marl does not show clear peaks in strength compared to Pietrafitta clay. In the case of normally consolidated (NC) samples, the undrained behaviors are different as for clay soil types, too. This shows that the reaction to loading depends on the source of the clay. The undrained strength behavior of clay can be greatly affected by different soils; therefore, there is no fixed result in terms of clay behavior.

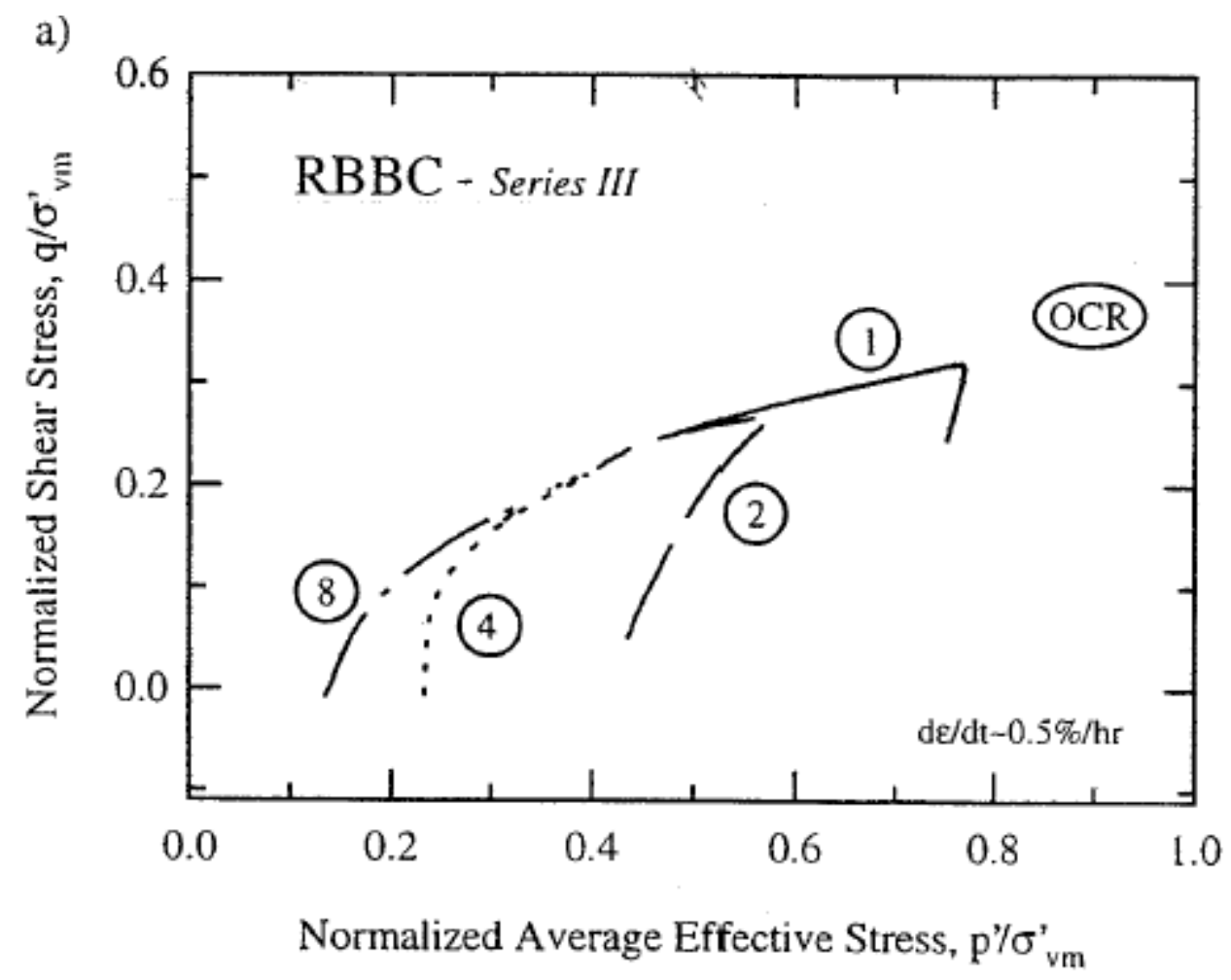



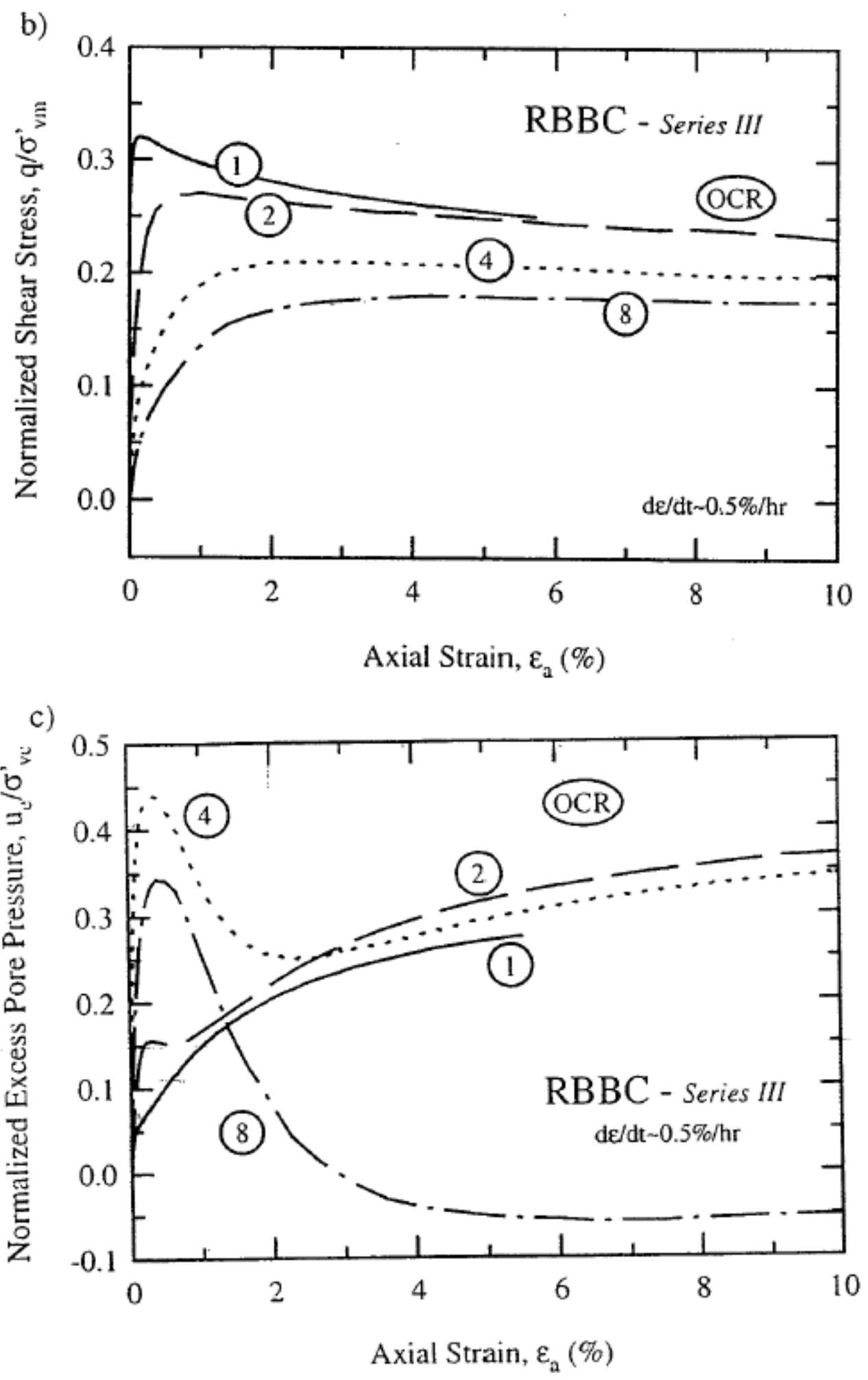

Figure 9 Behavior of reconstituted Boston blue clay in undrained triaxial compression (Santagata, 1994) 


\section{Compressibility of Clay Soils}

Compressibility of reconstituted clays has been investigated with one dimensional compression curves like that in Figure 10. All the curves are similarly slightly concave. The effect of water contents was examined using the Oedometer test for three clays, as shown in Figure 11. The number against each curve gives the mixing water content expressed as a proportion of the liquid limit of the clay. At pressures more than $100 \mathrm{kPa}$, the compression curves for each soil are likely to converge (Leonards and Ramiah, 1959). The influence of load increment duration was investigated for two clays and it shows there is little difference between the curve of each clay.

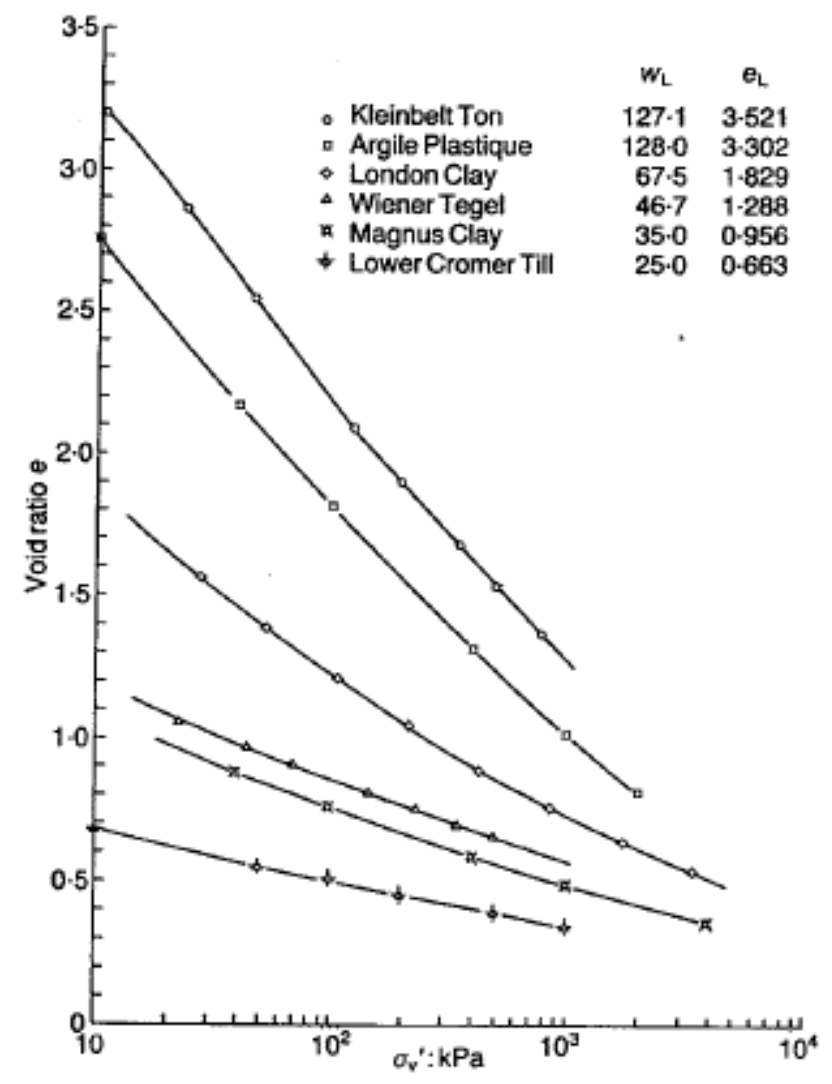

Figure 10 One dimensional compression curves for various reconstituted clays (Burland, 1990) 


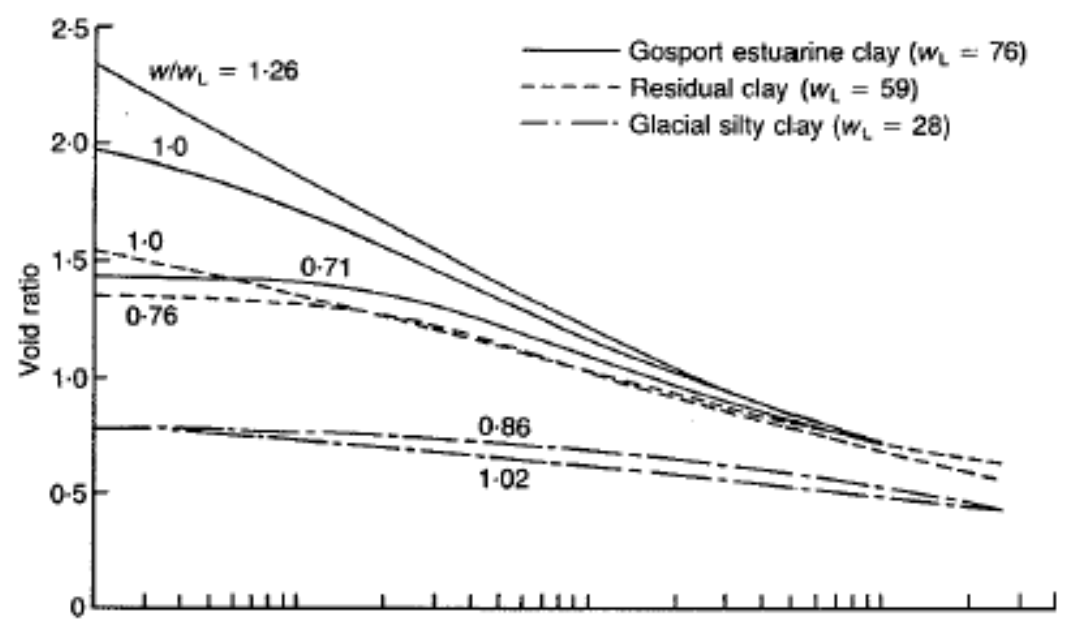

(a)

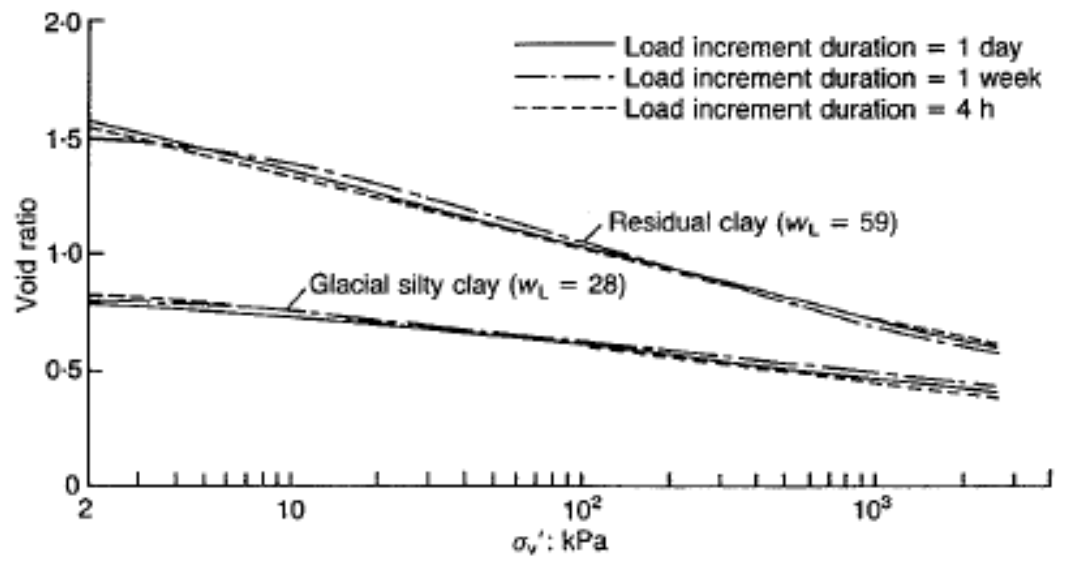

(b)

Figure 11 Influence of (a) mixing moisture contents; (b) load increment duration on compression curves for reconstituted clays (Leonards and Ramiah, 1959)

For Boston blue clays, one dimensional compression curves from 40 incremental Oedometers and 27 CRS consolidations were drawn and compared (Ladd et al., 1999). It provides the compressibility characteristic for heavily over-consolidated clay (OCR>2) and lightly over-consolidated clay $(\mathrm{OCR}<2)$, as shown in Figure 12. The former has a rounded curve in the vicinity of $\sigma_{p}^{\prime}$ and a linear virgin compression line, as illustrated by CRS 24. The latter exhibits a non-linear and S-shaped virgin compression curve, as illustrated by CRS 19 (Ladd et al., 1999). 


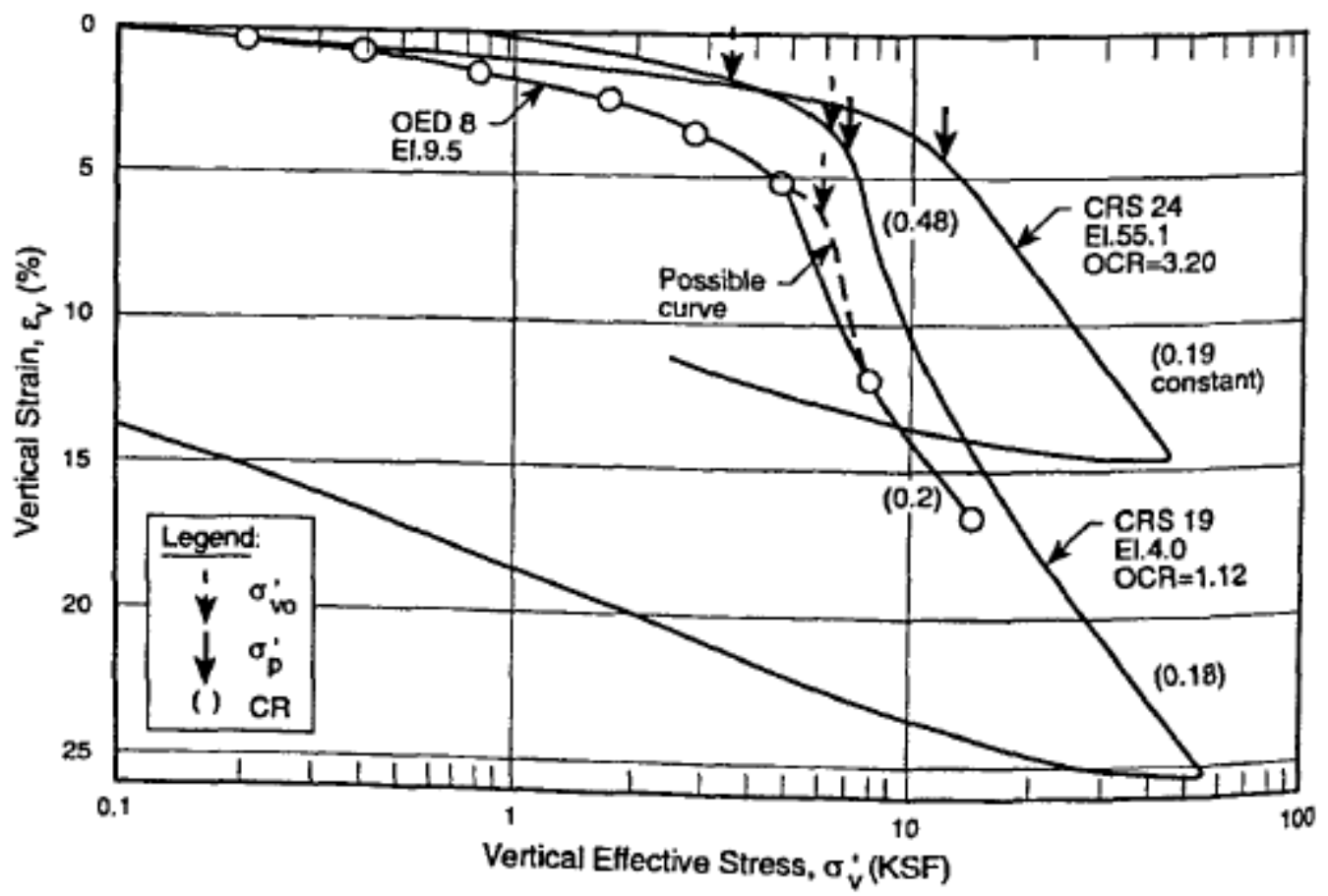

Figure 12 Typical one dimensional compression curves for Boston blue clay (Ladd et al., 1999)

The database containing information on one dimensional compression behavior of reconstituted Boston blue clay shows that the compression ratio $\mathrm{CR}$, which is defined by the slope of the virgin compression line, varies in the range of $0.155-$ 0.180. The swelling ratio SR, which is defined by the slope of the line drawn through the points corresponding to the unloading phase, is approximately an order of magnitude smaller than the CR (Santagata, 1994). The SR for reconstituted Boston blue clay with over-consolidation ratio (OCR) 4 varies from 0.012 to 0.017 according to the database. The SR increases as the soil is unloaded to higher over-consolidation ratios (OCR). Ahmed (1990) obtained 0.011 for over-consolidation ratio (OCR) 2 and Sheahan (1991) obtained 0.019 for overconsolidation ratio (OCR) 8 .

2.3.2 Behavior of Clayey Soils in Indiana 
In order to observe the behavior of clayey soils in Indiana, 9 clayey soils from 4 sites in Indiana were examined. The sites are I-69, SR-49, US-24, and US-31. A laboratory test program including index tests, one dimension consolidation tests, and isotropic consolidated undrained compression tests (CIUC) was conducted using undisturbed soil from Shelby tube sampling. The results from index tests and one dimensional consolidation tests will be reviewed in later chapters. The undrained shear strength behavior is studied in this section.

According to one dimensional consolidation test results, all of the specimens studied in this research are over-consolidated (OC) clay. This is because the locations of the collected Shelby tubes are not very far from the surface due to the workability of a boring machine. The deepest Shelby tube in this research is located $3 \mathrm{~m}$ from the surface. The over-consolidation ratios (OCR) for I-69, US-24, RB-99 (US-31), RB-114 (US-31) and RB-31 (US-31) are 4.2, 2.8, 3.6, 5.1 and 11.8, respectively; this includes both lightly OC and highly OC clays. The stress-strain curve and excess pore pressure distribution for the soils are shown in Figure 13 to Figure 22. The fact that all of the specimens tested were over-consolidated (OC) clay is verified by the behavior of excess pore pressure. As mentioned before, excess pore pressures for over-consolidated clays (OC) start to develop as positive, approach zero and then, for samples with an over-consolidation ratio (OCR) greater than about 6, become negative (Salgado, 2006). The excess pore pressure distribution for RB-31 (US-31), which has the highest OCR at 11.8, shows the steep decline for negative pore pressures compared to soil samples with smaller OCR. The development of negative pore pressure causes an increase of mean effective stress $p^{\prime}$, and it prevents a rapid peak in the stress-strain curve. This stress-strain behavior parallels the behavior of Boston blue clay. 


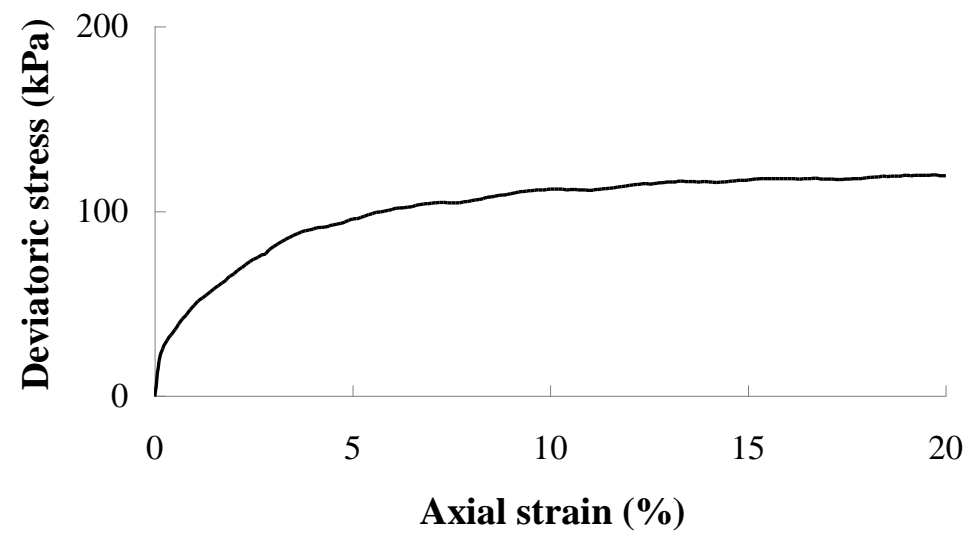

Figure 13 Stress-strain curve for I-69

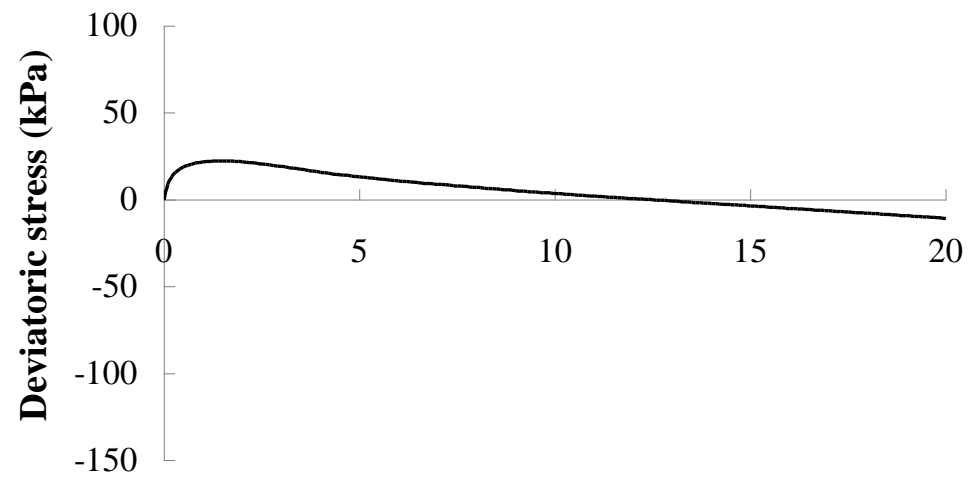

Axial strain (\%)

Figure 14 Excess pore pressure distribution for I-69

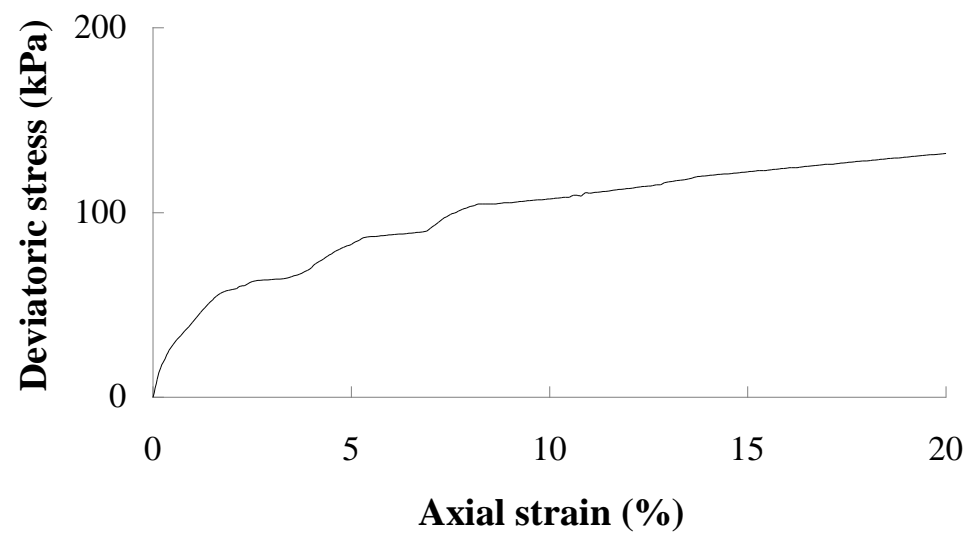

Figure 15 Stress-strain curve for US-24 


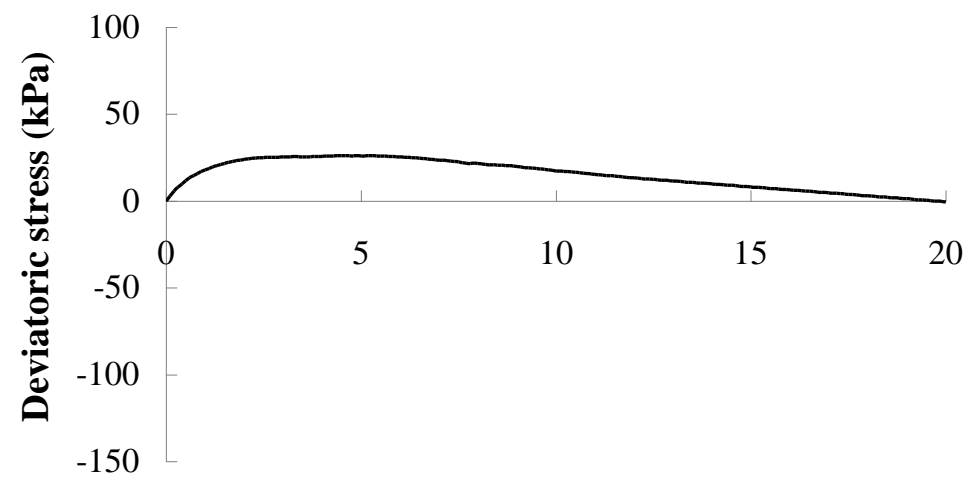

Axial strain (\%)

Figure 16 Excess pore pressure distribution for US-24

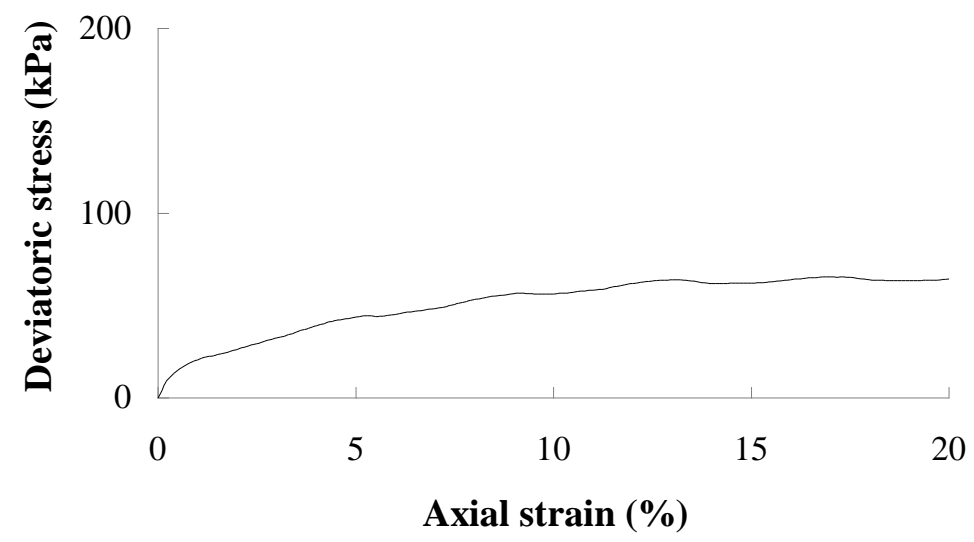

Figure 17 Stress-strain curve for RB-99 (US-31) 


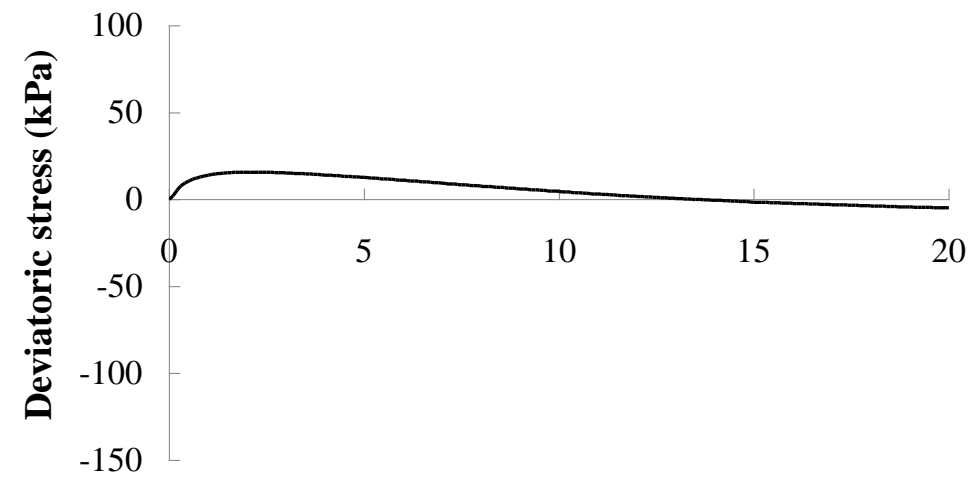

Axial strain (\%)

Figure 18 Excess pore pressure distribution for RB-99 (US-31)

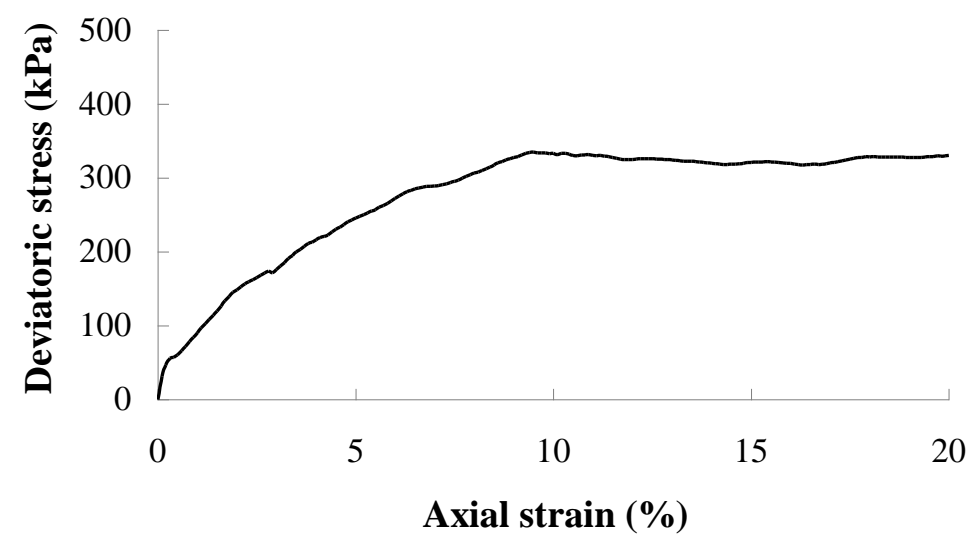

Figure 19 Stress-strain curve for RB-114 (US-31)

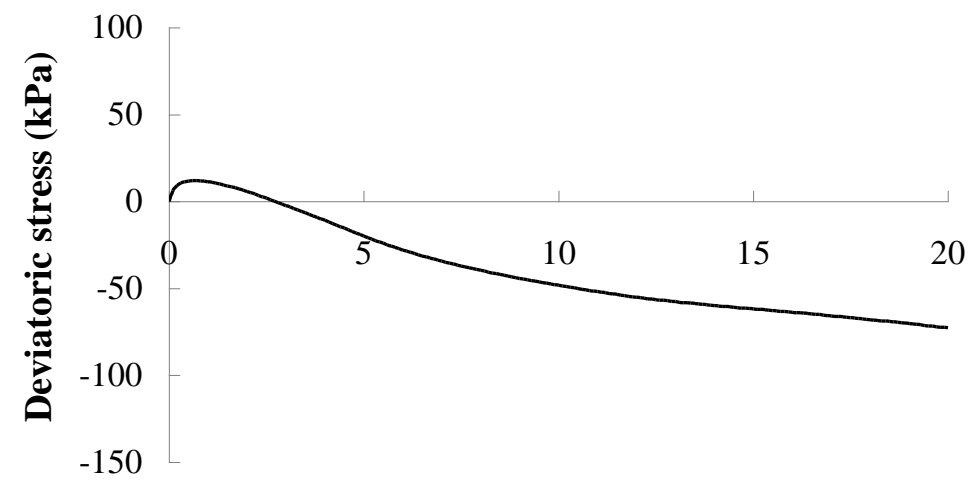

Axial strain (\%) 
Figure 20 Excess pore pressure distribution for RB-114 (US-31)

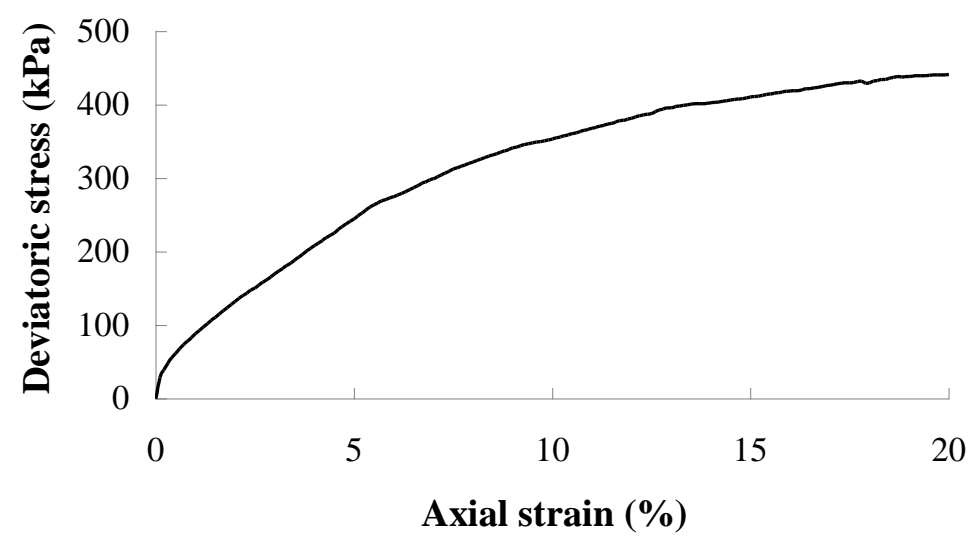

Figure 21 Stress-strain curve for RB-31 (US-31)

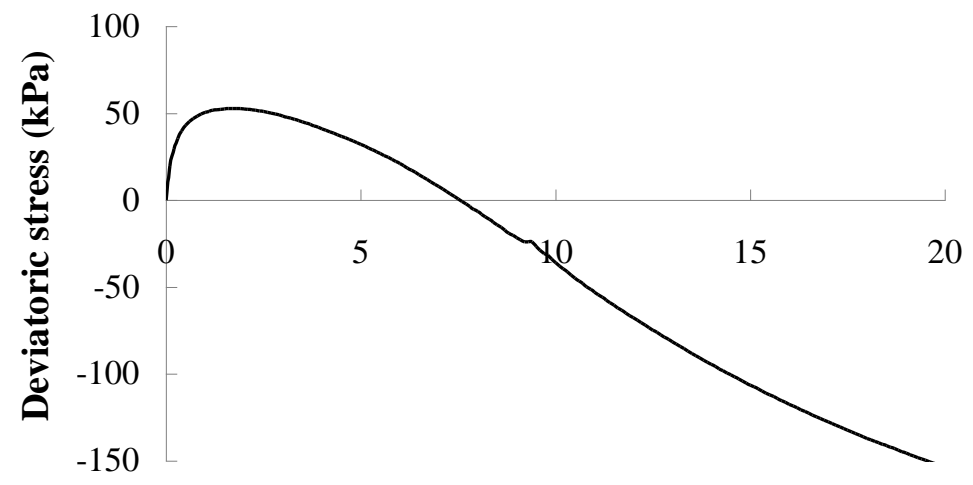

Axial strain (\%)

Figure 22 Excess pore pressure distribution for RB-31 (US-31) 


\section{CHAPTER 3 PILE DESIGN BASED ON IN-SITU TESTS}

\section{$\underline{3.1 \text { Introduction }}$}

Piles are relatively long and generally slender structural foundation members that transmit superstructure loads to deep soil layers. In geotechnical engineering, piles usually serve as foundations when soil conditions are not suitable for the use of shallow foundations. Moreover, piles have other applications in deep excavations and in slope stability. As presented in the literature, piles are classified according to:

(1) nature of load support (friction and end-bearing piles),

(2) displacement properties (full-displacement, partial displacement, and nondisplacement piles),

(3) composition of piles (timber, concrete, steel and composite piles).

The behavior of the pile depends on many different factors including pile characteristics, soil conditions and properties, installation method, and loading conditions. The performance of piles affects the serviceability of the structure they support. The estimation of pile load carrying capacity can be achieved using different methods such as pile load tests, dynamic analysis, static analysis based on soil properties from laboratory tests, and static analysis utilizing the results of in-situ tests such as SPT or CPT.

In the design and analysis of piles, it is important to identify piles based on the nature of support provided by the surrounding soil (i.e. to classify piles as end-bearing piles or friction piles). While end-bearing piles transfer most of their loads to an endbearing stratum, friction piles resist a significant portion of their loads via the skin friction developed along the surface of the piles. The behavior of friction piles mainly depends on the interaction between the surrounding soil and the pile shaft. 
The ultimate axial load carrying capacity of the pile $\left(Q_{u}\right)$ is composed of the endbearing capacity of the pile $\left(Q_{t}\right)$ and the shaft capacity $\left(Q_{s}\right)$. The general equation is given as:

$$
Q_{u}=Q_{t}+Q_{s}=q_{t} A_{t}+f A_{s}
$$

where $q_{t}$ is the unit tip bearing capacity, $A_{t}$ is the area of the pile tip, $f$ is the unit skin friction, and $A_{s}$ is the area of the pile shaft. In sands, the end-bearing capacity $Q_{t}$ dominates; in soft clays, the friction capacity $Q_{s}$ dominates. The design load carrying capacity $Q_{d}$ of the pile can be calculated by:

$$
Q_{d}=\frac{Q_{u}}{F . S .}
$$

where $Q_{u}$ is the ultimate load carrying capacity and F.S. is the factor of safety.

In general, the application of in-situ tests to pile design is done through:

\section{(1) Direct Method and \\ (2) Indirect Method.}

When utilizing the direct method, one can make use of the results from in-situ test measurements for the analysis and the design of foundations directly. It is simple and powerful, but a huge database is needed to get meaningful results. The application of the direct method to the analysis and design of foundations is usually based on empirical relationships. On the other hand, the indirect method requires the evaluation of soil characteristic parameters, such as the undrained shear strength $S_{u}$ from in-situ test results.

The direct method, used for pile design, has been mainly based on the standard penetration test (SPT) and the cone penetration test (CPT). Although the SPT has been used more extensively, it is widely recognized that the SPT has a number of limitations. A serious limitation is that SPT blow count is not well related to the pile loading process. The SPT blow count can also vary depending on operation procedures. The CPT is a superior test for pile design purposes. The indirect method for pile design includes Vesic 
(1977), Coyle and Castello (1981), and $\beta$ method (Burland, 1973) for cohesionless soil, and $S_{u}$ method (Bowles, 1982) along with $\alpha$ method (Tomlinson, 1975) for cohesive soil. Most indirect pile design methods define the correlation between soil parameters and base or shaft resistance.

In this research, laboratory test results including index tests, oedometer tests, and triaxial tests are compared with cone penetration test results in order to make a proper correlation between both of them for Indiana clayey soil. Therefore, the main focus of this study is on the estimation of soil properties for indirect CPT-base design. In this chapter, the existing methods for pile design using CPT will be reviewed.

\subsection{Direct Estimation of Pile Load Capacity Based on CPT}

The determination of pile load capacity based on CPT results can be expressed as:

$q_{b}=c_{b} q_{c}$

$q_{s}=\sum c_{s i} q_{s i}$

where $q_{b}$ is the base resistance, $c_{b}$ is the empirical parameter to convert $q_{c}$ to base resistance, $q_{c}$ is the cone resistance at the pile base level, $q_{s}$ is the shaft resistance, $c_{s i}$ is the empirical parameter to convert $q_{s i}$ to shaft resistance, and $q_{s i}$ is the representative cone resistance for layer $\mathrm{i}$.

Values for $c_{b}$ and $c_{s i}$ have been proposed mostly based on empirical correlations developed between pile load test results and CPT results. Because different authors have proposed different values for $c_{b}$ and $c_{s i}$, the use of such parameters should be applied under conditions similar to those under which they were determined. Although most expressions were based on cone resistance $q_{c}$, some authors (Price and Wardle 1982, Schmertmann 1978) have suggested the use of cone sleeve friction $f_{s}$ for the estimation of shaft resistance with the following general expression:

$q_{s}=c_{s f i} f_{s i}$ 
where $c_{s f i}$ is an empirical parameter to convert cone sleeve friction to shaft resistance and $f_{s i}$ is a representative cone sleeve friction for layer $\mathrm{i}$.

\subsubsection{Schmertmann`s method}

For the estimation of pile base resistance in stiff cohesive soil, Schmertmann (1978) proposed the use of an average cone resistance by multiplying the reducing factor. The average cone resistance's depth is calculated to be between $8 \mathrm{~B}$ above a pile and $0.7 \mathrm{~B}$ to $4 \mathrm{~B}$ below a pile. For shaft resistance in sand, the following values of the shaft resistance factor $c_{s}$ of (4) were proposed for different pile types:

$c_{s}=0.008$ for open-end steel tube piles,

$c_{s}=0.012$ for precast concrete and steel displacement piles,

$c_{s}=0.018$ for vibro and cast-in-place displacement piles with steel driving tube removal, as well as timber piles.

According to Schmertmann`s method, the unit skin friction of the pile is given by:

$f=\alpha_{c} f_{s}$

where $\alpha_{c}$ is a reduction factor which varies from 0.2 to 1.25 for clayey soil, and $f_{s}$ is the sleeve friction.

\subsubsection{Aoki and Velloso`s method}

Based on the load test and CPT results, Aoki and Velloso (1975) proposed the following relationship for both shaft and base resistance in terms of cone resistance $q_{c}$ :

$$
\begin{aligned}
& q_{b}=\frac{1}{F_{1}} q_{c} \\
& q_{s}=\frac{\alpha}{F_{2}} q_{c}
\end{aligned}
$$

where $\alpha, F_{1}$, and $F_{2}$ are the empirical parameters. 


\subsubsection{LCPC method}

Bustamante and Gianeselli (1982) presented the LCPC method for the French Highway Department based on an analysis of 197 pile load tests using a variety of pile types and soil conditions. It is also known as the French method. In this method, both the unit tip bearing capacity and the unit skin friction of the pile are obtained from the cone tip resistance. The sleeve friction is not used. The basic formula for the LCPC method can be written as:

$q_{b}=k_{c} q_{c a}$

$q_{s}=\frac{1}{k_{s}} q_{c}$

where $k_{c}$ is the base resistance factor, $q_{c a}$ is equivalent cone resistance at pile base level, $k_{s}$ is the shaft resistance factor, and $q_{c}$ is representative cone resistance for the corresponding layer. The values of $k_{c}$ and $k_{s}$ depend on the nature of the soil and its degree of compaction as well as the pile installation method. According to Bustamante and Gianeselli (1982), the values of $k_{c}$ for driven piles cannot be directly applied to Hpiles and tubular piles with an open base without proper investigation of full scale load tests. The equivalent cone resistance $q_{c a}$ used in (9) represents an arithmetical mean of the cone resistance measured along the distance equal to $1.5 \mathrm{~B}$ above and below the pile base.

In the LCPC method, separate factors of safety are applied to shaft and base resistance. A factor of safety equal to 2 for shaft resistance and 3 for base resistance were considered, so that the carrying load is given by:

$Q_{w}=\frac{Q_{L}^{s}}{2}+\frac{Q_{L}^{b}}{3}$

where $Q_{w}$ is allowable load, $Q^{s}{ }_{L}$ is limit shaft load, and $Q^{b}{ }_{L}$ is limit base load. 


\section{$\underline{3.3 \text { Indirect Estimation of Pile Load Capacity Based on Soil Property }}$}

Since a pile is assumed to fail under undrained conditions in clayey soils, the capacity of piles installed in clayey soils in soil property-based design is calculated using the total stress approach. These indirect methods require the evaluation of soil characteristic parameters. The ultimate unit base resistance is defined in terms of the undrained shear strength $\left(S_{u}\right)$ as:

$q_{u}=N_{c} S_{u}$

where $N_{c}$ is the bearing capacity factor. This value varies according to pile type and ultimate load criteria.

\subsection{1 $\alpha$ method}

For shaft capacity calculations of piles installed in clays, the $\alpha$ method is used:

$q_{s}=\alpha S_{u}$

where $\alpha$ is a correction factor.

The main concept of the $\alpha$ method is to correlate pile shaft capacity to the $S_{u}$ of an in-situ soil through a reduction factor referred to as $\alpha$. Many variations of the $\alpha$ method have been developed based on empirical correlations induced from collected pile load test results.

Randolph and Murphy (1985) proposed an equation for $\alpha$ for use in the $\alpha$ method that was developed based on the database compiled by Olson and Dennis (1982). They assumed that mobilized skin friction depends on the angle of friction between pile and soil, undrained shear strength, and effective stress. According to them, the effects of all these parameters are captured by the equation $S_{u} / \sigma_{v}^{\prime}$. The method developed by Randolph and Murphy (1985) was included in the API design method published in 1993. In the API method, the equations for estimating the shaft friction are defined as follows:

$$
\begin{aligned}
& \alpha=0.5\left(S_{u} / \sigma_{v}^{\prime}\right)^{-0.5} S_{u} / \sigma^{\prime} \leq 1.0 \\
& \alpha=0.5\left(S_{u} / \sigma_{v}^{\prime}\right)^{-0.25} S_{u} / \sigma^{\prime}>1.0
\end{aligned}
$$

where $\sigma_{v}^{\prime}=$ effective overburden pressure. 


\section{CHAPTER 4 FIELD CONE PENETRATION TEST PROGRAM}

\subsection{Introduction}

A field cone penetration test program was undertaken to investigate the correlation between undrained shear strength $S_{u}$ and cone resistance $q_{T}$ for clayey soils in Indiana. The drainage condition during the cone penetration test (CPT) was examined with the criteria for establishing drainage condition rate thresholds for CPT (Kim et al., 2006). The cone penetration tests (CPT) were performed at 4 sites in the state of Indiana and the sites were determined using the boring log database of the Indiana Department of Transportation (INDOT). Clayey soils with some amounts of sand or silt were collected for the test program. The procedure followed for the cone penetration tests (CPT) is in agreement with ASTM D 5778. The rate of cone penetration tests (CPT) was $2 \mathrm{~cm} / \mathrm{s}$ at all the sites. The sites are I-69, SR-49, US-24, and US-31. The laboratory test program included index tests, one dimension consolidation tests, and triaxial tests using undisturbed soil from Shelby tube sampling. Among the triaxial tests, the isotropic consolidated undrained compression test (CIUC) was chosen in order to effectively simulate in-situ conditions and estimate undrained shear strength $q_{T}$.

\subsection{Site 1: I-69}

The first site is located near the Interstate Highway 69 in Madison County, Indiana. The Cone Penetration Tests (CPT) were performed and undisturbed samples were taken. The soil profile from the boring test is presented in Figure 23. Upon discovery of the location of the clayey soil layer, several Shelby tubes were collected for laboratory tests. The CPT results from the I-69 test site are shown in Figure 24. 


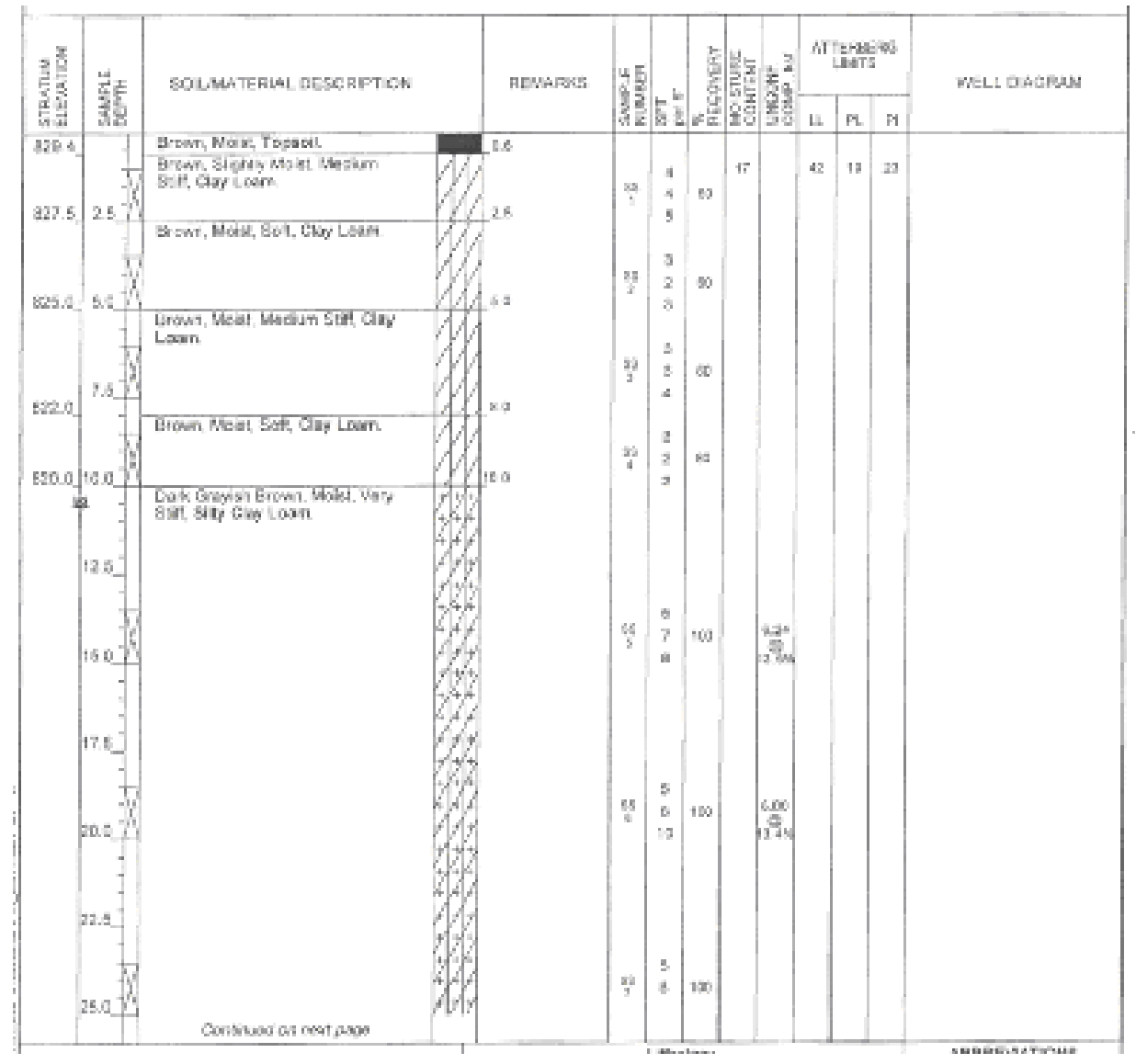

Figure 23 Soil boring test result for the I-69 site 


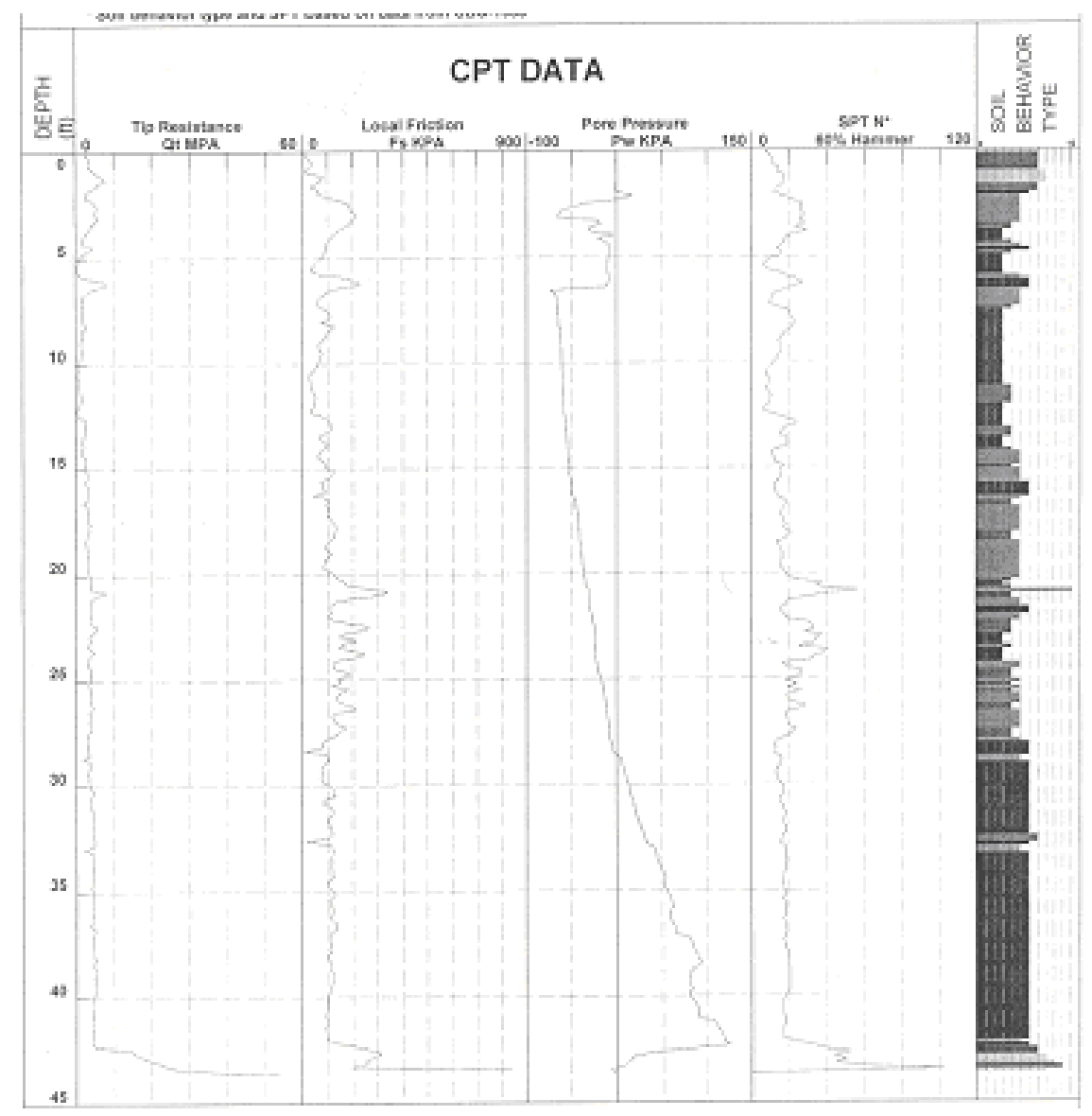

Figure 24 CPT results at I-69 site

\subsubsection{Laboratory Test Program}

In order to estimate the mechanical behavior of soil, several laboratory tests were performed. Shelby tubes were taken in order to collect undisturbed specimens so that the in-situ condition of soil masses could be represented during laboratory tests. The usage of reconstituted specimen is more convenient for preparing test specimen, but there is a considerable possibility that it may lose its intrinsic characteristic. The results from cone penetration tests (CPT) should be influenced by the intrinsic composition of soil-mass; therefore, several laboratory tests were performed using undisturbed samples in order to make a qualified relationship between both of them. This laboratory test program was composed of index tests, one dimension consolidation tests, and triaxial tests. The undrained shear strength $S_{u}$ from the triaxial test was related to the results from cone 
penetration tests (CPT), and this relation would be classified with plasticity index $I_{p}$ from index tests. The drainage condition during cone penetration tests (CPT) should be identified using the coefficient of consolidation $C_{v}$ from a one-dimensional consolidation test.

\subsubsection{Soil Index Tests}

Grain size distribution for the clayey soil layer (from $1.1 \mathrm{~m}$ to $2.3 \mathrm{~m}$ ) is shown in Figure 25. The results of the Atterberg limit tests are summarized in Table 1. The clays at a depth of $1.68 \mathrm{~m}$ have a liquid limit (LL) of $36.5 \%$ and a plastic limit (PL) of $16.4 \%$, and $I_{p}=20.1 \%$.

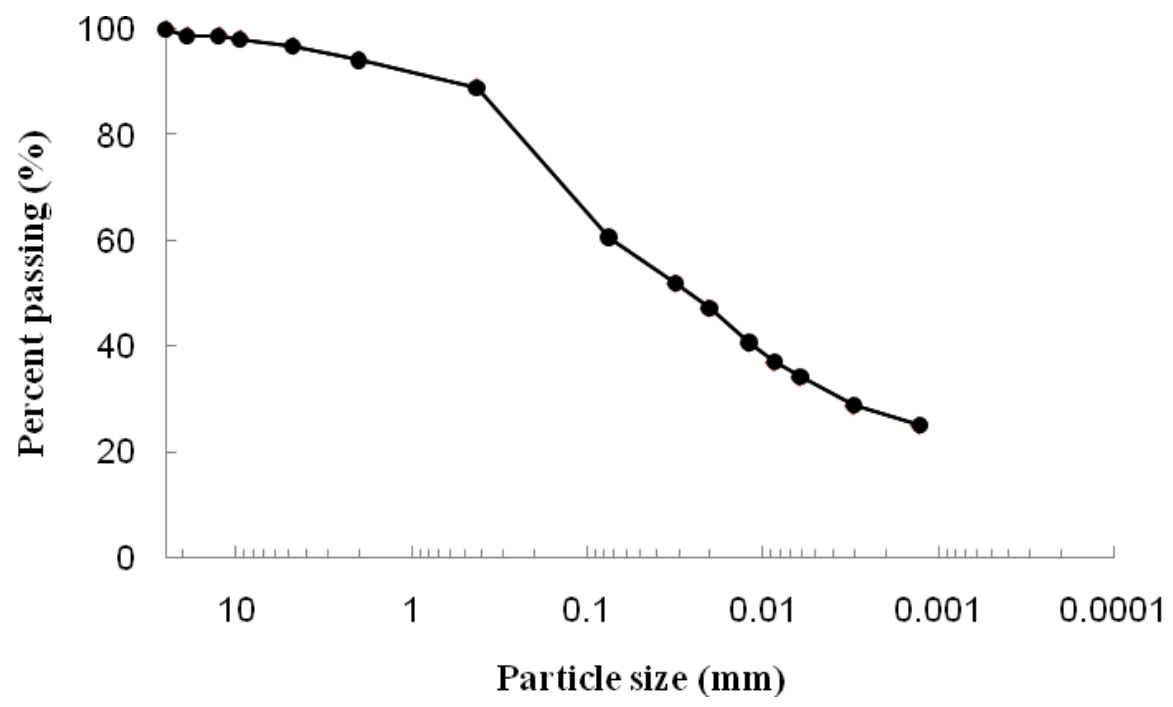

Figure 25 Grain size distribution of the clayey soil in I-69 
Table 1 Summary of laboratory index testing for I-69

\begin{tabular}{c|cccc}
\hline Depth (m) & $\mathrm{W}(\%)$ & LL $(\%)$ & PL $(\%)$ & $I_{p}(\%)$ \\
\hline 1.68 & 20.5 & 36.5 & 16.4 & 20.1 \\
\hline
\end{tabular}

\subsubsection{One Dimensional Consolidation Test}

Conventional one-dimensional consolidation tests were conducted according to the consolidation test procedure as described in ASTM D 2435. The coefficient of consolidation $C_{v}$ and the over-consolidation ratio (OCR) of the clayey soil layers were estimated. The tests were conducted using a Geocomp automated consolidation testing device shown in Figure 26. Specimens were loaded in 7 increments up to a maximum applied vertical stress of $760 \mathrm{kPa}$ and Cassagrande`s method was used to evaluate the over-consolidation ratio (OCR). Figure 27 presents a displacement versus the square root of time plot at vertical pressure $48 \mathrm{kPa}$. The coefficient of consolidation $C_{v}$ at each step was measured and is shown in Table 2 and Figure 28. Semi-log plots of settlement versus vertical stress were obtained and are shown in Figure 29. The effective preconsolidation stress was determined with Cassagrande`s method, and the calculated over-consolidation ratio at the I-69 site is 4.2 as shown in Table 3. In other words, this layer is an overconsolidated layer (OC). It is shown again in the graph illustrating the coefficient of consolidation, which increases by the preconsolidation stress and decreases. 


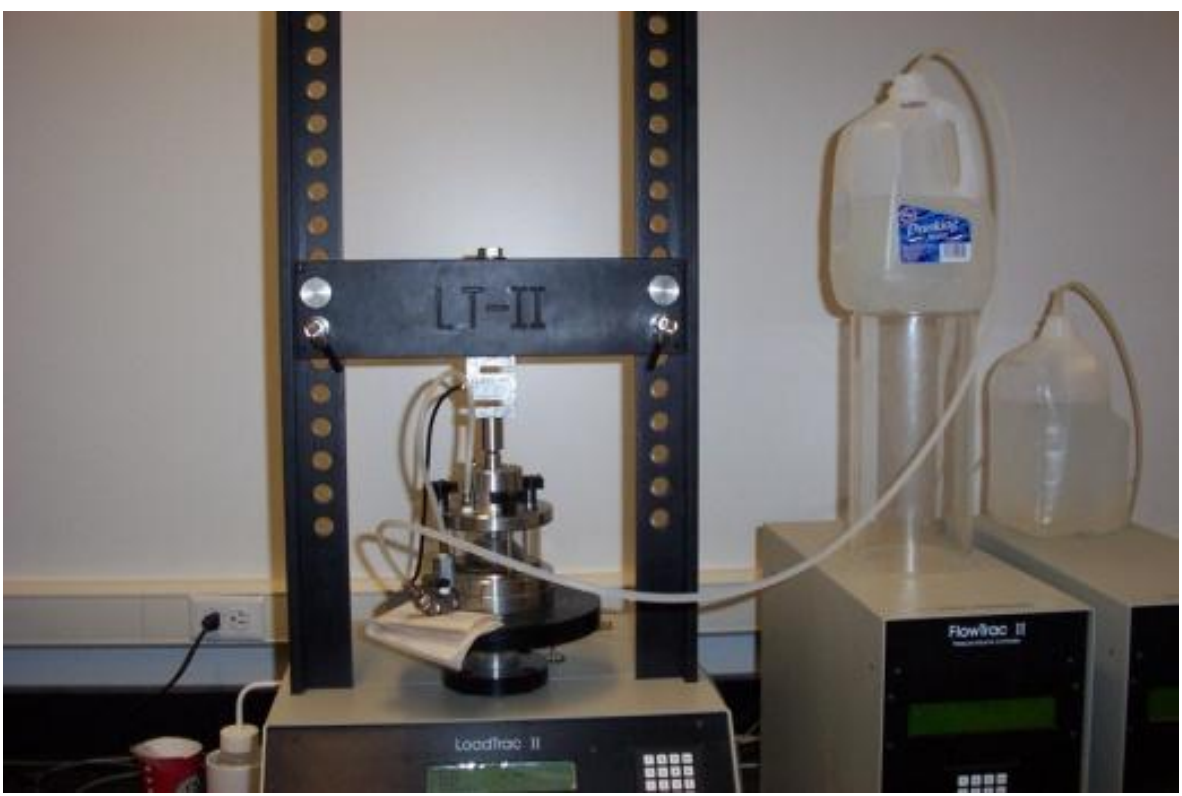

Figure 26 Geocomp automated consolidation testing apparatus

Table 2 Coefficient of consolidation $C_{v}\left(\mathrm{~cm}^{2} / \mathrm{sec}\right)$ for I-69

\begin{tabular}{c|ccccccc}
\hline $\begin{array}{c}\text { Depth } \\
(\mathrm{m})\end{array}$ & $12 \mathrm{kPa}$ & $24 \mathrm{kPa}$ & $48 \mathrm{kPa}$ & $96 \mathrm{kPa}$ & $192 \mathrm{kPa}$ & $382 \mathrm{kPa}$ & $766 \mathrm{kPa}$ \\
\hline 1.68 & 0.0137 & 0.00417 & 0.0197 & 0.0406 & 0.0140 & 0.0018 & 0.00073 \\
\hline
\end{tabular}

Table 3 Effective preconsolidation stress $\sigma_{p}^{\prime}$ and OCR

\begin{tabular}{c|ccc}
\hline Depth $(\mathrm{m})$ & $\begin{array}{c}\text { Effective Preconsolidation } \\
\text { stress }(\mathrm{kPa})\end{array}$ & $\begin{array}{c}\text { Vertical effective stress } \\
(\mathrm{kPa})\end{array}$ & OCR \\
\hline \multirow{2}{*}{1.68} & 101 & 23.8 & 4.2 \\
\hline
\end{tabular}




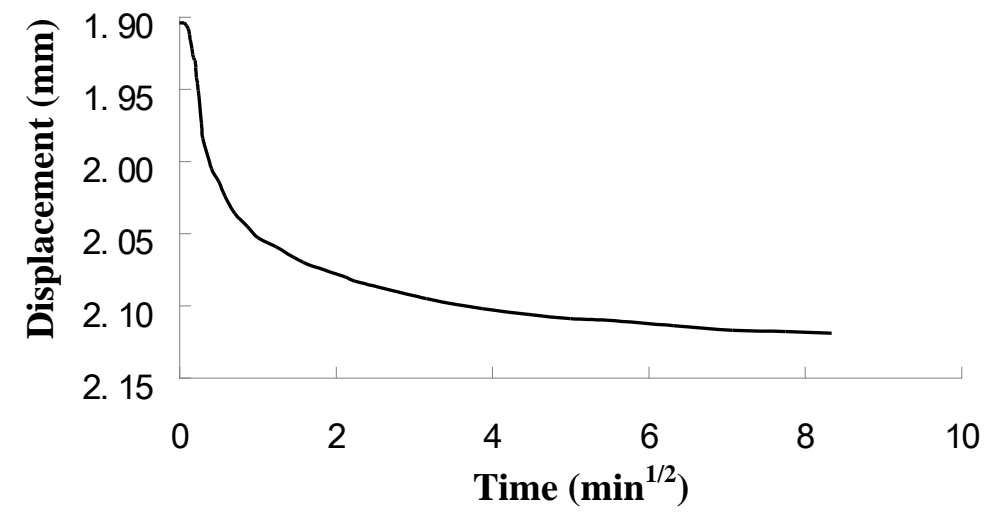

Figure 27 Specimen displacements versus square root of time (48 kPa) for I-69

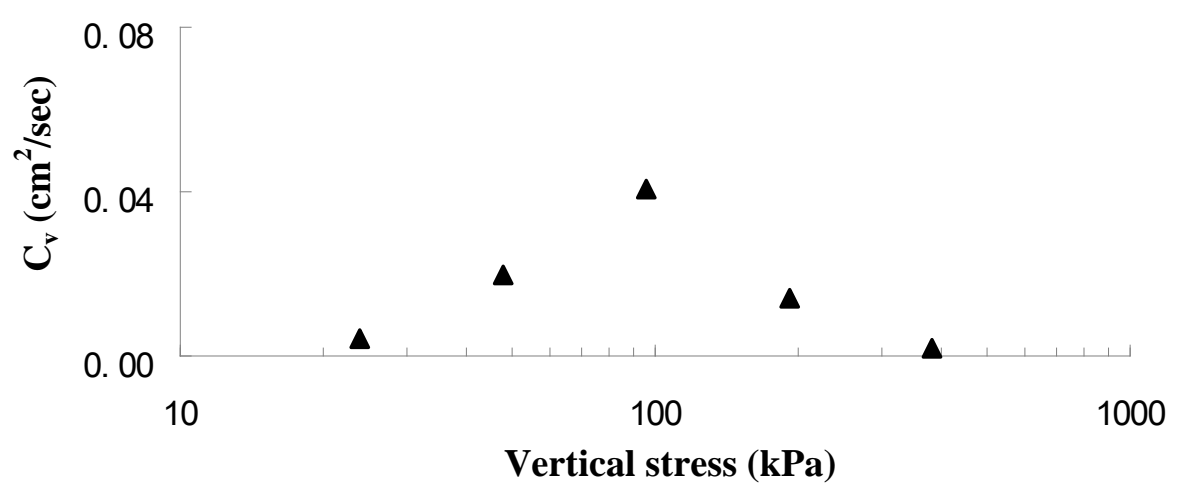

Figure 28 Semi-log plots $C_{v}$ versus $\sigma_{v}^{\prime}$ for I-69 


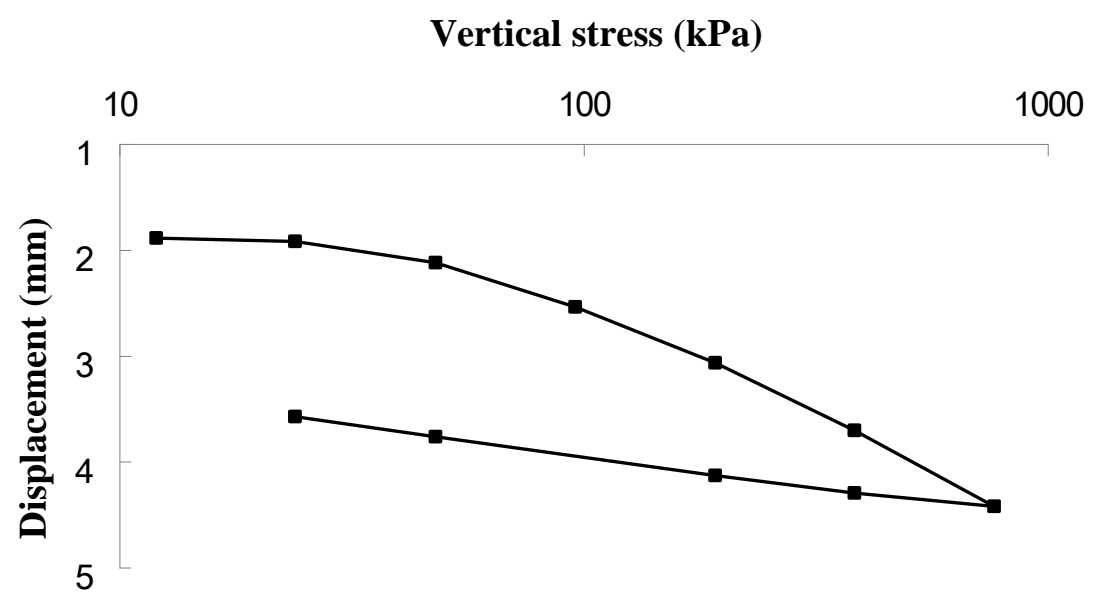

Figure 29 Semi-log plots of settlement versus vertical stress for I-69

\subsubsection{Triaxial Test}

From a triaxial test, it is possible to extract fundamental material parameters about the soil sample including its angle of internal friction, cohesion, and undrained shear strength. These parameters are then used to predict how the material will behave in a larger-scale engineering application. In this research, an isotropic consolidation undrained compression test (CIUC) was performed on the collected undisturbed sample, which was consolidated with mean effective stress at a depth where the sample was collected. For the tests, a Geocomp automated static triaxial testing device like the one shown in Figure 30 was used. The location for the test specimen was selected according to the soil boring test and the field CPT test results. The usual specimen size was $72 \mathrm{~mm}$ in diameter and about $150 \mathrm{~mm}$ in height. The specimen was saturated by backpressure saturation. Back pressure was gradually increased until B value exceeded 0.95. After saturation, the specimens were isotropically consolidated by applying effective confining stress and sheared. The CU triaxial test results for I-69 site are summarized in Table 4. 


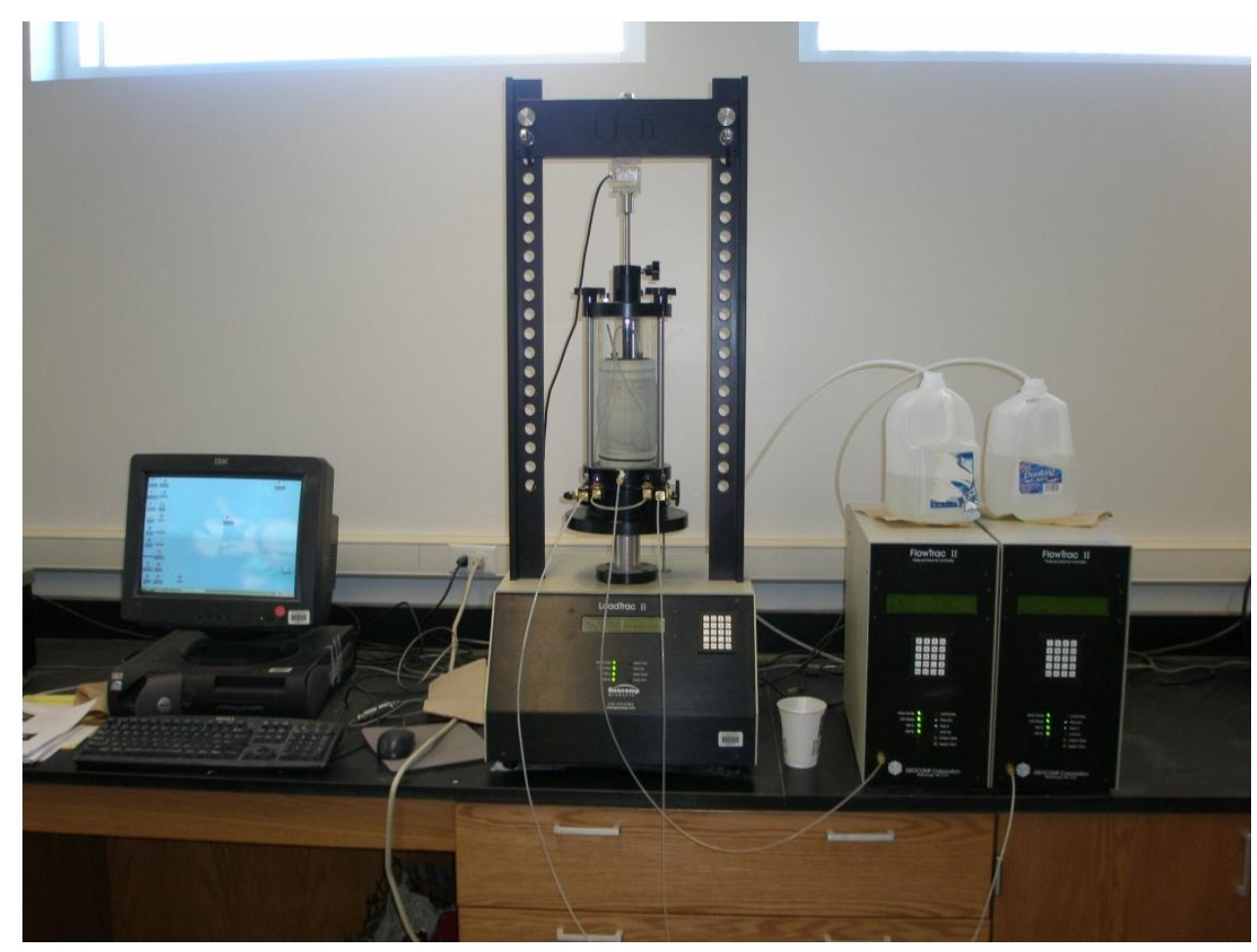

Figure 30 Geocomp automated static triaxial testing apparatus

Table 4 Summary of triaxial test results for I-69

\begin{tabular}{c|cc}
\hline Depth $(\mathrm{m})$ & Overburden stress $(\mathrm{kPa})$ & Undrained shear strength $(\mathrm{kPa})$ \\
\hline 1.68 & 35.2 & 55.2 \\
\hline
\end{tabular}

\subsection{Site 2: SR-49}

The second site is located on SR-49 (on the north side of Oliver Ditch) in Jasper County, Indiana. Cone penetration test (CPT) results and the soil profile for the main pile location are shown in Figure 31. The subsoil profile is composed of multiple layers of various types of soils. The groundwater table is encountered at a depth of $1 \mathrm{~m}$ from the surface. Shelby tube samples taken from different depths are numbered from TB-1 to TB16. Clayey soils are found from $9 \mathrm{~m}$ to $20 \mathrm{~m}$. 


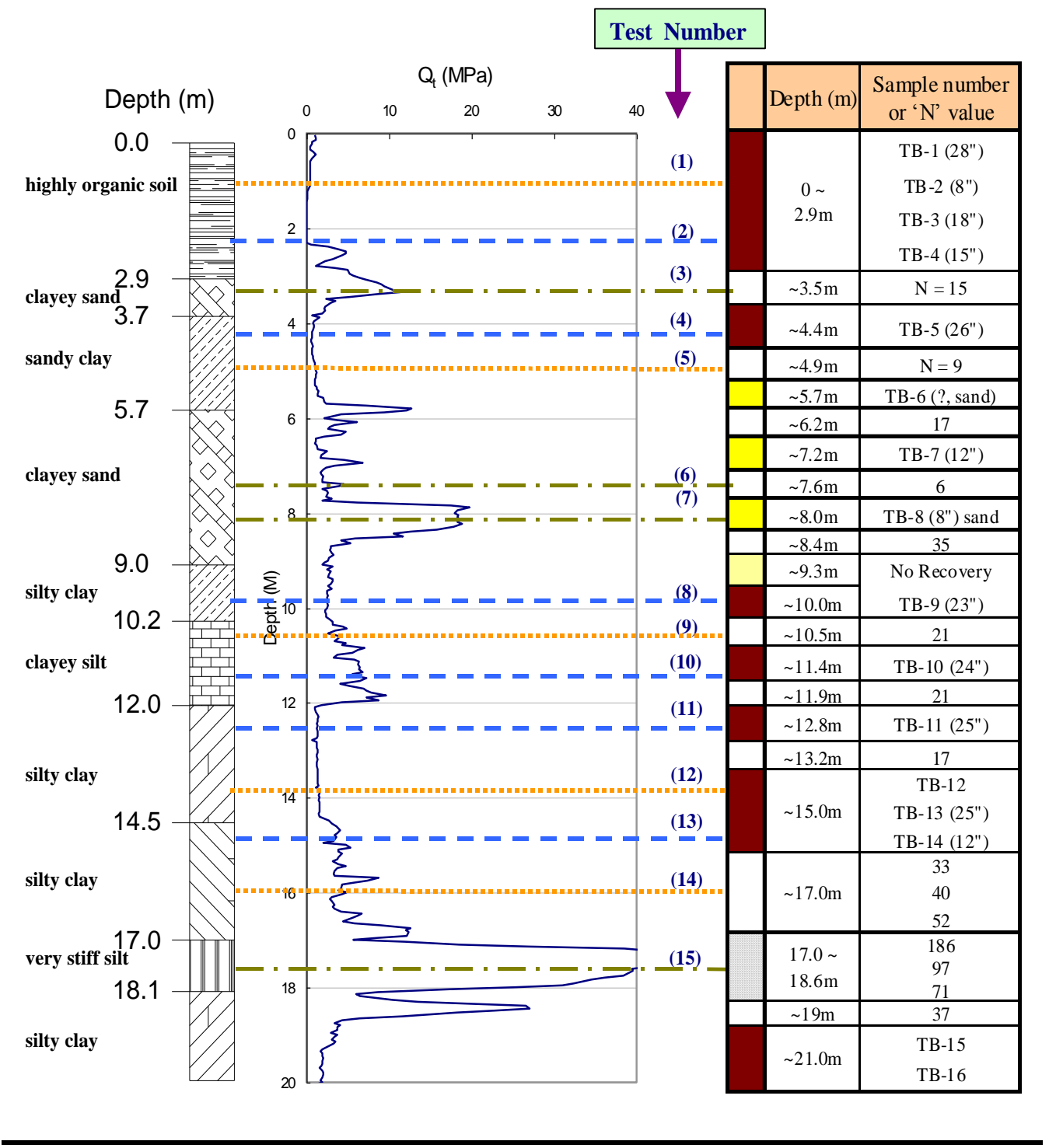

Figure 31 Soil profile for the SR-49 site

A series of laboratory tests were carried out to estimate the mechanical behavior of soil where the cone penetration test (CPT) was done. The same test program applied to site 1: I-69 was used. TB-9, TB-10, TB-11 and TB-14 were clayey soils. Sieve and hydrometer analysis were undertaken for all the clayey soil layers. Atterberg limits and the natural water content was obtained. Table 5 summarizes these basic properties of the soil layers. One dimensional consolidation tests were performed on samples collected 
from the same soil layers. The coefficients of consolidation $C_{v}$ for all the soil layers are presented in Table 6 and Figures 32, 33, 34 and 35. An isotropic consolidation undrained compression test (CIUC) was also performed following the same sequence and the triaxial test results are summarized in Table 7.

Table 5 Summary of index test results for SR-49

\begin{tabular}{|c|c|c|c|c|c|c|c|c|c|}
\hline \multirow{2}{*}{ Soil Layer } & $\begin{array}{c}\text { Gravel } \\
(\%)\end{array}$ & Sand $(\%)$ & Silt (\%) & \multirow{2}{*}{$\begin{array}{l}\text { Clay } \\
(\%)\end{array}$} & \multirow{2}{*}{$\begin{array}{l}\mathrm{LL} \\
(\%)\end{array}$} & \multirow{2}{*}{$\begin{array}{l}\text { PL } \\
(\%)\end{array}$} & \multirow{2}{*}{$\begin{array}{c}I_{p} \\
(\%)\end{array}$} & \multirow{2}{*}{$\begin{array}{l}\mathrm{W} \\
(\%)\end{array}$} & \multirow{2}{*}{$\begin{array}{c}\mathrm{LI} \\
(\%)\end{array}$} \\
\hline & $\sim 2 \mathrm{~mm}$ & $\sim 0.075 \mathrm{~mm}$ & $\begin{array}{c}\sim 0.002 \\
\mathrm{~mm}\end{array}$ & & & & & & \\
\hline TB-9 & - & 1.6 & 82 & 16.4 & 36.6 & 17.5 & 19.1 & 25.4 & 0.41 \\
\hline TB-10 & - & 1.7 & 83.2 & 15.1 & 28.6 & 18.8 & 9.8 & 23.2 & 0.45 \\
\hline TB-11 & - & 14.9 & 63.7 & 21.4 & 21.1 & 11.8 & 9.3 & 15.4 & 0.38 \\
\hline TB-14 & - & 5.1 & 65.4 & 29.5 & 21.9 & 11.8 & 10.2 & 11.3 & \\
\hline
\end{tabular}

Table 6 Coefficient of consolidation $C_{v}\left(\mathrm{~cm}^{2} / \mathrm{sec}\right)$ for TB-9 for SR-49

\begin{tabular}{c|ccccccc}
\hline $\begin{array}{c}\text { Soil } \\
\text { Layer }\end{array}$ & $12 \mathrm{kPa}$ & $50 \mathrm{kPa}$ & $100 \mathrm{kPa}$ & $200 \mathrm{kPa}$ & $400 \mathrm{kPa}$ & $800 \mathrm{kPa}$ & $1600 \mathrm{kPa}$ \\
\hline TB-9 & 0.0025 & 0.0052 & 0.0068 & 0.0173 & 0.0116 & 0.0126 & 0.0121 \\
\hline TB-10 & 0.0251 & 0.0455 & 0.0343 & 0.0861 & 0.0835 & 0.0800 & 0.0532 \\
\hline TB-11 & 0.0012 & 0.0022 & 0.0053 & 0.0035 & 0.0037 & 0.0062 & 0.0083 \\
\hline TB-14 & 0.0038 & 0.0010 & 0.0006 & 0.0012 & 0.0004 & 0.0003 & 0.0002 \\
\hline
\end{tabular}




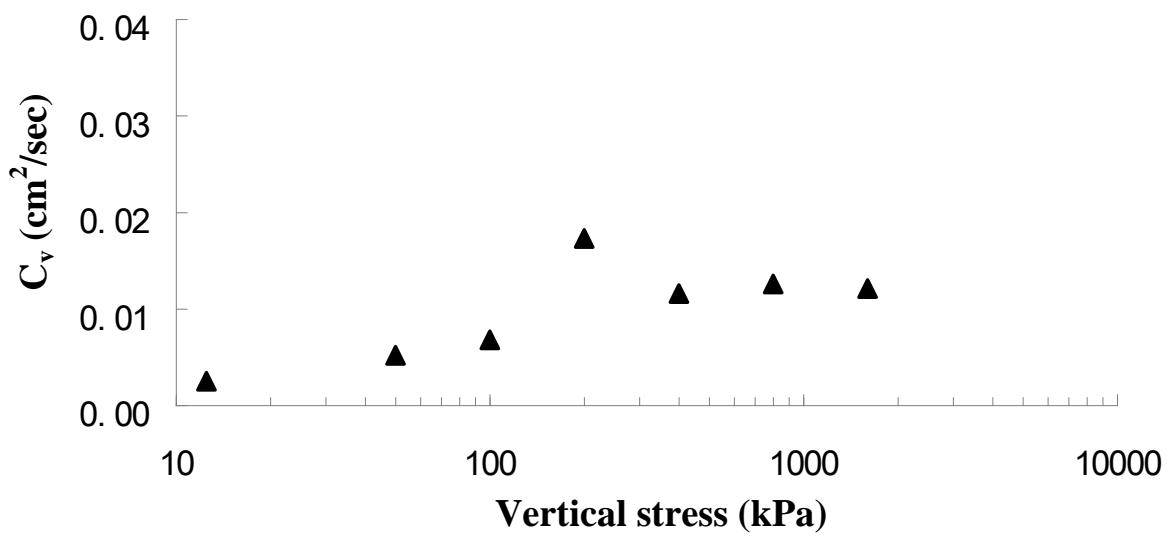

Figure 32 Semi-log plots $C_{v}$ versus $\sigma_{v}^{\prime}$ for TB-9

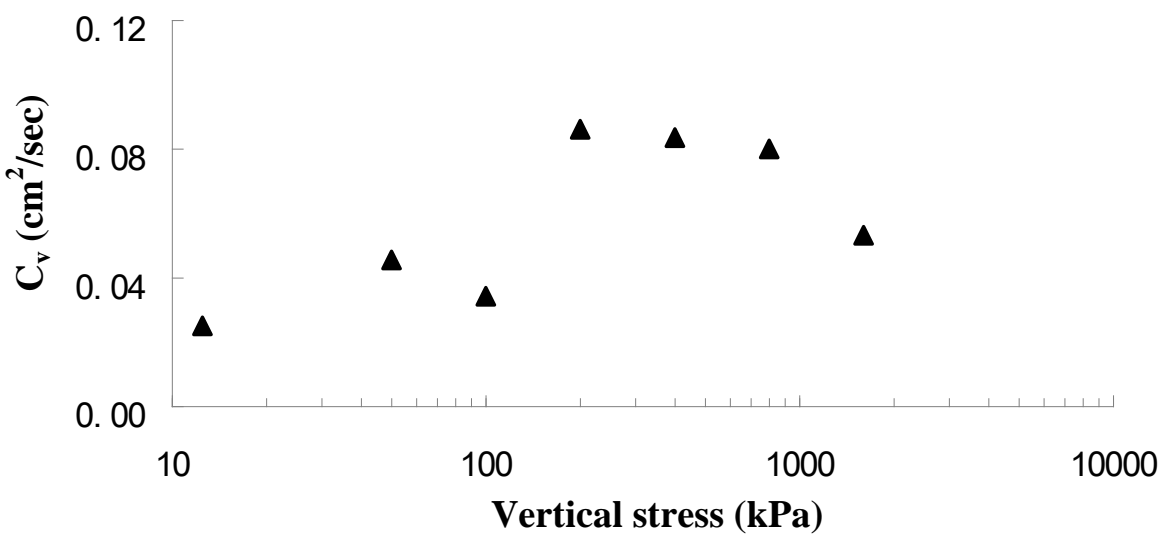

Figure 33 Semi-log plots $C_{v}$ versus $\sigma_{v}^{\prime}$ for TB-10 


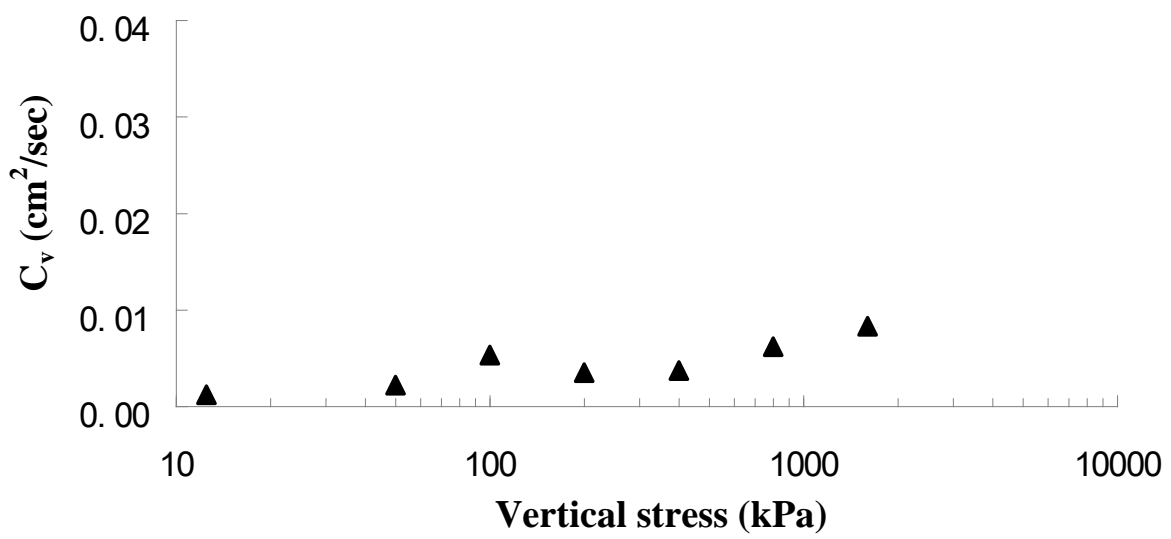

Figure 34 Semi-log plots $C_{v}$ versus $\sigma_{v}^{\prime}$ for TB-11

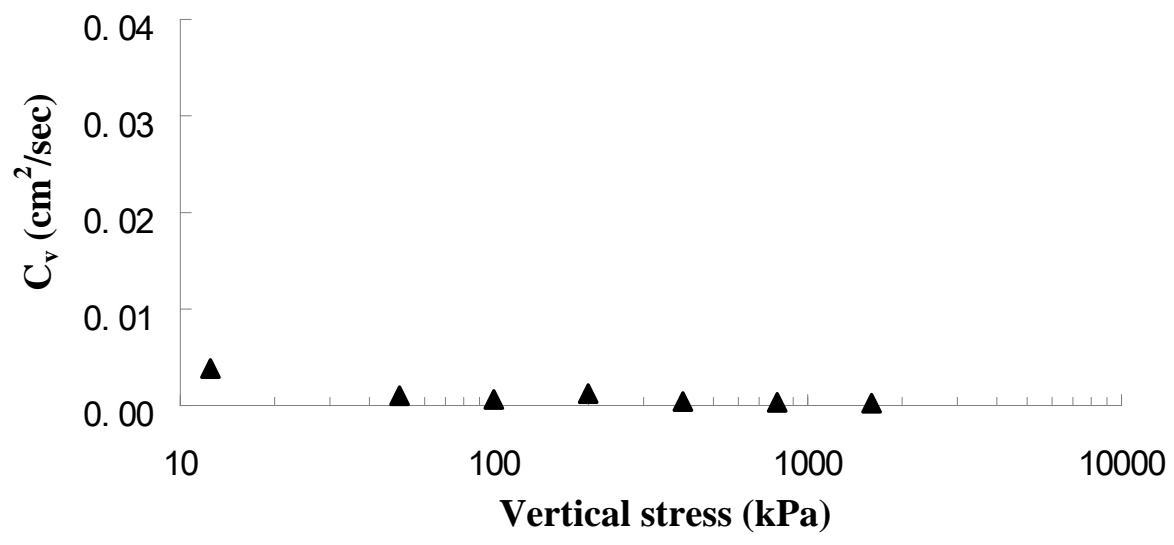

Figure 35 Semi-log plots $C_{v}$ versus $\sigma_{v}^{\prime}$ for TB-14

Table 7 Summary of triaxial test results for SR-49 


\begin{tabular}{c|cc}
\hline Soil layer & Overburden stress $(\mathrm{kPa})$ & Undrained shear strength $(\mathrm{kPa})$ \\
\hline TB-9 & 105 & 183 \\
\hline TB-10 & 126 & 319 \\
\hline TB-11 & 133 & 102 \\
\hline TB-14 & 174 & 290 \\
\hline
\end{tabular}

\subsection{Site 3: US-24}

The third site is along the US-24 highway and is located in Milan and Maumee Townships, Allen County, Indiana. Cone penetration test (CPT) results and the soil profile are shown in Figure 36. As shown in Figure 36, the soil profile up to $15 \mathrm{~m}$ is composed of clayey soil layers. Shelby tube samples were taken from $5 \mathrm{~m}$ to $7 \mathrm{~m}$ in order to run the test program. 


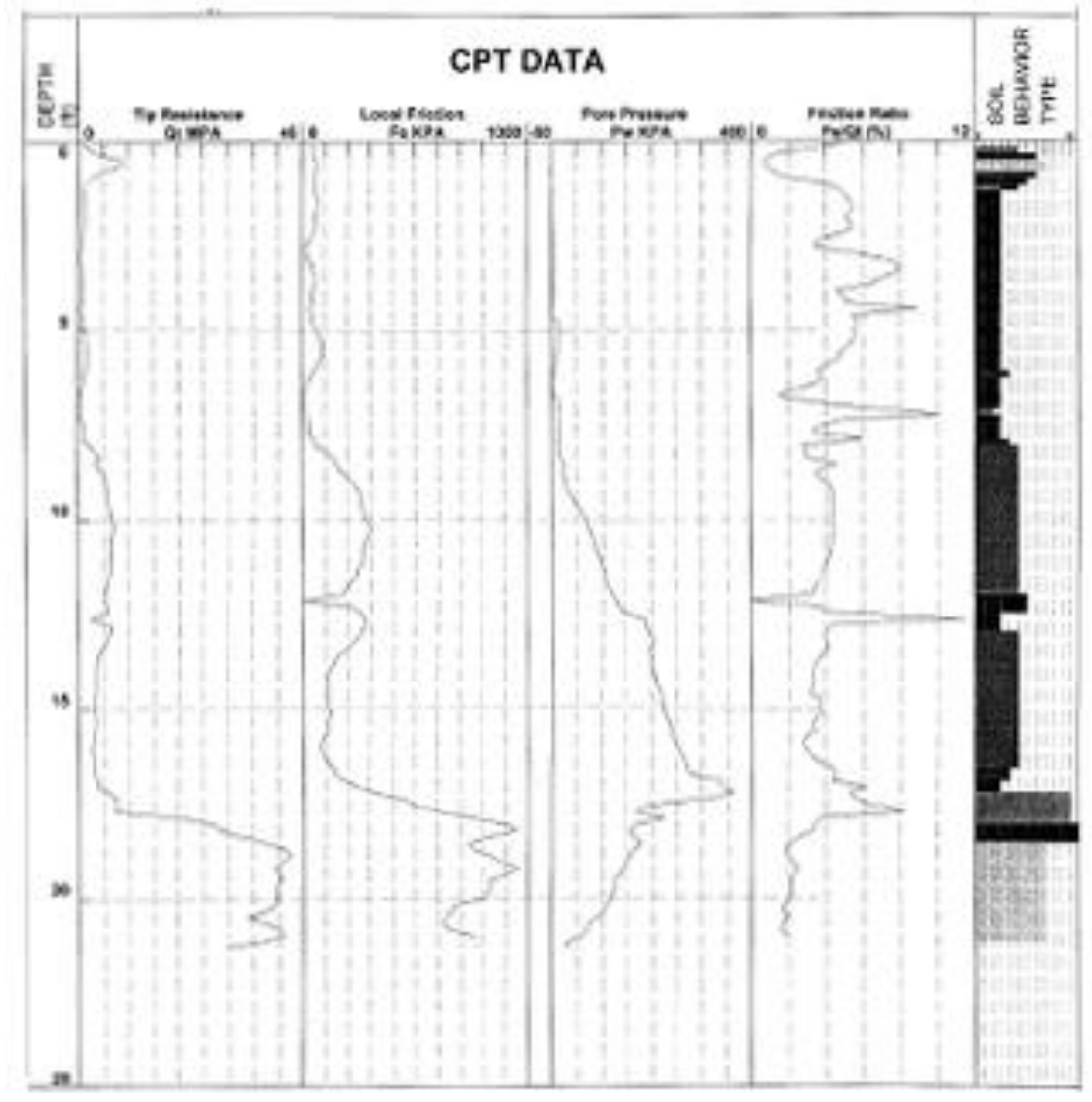

Figure 36 Soil profile for the US-24 site

A series of laboratory tests were carried out to estimate the mechanical behavior of soil where the cone penetration test (CPT) was done. The same test program applied to the first and second sites was used. Sieve and hydrometer analysis for the clayey soil layer from $1.5 \mathrm{~m}$ to $2.1 \mathrm{~m}$ is shown in Figure 37 . Table 8 summarizes the results of the Atterberg limit tests for the soil layers. The clays at $1.83 \mathrm{~m}$ depth have a liquid limit (LL) of $38 \%$ and a plastic limit (PL) of $20 \%$, and $I_{p}=18 \%$. One-dimensional consolidation tests were performed on samples collected from the same soil layers. The coefficients of consolidation $C_{v}$ for the clayey soil layer are presented in Table 9 and Figure 38. Semi$\log$ plots of settlement versus vertical stress are obtained in Figure 39. The effective preconsolidation stress was determined with Cassagrade`s method and the calculated over-consolidation ratio at the US-24 site was 2.8 as shown in Table 10. An isotropic 
consolidation undrained compression test (CIUC) was also performed following the same sequence. The triaxial test results are summarized in Table 11.

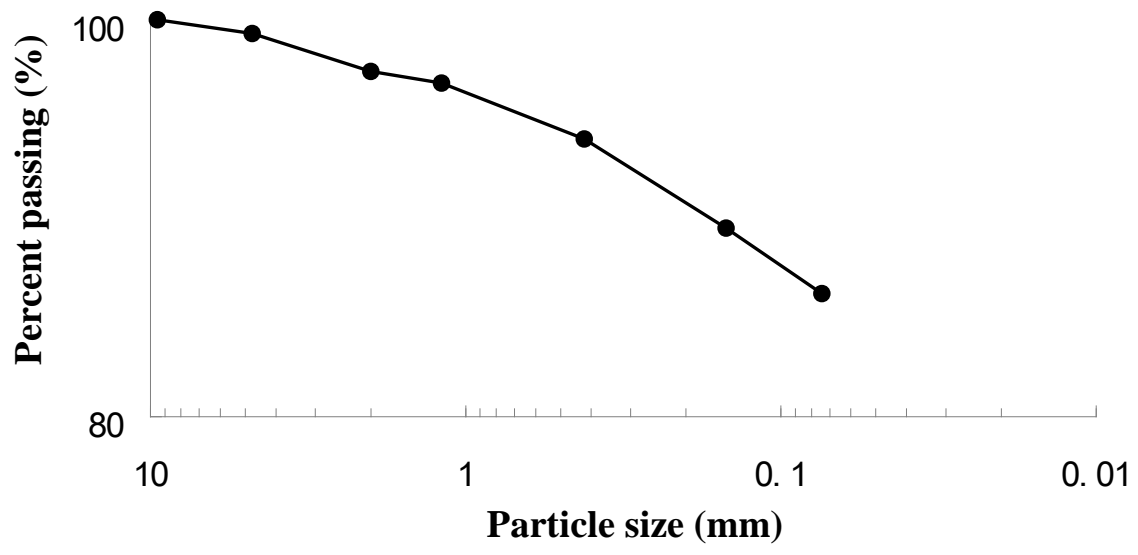

Figure 37 Grain size distribution of the clayey soil in US-24

Table 8 Summary of laboratory index testing for US-24

\begin{tabular}{c|cccc}
\hline Depth (m) & $\mathrm{W}(\%)$ & LL $(\%)$ & PL (\%) & $I_{p}(\%)$ \\
\hline 1.83 & 24.0 & 38.0 & 20.0 & 18.0 \\
\hline
\end{tabular}

Table 9 Coefficient of consolidation $C_{v}\left(\mathrm{~cm}^{2} / \mathrm{sec}\right)$ for US-24

\begin{tabular}{c|ccccccc}
\hline Depth (m) & $12 \mathrm{kPa}$ & $24 \mathrm{kPa}$ & $48 \mathrm{kPa}$ & $96 \mathrm{kPa}$ & $192 \mathrm{kPa}$ & $382 \mathrm{kPa}$ & $766 \mathrm{kPa}$ \\
\hline 1.83 & 0.0157 & 0.0102 & 0.0212 & 0.0230 & 0.0232 & 0.0039 & 0.0035 \\
\hline
\end{tabular}


Table 10 Effective preconsolidation stress $\sigma_{p}^{\prime}$ and OCR for US-24

\begin{tabular}{c|ccc}
\hline Depth $(\mathrm{m})$ & $\begin{array}{c}\text { Effective Preconsolidation } \\
\text { stress }(\mathrm{kPa})\end{array}$ & $\begin{array}{c}\text { Vertical effective stress } \\
(\mathrm{kPa})\end{array}$ & OCR \\
\hline 1.83 & 57.8 & 20.5 & 2.8 \\
\hline
\end{tabular}

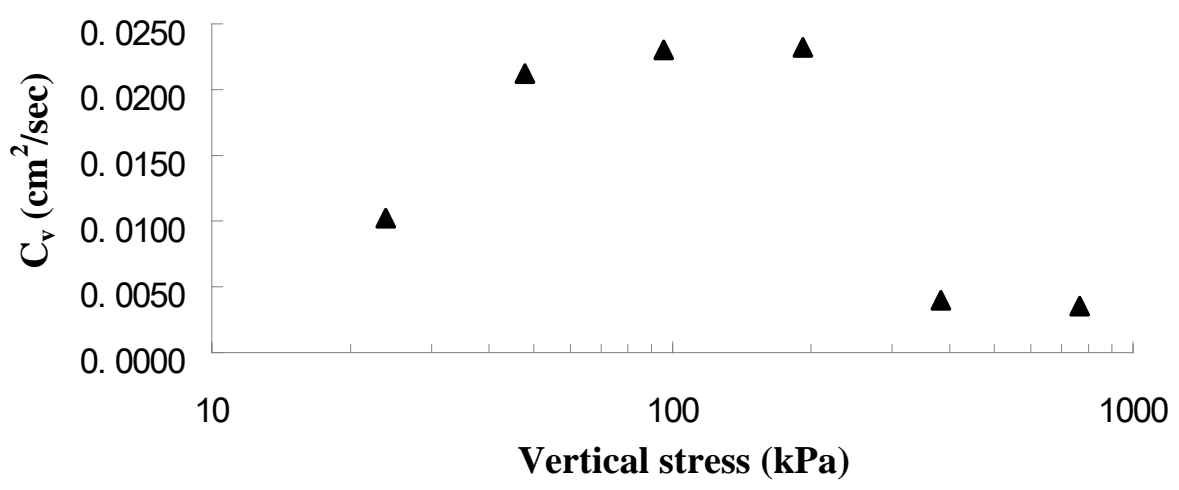

Figure 38 Semi-log plots $C_{v}$ versus $\sigma_{v}^{\prime}$

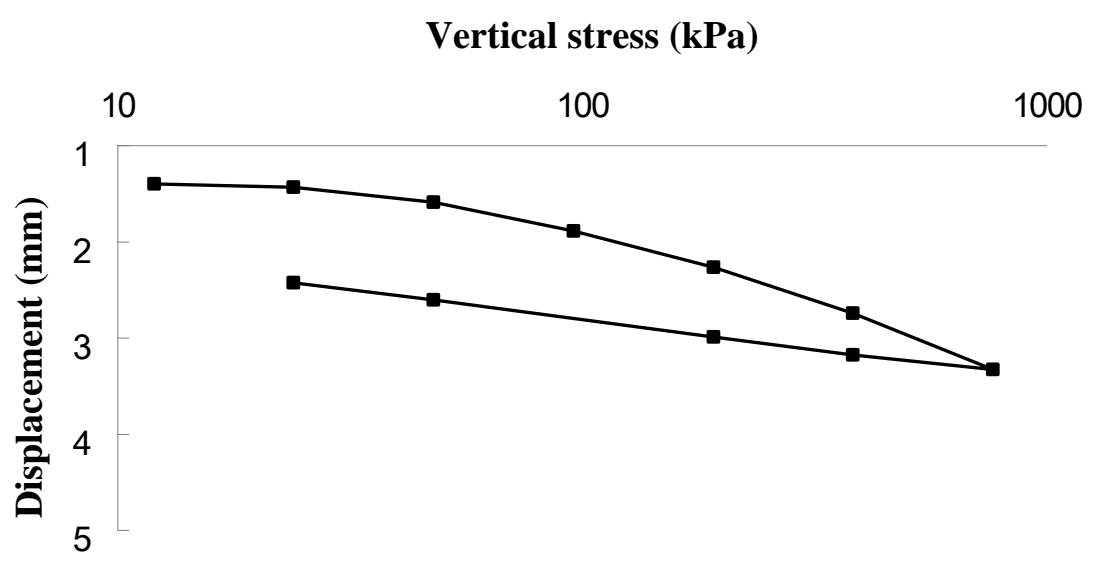

Figure 39 Semi-log plots of settlement versus vertical stress for US-24 
Table 11 Summary of triaxial test results for US-24

\begin{tabular}{c|cc}
\hline Depth $(\mathrm{m})$ & Overburden stress $(\mathrm{kPa})$ & Undrained shear strength $(\mathrm{kPa})$ \\
\hline 1.83 & 40.2 & 120.1 \\
\hline
\end{tabular}

\subsection{Site 4: US-31}

The fourth site is located on the US-31 highway in Howard County, Indiana. Cone penetration test (CPT) results and the soil profile are shown in Figure 40. The subsoil profile includes multiple layers of several types of soils. Shelby tube samples taken from several sites near US-31 are numbered from RB-1 to RB-114. Clayey soils from RB-99, RB-114 and RB-31 were investigated by the test program. 


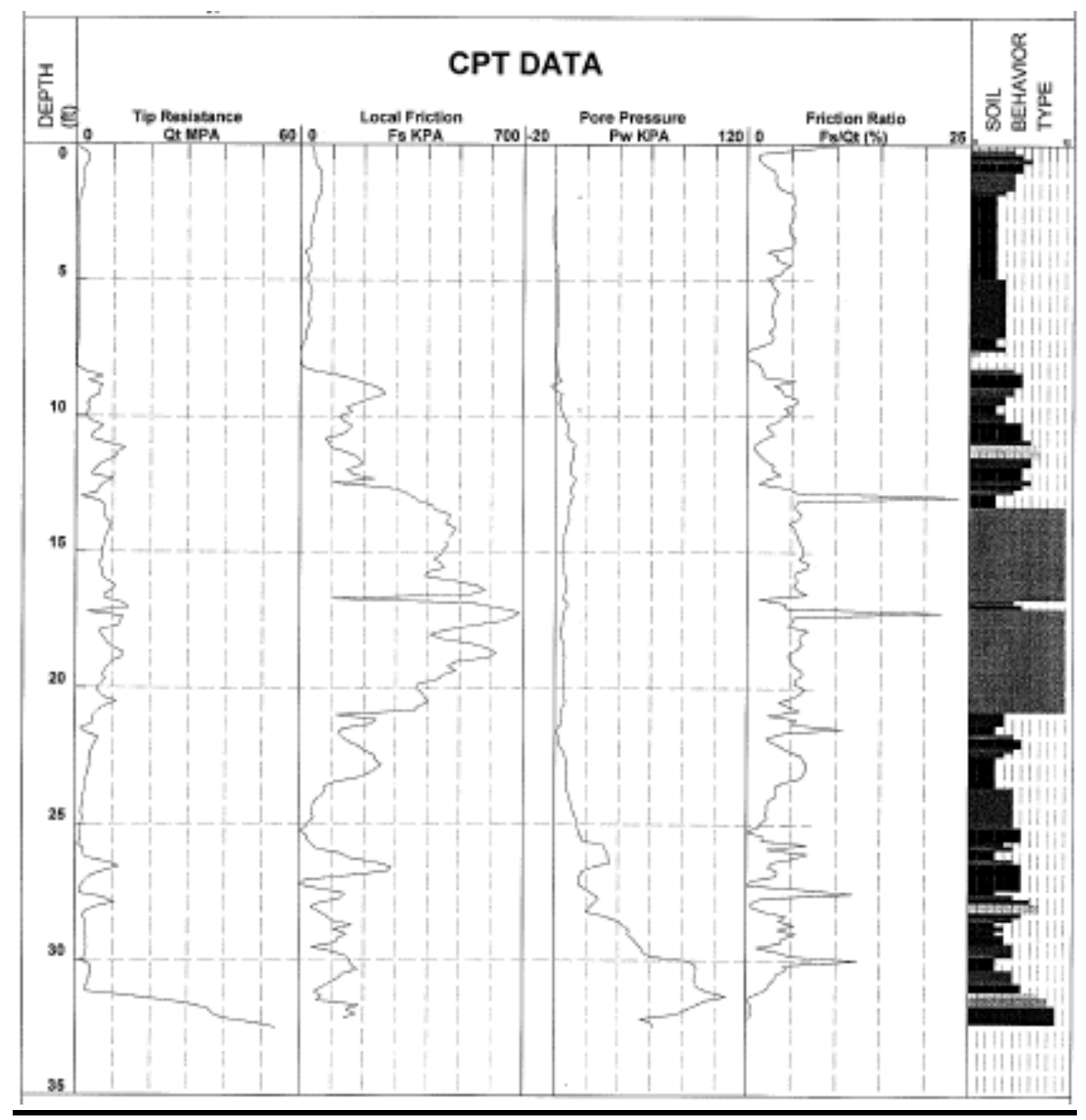

Figure 40 Soil profile for the US-31 site

A series of laboratory tests were carried out to estimate the mechanical behavior of soil where cone penetration tests (CPT) were done. The same test program as before was used. The soils used were from $1.83 \mathrm{~m}$ to $2.43 \mathrm{~m}$ for RB-99 and RB-114, and from $2.43 \mathrm{~m}$ to $3.04 \mathrm{~m}$ from RB-31. Atterberg limits as well as natural water content for all these clayey soil layers were summarized in Table 12. One-dimensional consolidation tests were performed on samples collected from the same soil layers. The coefficients of consolidation $C_{v}$ for all the soil layers are presented in Table 13 and Figures 41, 42, and 43. Semi-log plots of settlement versus vertical stress are obtained in Figures 44, 45, and 46. The effective preconsolidation stress was determined with Cassagrande`s method and the calculated over-consolidation ratios at RB-99, RB-114 and RB-31 are 3.6, 5.1 and 11.8 respectively, as shown in Table 14. An isotropic consolidation undrained 
compression test (CIUC) was also performed according to the same sequence and the triaxial test results are summarized in Table 15.

Table 12 Summary of laboratory index testing for US-31

\begin{tabular}{c|cccc}
\hline Soil layer & W (\%) & LL $(\%)$ & PL $(\%)$ & $I_{p}(\%)$ \\
\hline RB-99 & 12.1 & 18.9 & 13.6 & 5.3 \\
\hline RB-114 & 15.1 & 23.0 & 15.1 & 7.9 \\
\hline RB-31 & 13.1 & 17.9 & 13.1 & 4.8 \\
\hline
\end{tabular}

Table 13 Coefficient of consolidation $C_{v}\left(\mathrm{~cm}^{2} / \mathrm{sec}\right)$ for US-31

\begin{tabular}{c|cccccc}
\hline $\begin{array}{c}\text { Soil } \\
\text { Layer }\end{array}$ & $12 \mathrm{kPa}$ & $50 \mathrm{kPa}$ & $100 \mathrm{kPa}$ & $200 \mathrm{kPa}$ & $400 \mathrm{kPa}$ & $800 \mathrm{kPa}$ \\
\hline RB-99 & 0.0024 & 0.0002 & 0.0015 & 0.0086 & 0.0004 & 0.0008 \\
\hline RB-114 & 0.00008 & 0.00007 & 0.00005 & 0.00003 & 0.00001 & 0.00001 \\
\hline RB-31 & 0.0002 & 0.0002 & 0.0002 & 0.0004 & 0.0004 & 0.0003 \\
\hline
\end{tabular}


Table 14 Effective preconsolidation stress $\sigma_{p}^{\prime}$ and OCR for US-31

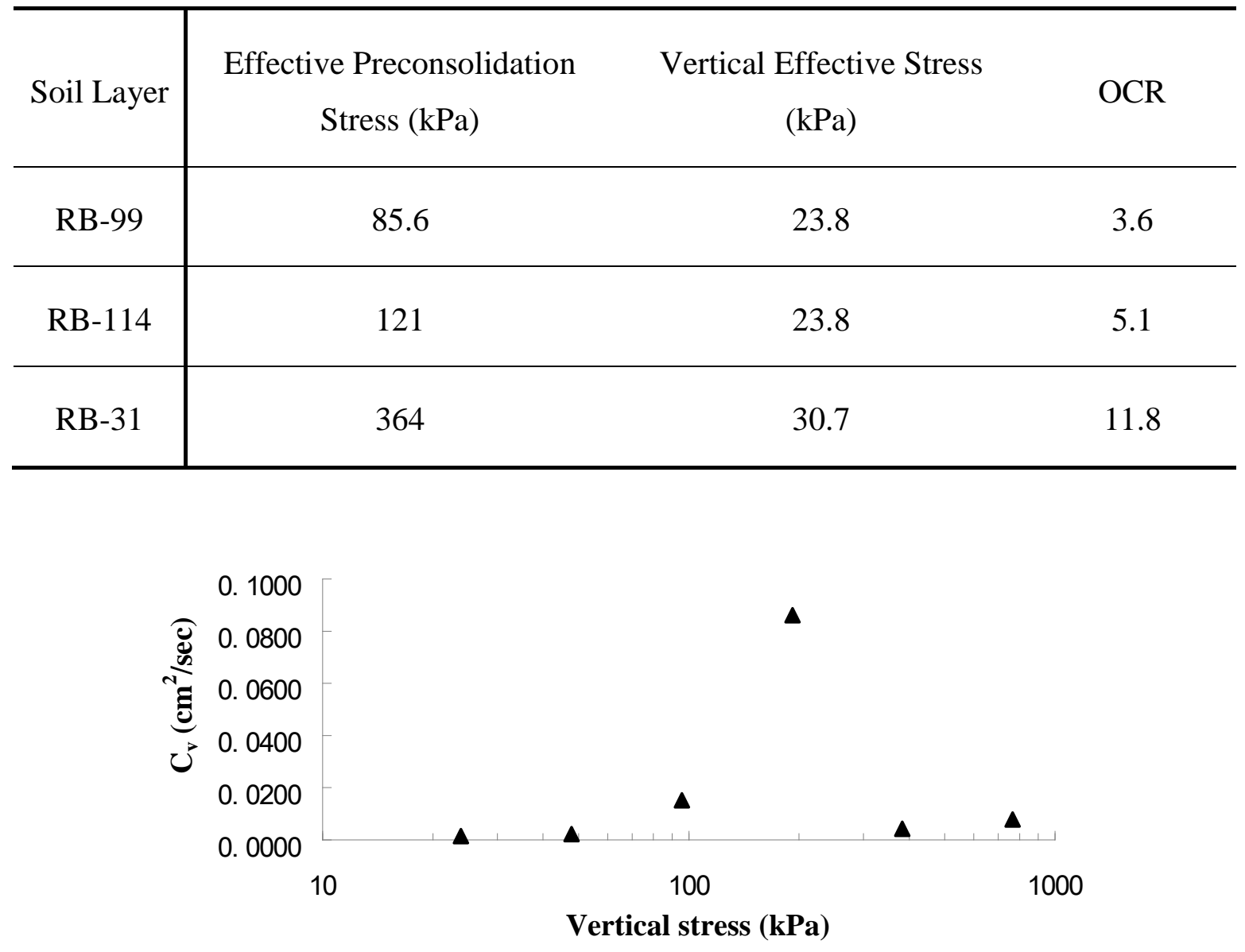

Figure 41 Semi-log plots $C_{v}$ versus $\sigma_{v}^{\prime}$ for RB-99 


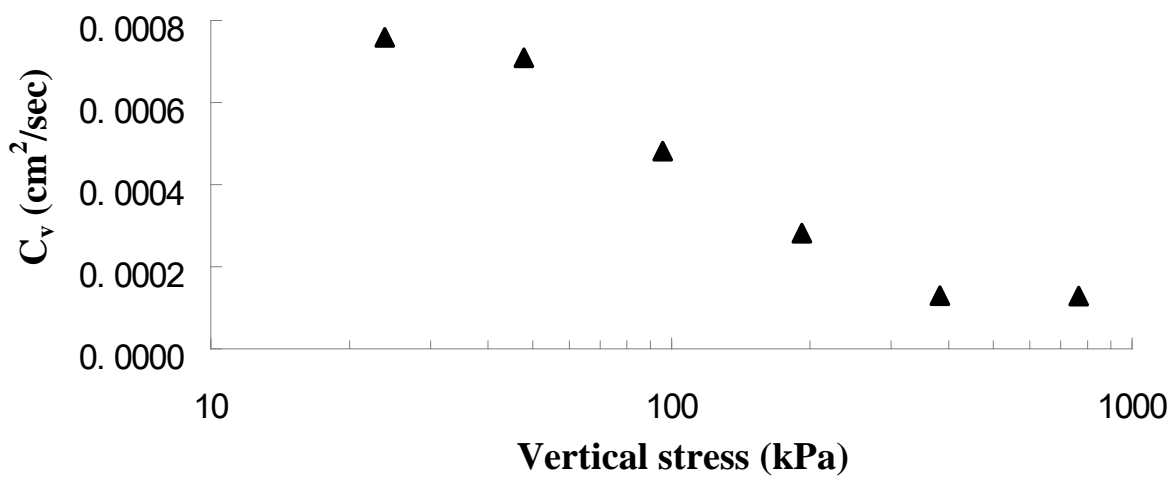

Figure 42 Semi-log plots $C_{v}$ versus $\sigma_{v}^{\prime}$ for RB-114

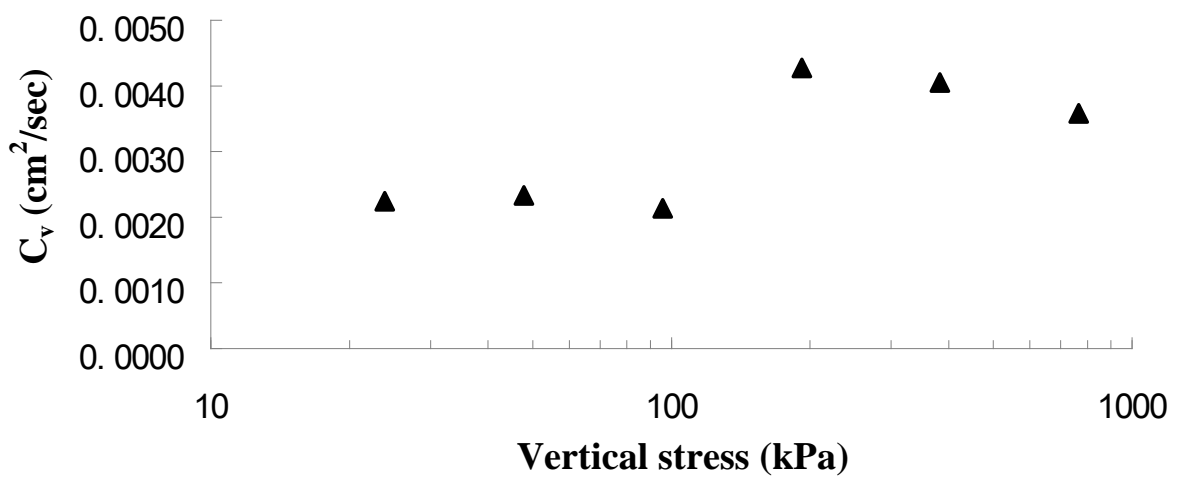

Figure 43 Semi-log plots $C_{v}$ versus $\sigma_{v}^{\prime}$ for RB-31 


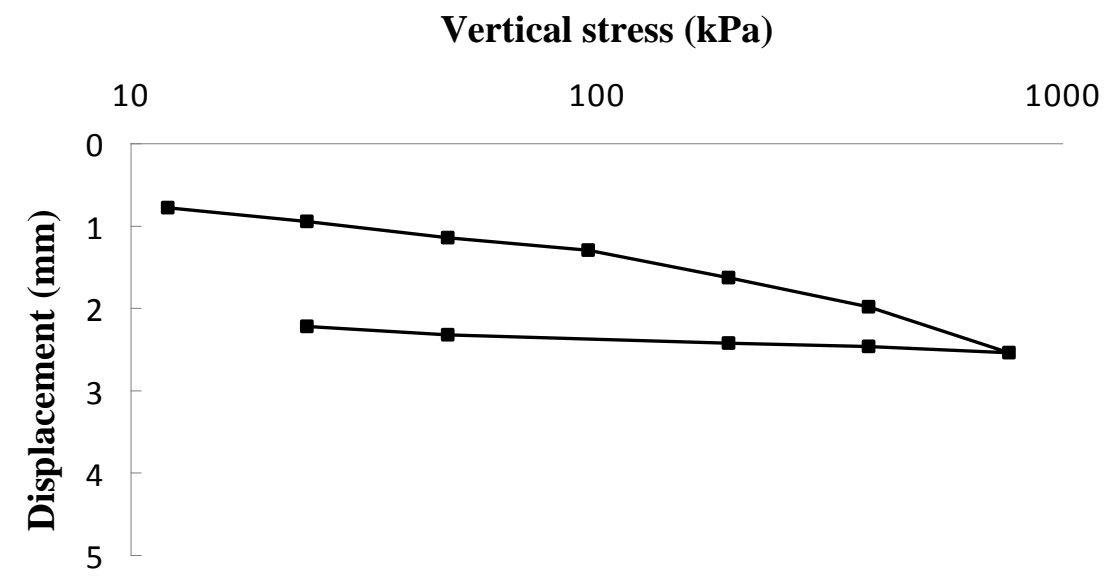

Figure 44 Semi-log plots of settlement versus vertical stress for RB-99

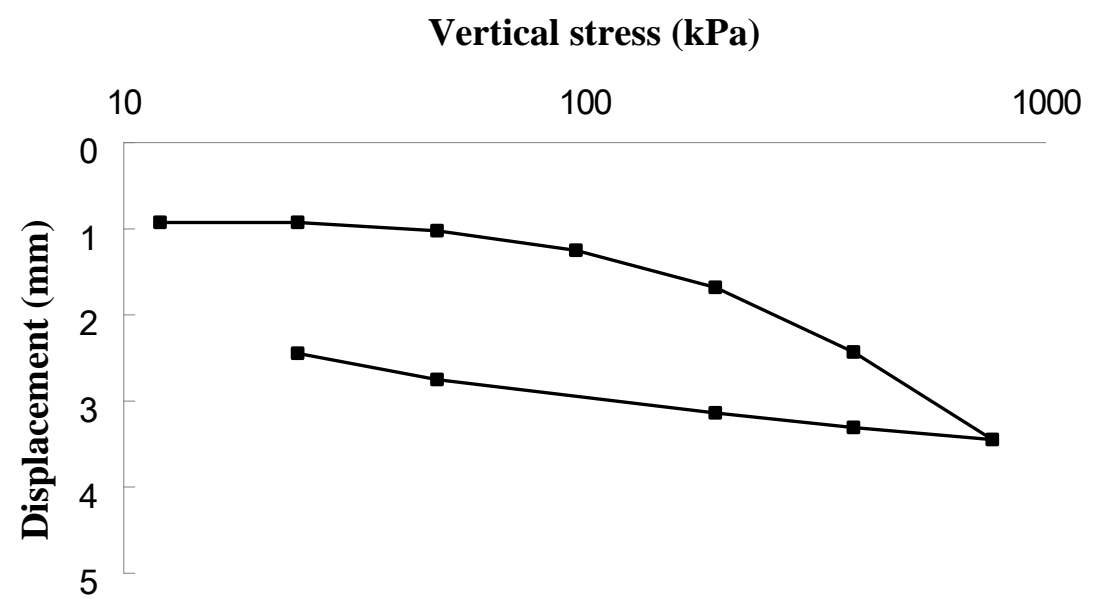

Figure 45 Semi-log plots of settlement versus vertical stress for RB-114 


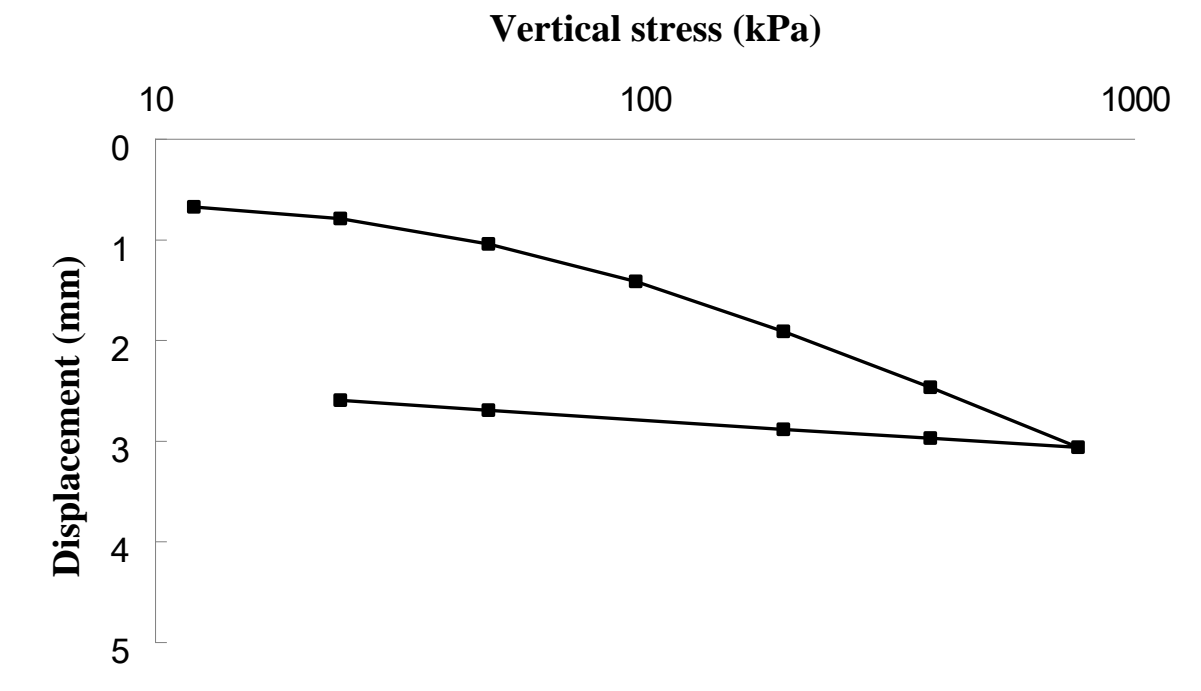

Figure 46 Semi-log plots of settlement versus vertical stress for RB-31

Table 15 Summary of triaxial test results for US-31

\begin{tabular}{c|cc}
\hline Soil layer & Overburden stress $(\mathrm{kPa})$ & Undrained shear strength $(\mathrm{kPa})$ \\
\hline RB-99 & 44.8 & 65.5 \\
\hline RB-114 & 45.0 & 333.5 \\
\hline RB-31 & 57.6 & 441.6 \\
\hline
\end{tabular}




\section{CHAPTER 5 SOIL PROPERTY ESTIMATION BASED ON CPT}

\section{$\underline{5.1 \text { Introduction }}$}

The cone penetration test (CPT) is considered one of the most useful in-situ tests and is widely used in onshore and offshore soil investigations at the present time. The cone penetration test (CPT) measures the cone resistance $q_{c}$, the sleeve friction resistance $f_{s}$, and the penetration pore pressure $u$. These measurements can be effectively used for applications: 1) to classify soil identification, 2) to directly estimate pile capacity from cone penetration tests (CPT) and 3) to evaluate soil properties through an appropriate correlation, especially the undrained shear strength $S_{u}$. Thus, the cone penetration test (CPT) can be used for a wide range of geotechnical engineering applications.

The undrained shear strength $S_{u}$ is one of the most important design parameters in clay soils, and most geotechnical designs in clay soils are conducted using undrained shear strength $S_{u}$. Undrained shear strength $S_{u}$ can be determined through several approaches: laboratory tests, in-situ tests, and empirical equations. The empirical equation is a powerful and simple method. However, some empirical correlations represent more or less local correlations, and are not always applicable to different types of soil (Robertson et al, 1986). Unless well-established local correlations have been developed, rational interpretation of undrained shear strength $S_{u}$ from cone penetration test (CPT) data is extremely difficult.

\section{$\underline{5.2 \text { Correlation between Undrained Shear Strength and Cone Resistance }}$}

The undrained shear strength $S_{u}$ of clay can be evaluated from cone resistance $q_{c}$ through an equation such as: 


$$
S_{u}=\frac{q_{t}-\sigma_{v}}{N_{k}}
$$

where $N_{k}$ is the cone factor and $\sigma_{v}$ is total overburden stress. The cone factor $N_{k}$ is most important for reliable estimation of undrained shear strength $S_{u}$ from cone resistance $q_{t}$. Therefore, numerous research programs have been conducted in order to develop accurate cone factor $N_{k}$ values (Lunne and Kleven, 1981; Aas et al., 1986; Rochelle et al., 1988; Lunne et al., 1986 and Strak and Juhrend, 1989). The cone factor is, however, influenced by types of soil, test methods for undrained shear strength $S_{u}$, and the penetration rate during cone penetration tests (CPT). It is necessary to calculate the cone factor $N_{k}$ values suitable for a localized soil. In this research, the cone factor $N_{k}$ values for Indiana clayey soils will be investigated for better and more accurate geotechnical design. Some examples of criteria suggested for cone factor $N_{k}$ values are shown in Figure 47 and Figure 48 (Nash and Duffin, 1982 and O`riordan et al., 1982).

Some researchers claim the cone factor $N_{k}$ is also affected by a plasticity index $I_{p}$, and suggest correlations between $N_{k}$ and $I_{p}$ (Lunne et al. 1976, Baligh et al. 1980, Lunne and Kleven 1981, Aas et al. 1986, and Rochelle et al. 1988). Lunne et al. (1976) collected 6 sites of Scandinavian soft to medium stiff clay and presented $N_{k}$ from undrained shear strength $S_{u}$ values obtained from field vane tests and $I_{p}$ as shown in Figure 49. The results of this study show the decreasing trend of cone factors for the plasticity index even though the results have some scatters. The cone factor $N_{k}$ decreases from 24 to 8 as plasticity index $I_{p}$ increases from 5 to 55. Baligh et al. (1980) gathered data from NGI and MIT, and suggested similarly decreasing behavior with the range of cone factor $N_{k}$ between 18 and 10 in case of plasticity index $I_{p}$ between 5 and 50, as shown in Figure 50. In addition, the values of undrained shear strength $S_{u}$ used for correlation were obtained from field vane tests. Aas et al. (1986) considered cone area ratio and presented an opposite trend for young and aged quick clays with Lunne et al. 
(1976) and Baligh et al. (1980). The cone factor $N_{k}$ increases with the plasticity index from 13 at $I_{p}=0$ to 19 at $I_{p}=50$. In the case of over-consolidated quick clays, the results fall outside the band (See Figure 51). La Rochelle et al. (1998) could not find any correlation between the cone factor and the plasticity index. In any case, the trend of cone factors $N_{k}$ are not consistent and based on localized soil data. It is evident that there is not a clear and reliable correlation between cone factor $N_{k}$ and plasticity index $I_{p}$ so far.

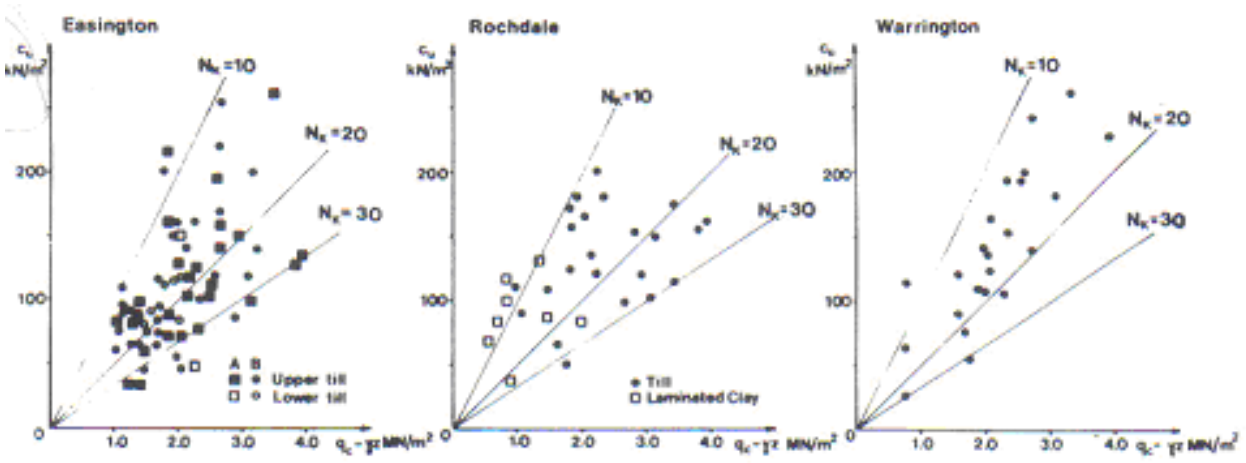

Figure 47 The cone factor $N_{k}$ values for clayey soils in England (Nash and Duffin, 1982)

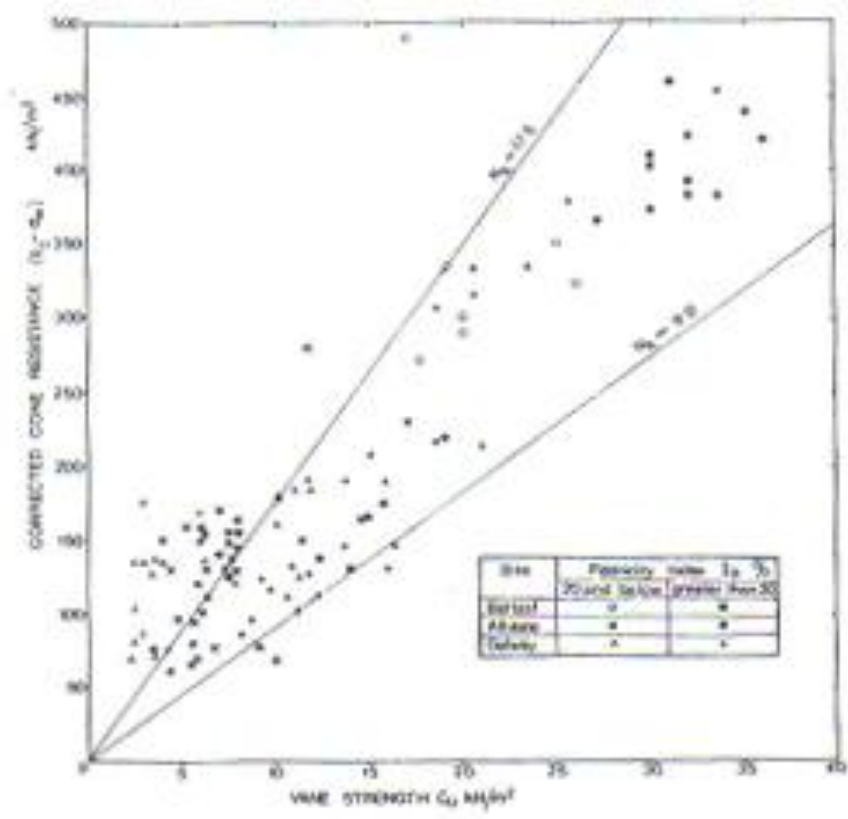

Figure 48 The cone factor $N_{k}$ values for clayey soils in England (O’riordan et al., 1982) 


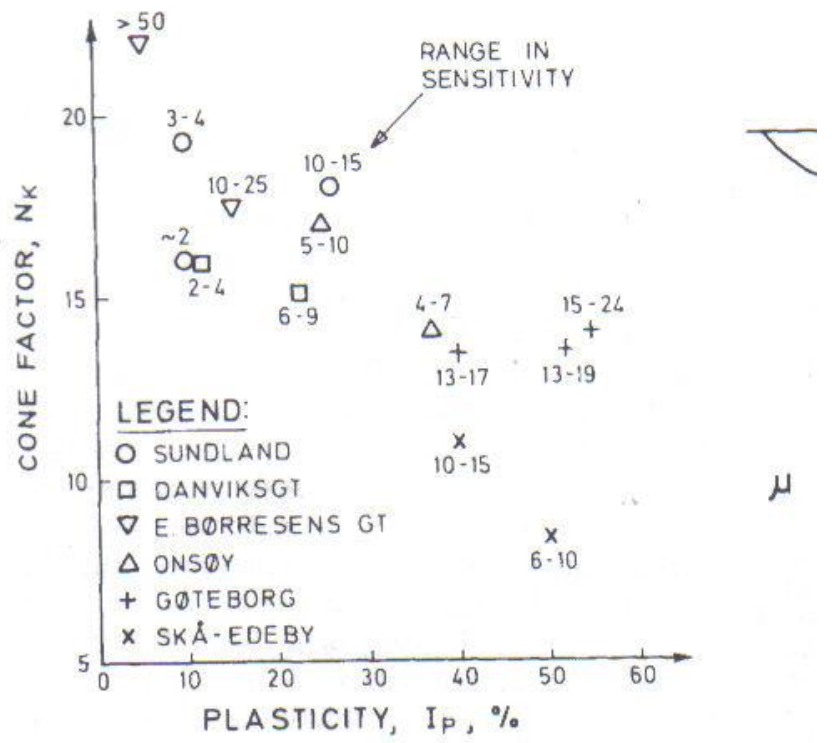

Fig. 8. Summary of $N_{\mathrm{k}}$ values from all sites.

Figure 49 Correlations between cone factor $N_{k}$ and plasticity index (Lunne et al., 1976)

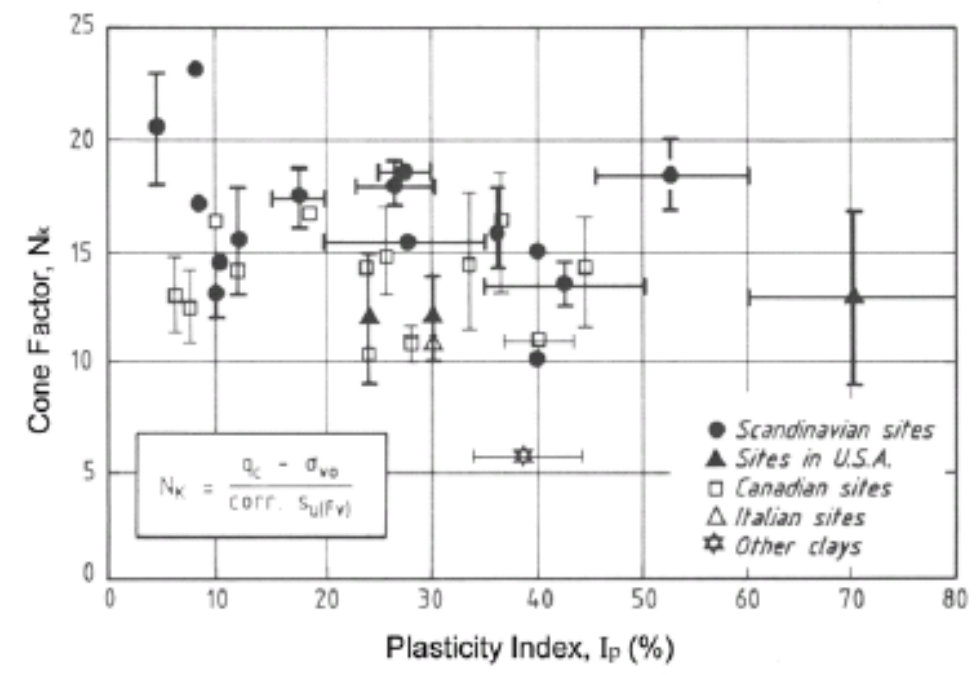

Figure 50 Correlations between cone factor $N_{k}$ and plasticity index $I_{p}$ (Baligh et al.,1980) 


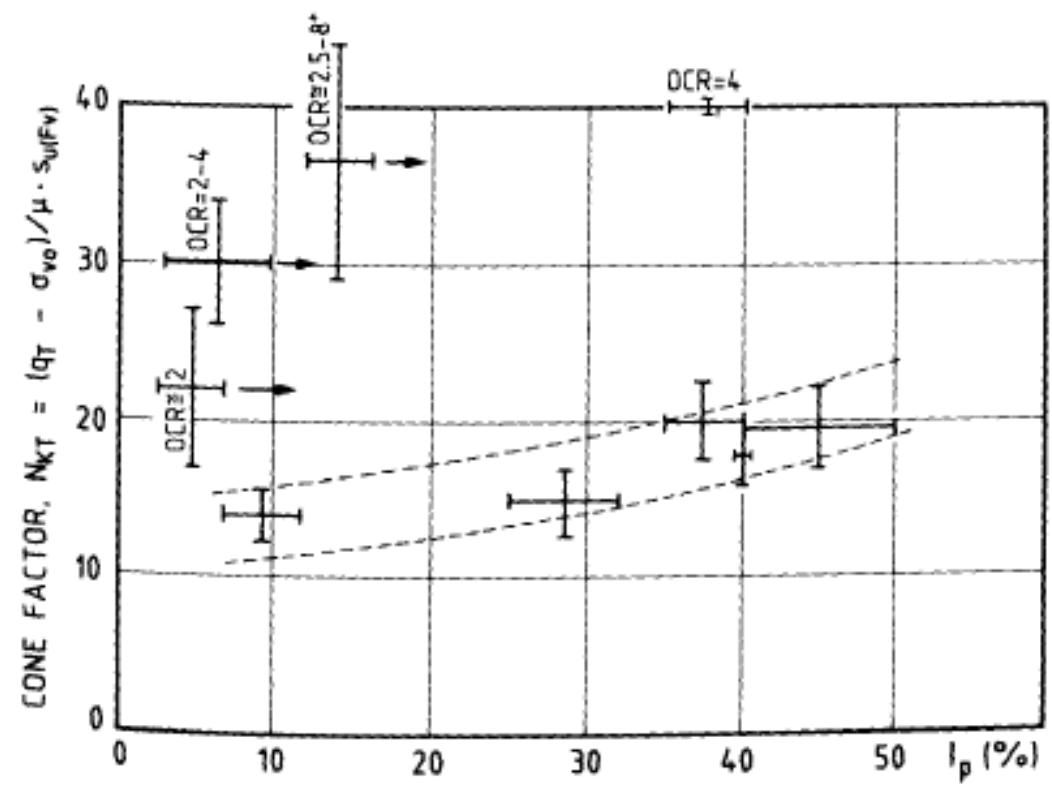

Figure 51 Correlations between cone factor $N_{k}$ and plasticity index (Aas et al., 1986)

\section{$\underline{5.3 \text { Influence of the rate of penetration on CPT }}$}

The standard rate for cone penetration tests is $2 \mathrm{~cm} / \mathrm{s}$ according to ASTM D 5778. This standard penetration rate is applied regardless of the soil type. Generally, it is assumed that drained behavior for clean sand prevails during penetration at standard penetration rates. Contrarily, undrained behavior is assumed to prevail for pure clay at the standard penetration rate. For intermediate soils which make up the majority of soils, partial drainage may occur at the standard penetration rate. When the drainage condition changes from undrained to partially drained, the soil ahead of the cone begins to consolidate. This consolidation induces an increase in soil strength and cone resistance. During penetration, the closer the conditions are to full drainage, the higher the value of cone resistance. This means the simplest idealized approach of a broad distinction between undrained and drained conditions for the interpretation of in-situ tests cannot be applied since test response can be affected by partial consolidation (Schnaid, 2005). The penetration rate strongly affects the value of cone penetration resistance. Therefore, 
drainage conditions at a certain penetration rate should be examined. If the drainage during CPT is not an undrained one when establishing a relationship between undrained shear strength and cone resistance, the CPT should be performed again at a rate of penetration that is sufficiently high to ensure undrained penetration.

Several research studies were conducted in order to investigate the rate effect of CPT. Roy et al. (1982) performed piezocone penetration tests in soft clays with 7 penetration rates whose range is between 0.5 and $40 \mathrm{~mm} / \mathrm{sec}$ (16). They argued that the increase of cone resistance at low penetration rates was due to the transition from undrained to drained penetration. Furthermore, Kamp (1982) investigated the comparison of cone resistances and friction resistances when the rate of penetration changes (17).

In addition to cone penetration rate, the coefficient of the soil is related to the drainage condition during cone penetration. Therefore, the terminology of the normalized penetration rate $V$ was suggested by several researchers in order to explain the rate effect of cone penetration tests. This value depends on the rate of penetration $v$, the coefficient of consolidation $c_{v}$, and the cone diameter $d$. An illustration is equation (17):

$$
V=\frac{v d}{c_{v}}
$$

Kim et al. (2006) performed a series of penetration tests in the field and in a calibration chamber using miniature cones and concluded that the change in drainage conditions during penetration is the main cause of the rate effects. The rate effects can be discussed separately for the undrained, partially drained and fully drained penetrations (See Figure 52):

1. Under fully drained penetration, cone penetration results are not affected by penet ration rate change $(V<0.05)$.

2. When drainage conditions change from undrained to partially drained penetration, the soil around the cone starts to consolidate as the cone advances. Therefore, con e resistance $q_{t}$ increases. However, the gain of soil strength due to increased drain age and loss of soil strength due to lower loading rates can compensate for each ot her. Therefore, the transition band is decided using excess pore pressure readings, and its range is $0.05<V<10$. 
3. Under undrained penetration, the undrained behavior of clay is rate-dependent. This is because clay soil has a viscous strength component $(V>10)$.

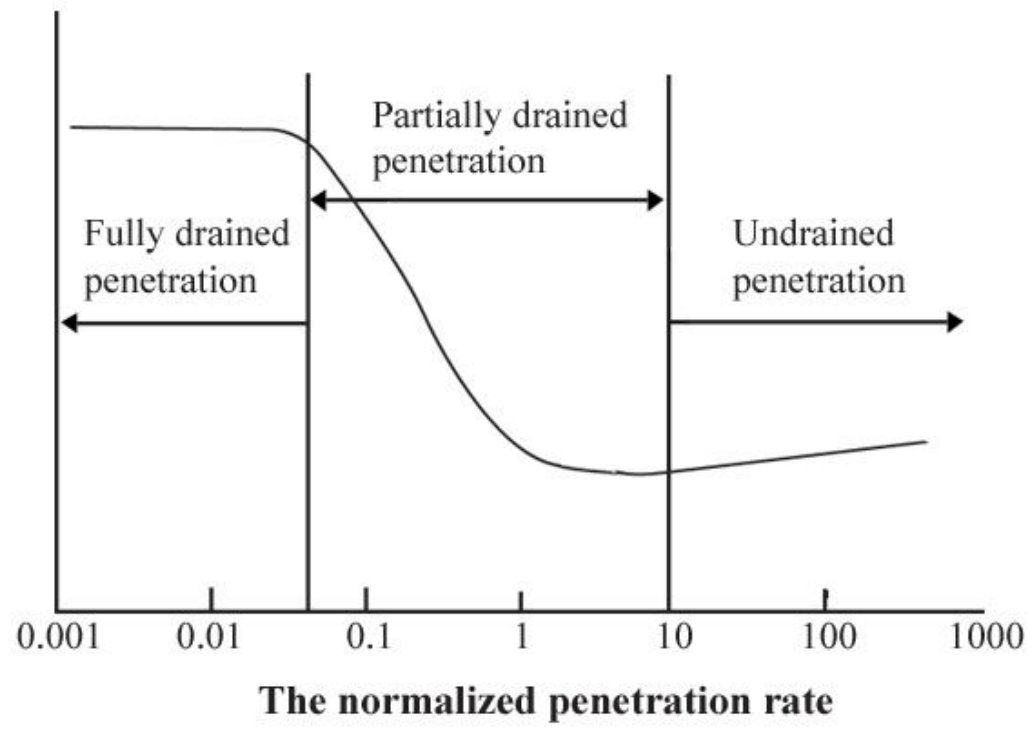

Figure 52 Effect of penetration rate on normalized cone resistance and pore pressure (Kim et al., 2006)

In this research, the rate effect for cone resistance has been examined to avoid overestimated or underestimated field test interpretation using results from Kim et al. (2006).

\section{$\underline{5.4 \text { Evaluation of Cone Factor }} N_{k}$}

As mentioned before, the estimation of undrained shear strength $S_{u}$ of cohesive soils using the cone resistance $q_{c}$ from the CPT is based on the cone factor $N_{k}$, as calculated by many researchers. Therefore, numerous researchers have tried to obtain values for $N_{k}$ from field cone penetration data and some of them have suggested that $N_{k}$ is related to the plasticity index $I_{p}$. 
In order to correlate $N_{k}$ and $I_{p}$ for clayey soils in Indiana, the cone penetration test program for clayey soils from 4 sites was performed. The drainage conditions considering the rate effect during CPTs have been examined with results from Kim et al. (2006). According to Kim et al's criterion, all the drainage conditions of soil samples fall within undrained penetration and are shown in Table 16.

The cone resistance $q_{c}$, the undrained shear strength $S_{u}$ and the overburden pressure $\sigma_{v}$ are calculated following the cone penetration test program; then, the cone factor $N_{k}$ is evaluated. Table 17 and Figure 55 show the cone factor $N_{k}$ and the plasticity index $I_{p}$ for clayey soils in Indiana. The cone factor $N_{k}$ values range from 8.0 to 13.4 (Kim et al., 2006). These results fall within the range of values reported in international literature (Lunne et al., 1997) and are comparable with the cone factor values from 8 to 25 for clays. In addition, these values show increasing trends and changes with a plasticity index from 8.0 at $I_{p}=7.9$ to 12.1 at $I_{p}=20.0$. As shown in Figure 53, these results are similar to the findings of Aas et al. (1986), while Lunne et al. (1976) and Baligh et al. (1980) show decreasing trends. Using the correlation between the cone factor and the plasticity index for clayey soils in Indiana in Figure 53, a localized equation $N_{k}=0.285 I_{p}+7.636$ with a correlation coefficient equal to 0.75 is suggested for estimating the cone factor. It must be mentioned that the results are dependent on the quantity and quality of data used. Therefore, it may not be possible to draw general conclusions. The analysis is meaningful as it indicates increasing trends of cone factor with plasticity index for clayey soils in Indiana. This equation should be implemented with more field data for more precise cone factor estimation. 
Table 16 Summary of drainage condition during CPT

\begin{tabular}{c|ccccc}
\hline & I-69 & SR-49(TB-9) & SR-49(TB-10) & SR-49(TB-11) & SR-49(TB-14) \\
\hline $\begin{array}{c}C_{v} \\
\left(\mathrm{~cm}^{2} / \mathrm{sec}\right)\end{array}$ & 0.002 & 0.007 & 0.03 & 0.005 & 0.004 \\
\hline $\mathrm{V}$ & 7112 & 2032 & 474 & 2844 & 3566 \\
\hline Drainage & Undrained & Undrained & Undrained & Undrained & Undrained \\
\hline OCR & 4.2 & - & - & - & - \\
\hline & & & & & \\
\hline & US-24 & US-31(RB-99) & US-31(RB-114) & US-31(RB-31) & \\
\hline $\begin{array}{c}C_{v} \\
(\mathrm{~cm} / \mathrm{sec})\end{array}$ & 0.02 & 0.0002 & 0.0007 & 0.0002 & \\
\hline V & 711 & 71120 & 20320 & 71120 & \\
\hline Drainage & Undrained & Undrained & Undrained & Undrained & \\
\hline OCR & 2.8 & 3.6 & 5.1 & 11.8 & \\
\hline
\end{tabular}


Table 17 Summary of cone factor $N_{k}$ and plasticity index $I_{p}$

\begin{tabular}{|c|c|c|c|c|c|}
\hline & $\mathrm{I}-69$ & SR-49(TB-9) & SR-49(TB-10) & SR-49(TB-11) & SR-49(TB-14) \\
\hline$q_{t}(\mathrm{kPa})$ & 700 & 2550 & 3600 & 1340 & 3550 \\
\hline$S_{u}(\mathrm{kPa})$ & 55.2 & 183 & 319 & 102 & 290 \\
\hline$\sigma_{v}(\mathrm{kPa})$ & 34 & 105 & 126 & 133 & 174 \\
\hline$N_{k}$ & 12.1 & 13.4 & 10.9 & 11.8 & 11.6 \\
\hline$I_{p}$ & 20.0 & 19.1 & 9.8 & 9.3 & 10.2 \\
\hline & US-24 & US-31(R & B-99) & 1(RB-114) & US-31(RB-31) \\
\hline$q_{t}(\mathrm{kPa})$ & 1620 & 600 & & 2720 & 4030 \\
\hline$S_{u}(\mathrm{kPa})$ & 120 & 65. & & 333 & 442 \\
\hline$\sigma_{v}(\mathrm{kPa})$ & 40 & 45 & & 45 & 58 \\
\hline$N_{k}$ & 13.2 & 8.5 & & 8.0 & 9.0 \\
\hline$I_{p}$ & 18.0 & 5.3 & & 7.9 & 4.8 \\
\hline
\end{tabular}




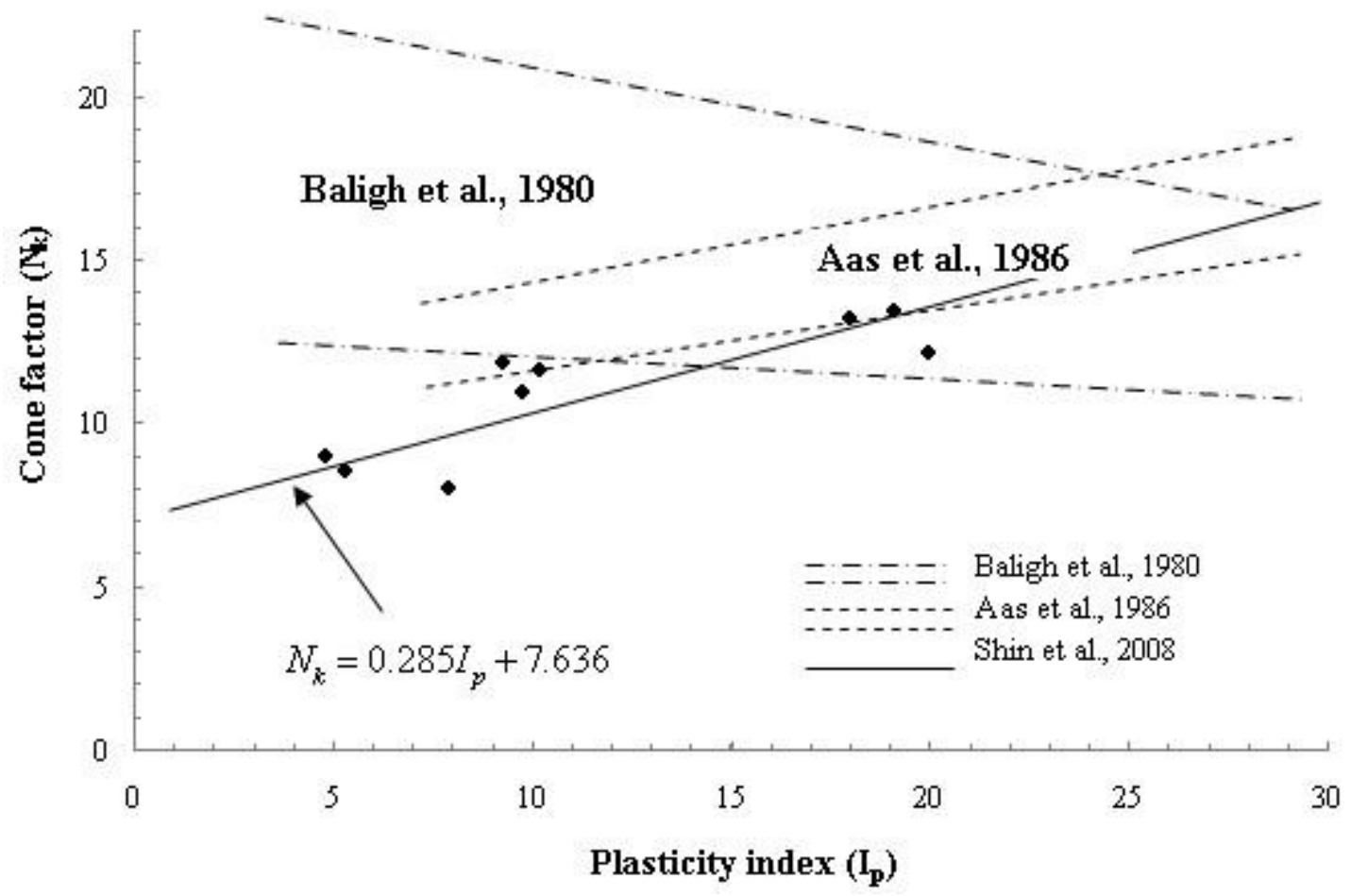

Figure 53 Correlation of factor $N_{k}$ and plasticity index $I_{p}$ 


\section{CHAPTER 6 CONCLUSIONS AND RECOMMENDATIONS}

\section{$\underline{6.1 \text { Conclusions }}$}

In this study, the empirical equation for cone factor with respect to the plasticity index for clayey soil in Indiana was suggested in order to correlate undrained shear strength and cone resistance from CPT results. Four field cone penetration test programs were conducted on 9 clayey soils: the CPT, the index tests, the one dimensional test, and the triaxial test. The following conclusions can be drawn from the study:

(1) The cone factor, which is essential to reliable estimation of undrained shear strength from cone resistance, is influenced by soil type, penetration rate during the CPT, and test methods for undrained shear strength.

(2) For most of the soils that are neither pure clay nor clean sand, partial drainage may occur at the standard penetration rate during the CPT. The standard penetration may induce partial consolidation in front of the cone and increase cone resistance.

(3) Drainage conditions at a certain penetration rate during CPT should be examined. If the drainage during CPT is not an undrained one when developing relationships with undrained shear strength, the CPT should be performed again at a rate of penetration that is sufficiently high to ensure undrained penetration.

(4) The undrained shear strength can vary with respect to test methods. Therefore, it is crucial to determine the proper evaluation method of undrained shear strength for the specific purpose of the project. In this paper, the isotropic consolidated undrained compression test (CIUC) was used.

(5) The results show increasing trends of cone factor with plasticity index similar to Aas et al. (1986), while Lunne et al. (1976) and Baligh et al. (1980) show decreasing trends.

(6) Based on the field cone penetration test program results, the empirical equation $N_{k}=0.285 I_{p}+7.636$ is suggested. 


\subsection{Recommendations for Future Research}

Future research on the topic of this report is suggested as follows:

(1) The empirical equation for cone factor with respect to the plasticity index for clayey soil in Indiana was suggested via this report. More data should be added for general correlation.

(2) This research focused on the influence of plasticity index on the cone factor. Some researchers insist that the over-consolidation ratio can be an affecting element in estimating cone factor. The influence of the over-consolidation ratio for CPT- based correlation needs to be studied. 


\section{LIST OF REFERENCES}

Aas, G., Lacasse, S., Lunne, T., and Hoeg, K. (1986). "Use of in situ tests for foundation design on clay,” Proceeding of In Situ '86: Use of In Situ Tests in Geotechnical Engineering, Virginia, pp. 1-30.

Ahmed, I. (1990). Investigation of normalized behavior of resedimented Boston blue clay using Geonor direct simple shear, M.S. Dissertation, Massachusetts Institute of Technology.

Aoki, N. and de Alencar, D. (1975). "An approximate method to estimate the bearing capacity of piles," Proceeding of the $5^{\text {th }}$ pan-American conference of soil mechanics and foundation engineering, Buenos Aires, Vol. 1, pp. 367-376.

Anagnostopoulous, A., Koukis, G., Sabatakis, N., and Tsiambaos, G. (2003). "Empirical correlations of soil parameters based on cone penetration test for Greek soils," Geotechnical and Geological Engineering, Vol. 21, pp. 377-387.

ASTM international (2004). Designation: D 2435: Standard Test Methods for OneDimensional Consolidation Properties of Soils Using Incremental Loading.

ASTM international (2004). Designation: D 4767: Standard Test Method for Consolidated Undrained Triaxial Compression Test for Cohesive Soils.

ASTM international (2007). Designation: D 5778: Standard Test Method for Electronic Friction Cone and Piezocone Penetration Testing of Soils.

Atkinson, J.H. and Bransby, P.L. (1978). The mechanics of soils, McGraw Hill.

Baligh, M.M., Vivatrat, V., and Ladd, C.C. (1980). "Cone penetration in soil profiling," Journal of the Geotechnical Engineering Division, Vol. 106, No. 4, pp. 447-461.

Bishop, A.W. and Henkel, D.J. (1962). The measurement of soil properties in the triaxial test, Edward Arnold.

Bowles, J.E. (1982). Foundation analysis and design, McGraw Hill. 
Burland, J.B. (1990). "On the compressibility and shear strength of natural clays," Geotechnique, Vol. 40, No. 3, pp. 329-378.

Burland, J.B., Rampello, S., Georgiannou, V.N., and Calabresi, G. (1996). “A laboratory study of the strength of four stiff clays," Geotechnique, Vol. 46, No. 3, pp. 491514.

Bustamante, M. and Gianeselli, L. (1982). "Pile bearing capacity predictions by means of static penetrometer CPT," Proceeding of $2^{\text {nd }}$ European Symposium on Penetration Testing, Amsterdam, pp. 493-500.

Jamiolkowski, M, Lancellotta, R., Tordella, L., and Battaglio, M. (1982). "Undrained strength from CPT," Proceeding of 2nd European Symposium on Penetration Testing, Amsterdam, pp. 599-606.

Jardine, R., Chow, F., Overy, R., and Standing, J. (2005). ICP design methods for driven piles in sands and clays, Thomas Telford.

Kamp, W.G.B. (1982). "The influence of the rate of penetration on the cone resistance in sand," Proceeding of $2^{\text {nd }}$ European Symposium on Penetration Testing, Amsterdam, pp. 627-633.

Kim, K.K., Prezzi, M., and Salgado, R. (2006). "Interpretation of cone penetration tests in cohesive soils,” Research No. FHWA/IN/JTRP-2006/22 Final report, Indiana Department of Transportation.

Ladd, C.C., Kraemer, Young, G.A., Kraemer, S.R., and Burke, D.M. (1999)."Engineering properties of Boston blue clay from special testing program," Proceeding of sessions of Geo-Congress 98, pp. 1-24.

La Rochelle, P., Zebdi, P.M., Leroueil, S., Tavenas, F., and Virely, D. (1988).“Piezocone tests in sensitive clays of Eastern Canada," Proceeding of 1st International Symposium on Penetration Testing, Orlando, pp. 831-841.

Leonards, G.A. and Ramiah, B.K. (1959).“Time effects in the consolidation of clay," ASTM special technical publication, No. 254, pp. 116-130.

Lunne, T., Eide, O., and de Ruiter, J. (1976). "Correlation between cone resistance and vane shear strength in some Scandinavian soft to medium stiff clays," Canadian Geotechnical Journal, Vol. 13, No. 4, pp. 430-441. 
Lunne, T., Eidsmoen, T., Gillespie, D., and Howland, J.D. (1986). "Laboratory and field evaluation of cone penetrometer," Proceeding of In Situ `86: Use of In Situ Tests in Geotechnical Engineering, Virginia, pp. 714-729.

Lunne, T. and Kleven, A. (1981) "Role of CPT in North Sea foundation engineering," Symposium on Cone Penetration Engineering Division, ASCE, pp. 49-75.

Lunne, T., Robertson, P.K., and Powell, J.J.M. (1997). Cone penetration testing in geotechnical practice, Blackie Academic Professional.

Mayne, P.W., Auxt, J.A., Mitchell, J.K., and Yilmaz, R. (1995). U.S. national report on CPT, Proceeding of International Symposium on Penetration Testing, Linkoping, pp. 263-276.

Mesri, G. and Huvaj, N. (2007). "Shear strength mobilized in undrained failure of soft clay and silt deposits," Proceedings of Sessions of Geo-Denver 2007 Congress: Advances in Measurement and Modeling of Soil Behavior, Denver, pp. 1-22.

Nash, D.F.T. and Duffin, M.J. (1982). "Site investigation of glacial soils using cone penetration tests," Proceeding of 2nd European Symposium on Penetration Testing, Amsterdam, pp. 733-738.

Olsen, R.E. and Dennis, N.D. (1982). Review and compilation of pile test results, O`riordan, N.J., Davies, J.A., and Dauncey, P.C. (1982). "The interpretation of static cone penetrometer tests in soft clays of low plasticity," Proceeding of 2nd European Symposium on Penetration Testing, Amsterdam, pp. 755-760.

Price, G and Wardle, I.F. (1982). "Comparison between cone penetration test results and the performance of small diameter instrumented pile in stiff clay" Proceeding of 2nd European Symposium on Penetration Testing, Amsterdam, pp. 775-780.

Rad, N.S. and Lunne, T. (1988). "Direct correlations between piezocone test results and undrained shear strength of clay," Proceeding of $1^{\text {st }}$ International Symposium on Penetration Testing, Orlando, pp. 911-917.

Randolph, M.F. and Murphy, B.S. (1985). "Shaft capacity of driven piles in clay," Proceeding of $17^{\text {th }}$ offshore technology conference, Houston, pp. 371-378.

Robertson, P.K., Campanella, R.G., and Wightman, A. (1983). "SPT-CPT correlations," Journal of Geotechnical Engineering, Vol. 109, No. 11, pp. 1449-1459. 
Roy, M., Tremblay, M., Tavenas, F., and La Rochelle, P. (1982). "Development of pore pressures in quasi-static penetration tests in sensitive clay," Canadian Geotechnical Journal, Vol. 19, No. 2, pp. 124-138.

Salgado, R. (2007). The engineering of foundations, McGraw Hill.

Santagata, M. (1998). Factors affecting the initial stiffness and stiffness degradation of cohesive soils, Ph.D. Dissertation, Massachusetts Institute of Technology.

Schnaid, F. (2005). "Geo-characterization and properties of natural soils by in situ tests," Ground Engineering, Vol. 38, No. 9, pp. 23-24.

Schmertmann, J.H. (1978). "Guideline for cone penetration test," Research No. FHWA/TS/-78-209, U.S. Department of Transportation.

Sheahan, T.C. (1991). An experimental study of the time-dependent undrained shear behavior of resedimented clay using automated stress-path triaxial equipment, Sc.D. Dissertation, Massachusetts Institute of Technology.

Stark, T.D. (1989). "Undrained shear strength fro cone penetration tests," Proceeding of $12^{\text {th }}$ International conference on soil mechanics and foundation engineering, Rio de Janeiro, pp. 327-330.

Tomlinson, M.J. (1975). Foundation analysis and design, Pitman, London.

Zevgolis, I. and Bourdeau, P. (2005). "Mechanically stabilized earth wall abutments for bridge support," Research No. F HWA/IN/JTRP-2006/38 Final report, Indiana Department of Transportation. 
APPENDICES 
Appendix A: Triaxial Test Results of Project Soils

This chapter presents the triaxial test results of all the soils used in the project - I-69, US-

24, RB-99(US-31), RB-114(US-31) and RB-31(US-31).
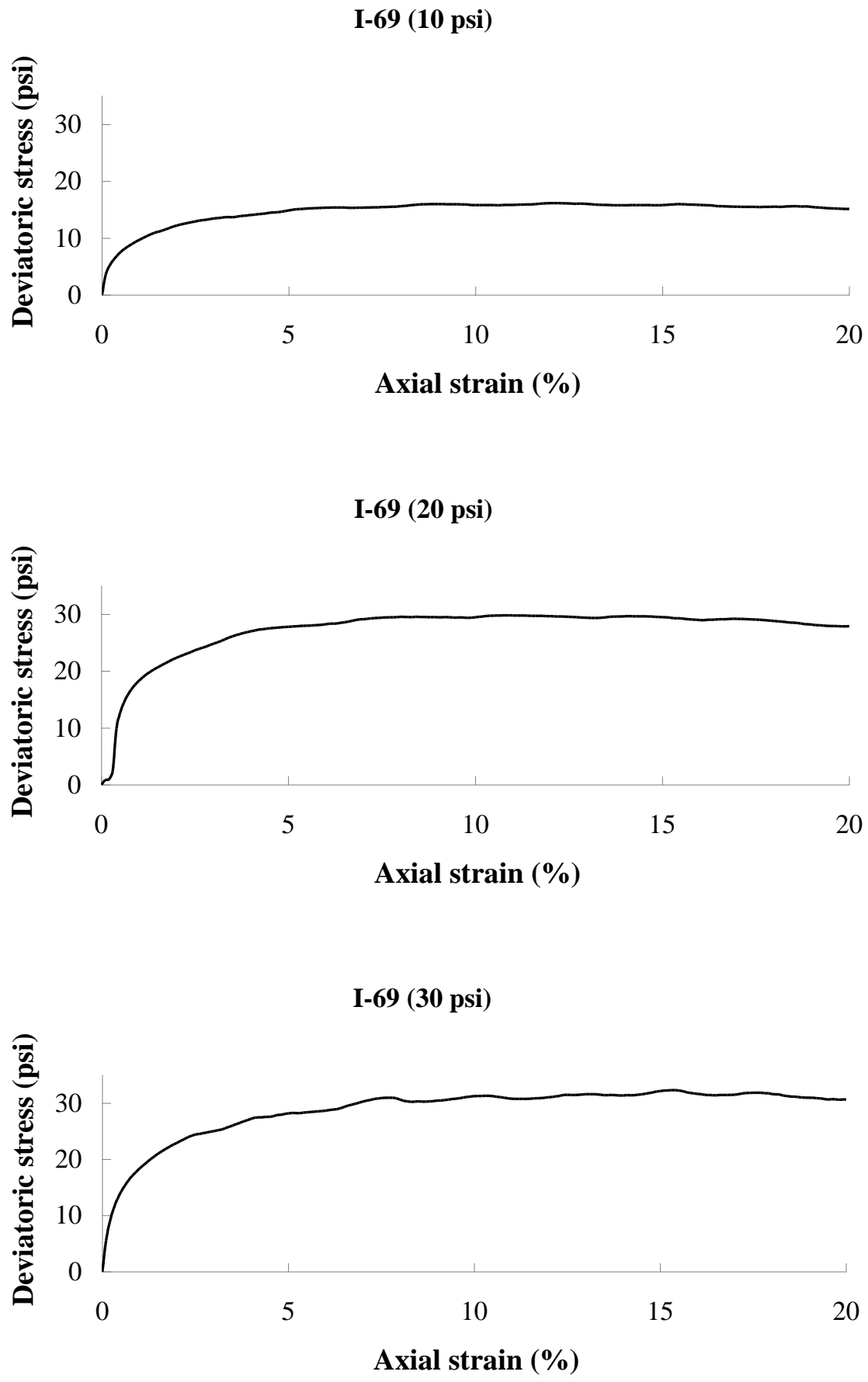

Figure 54 Stress-strain curve for I-69 
I-69 (10 psi)

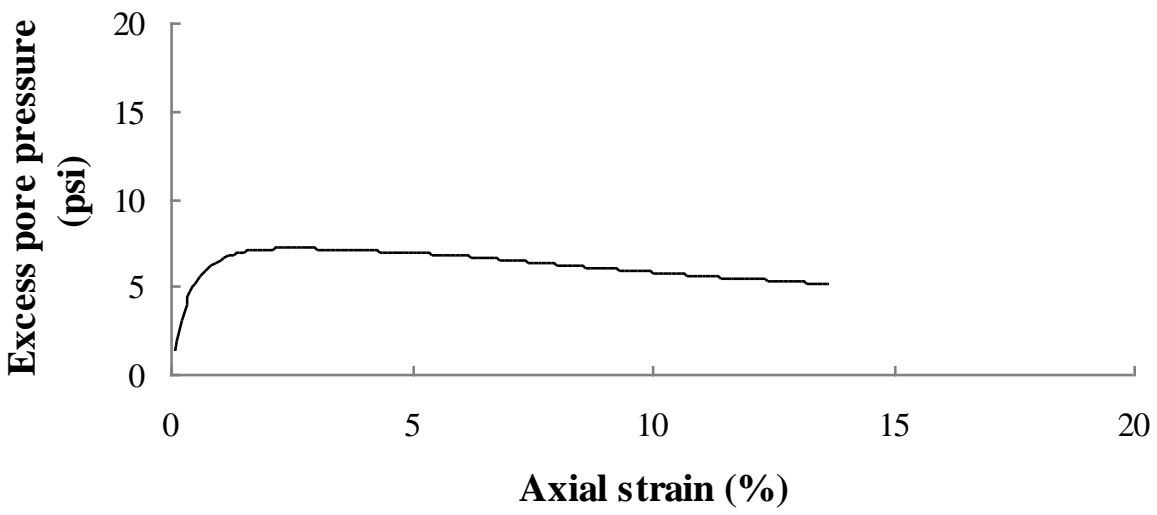

I-69 (20 psi)

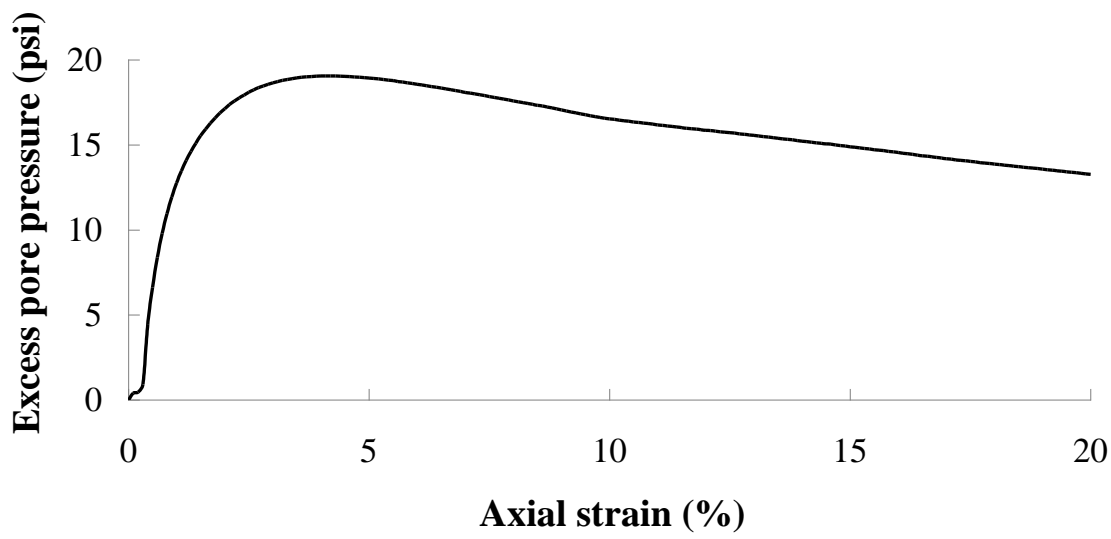

I-69 (30 psi)

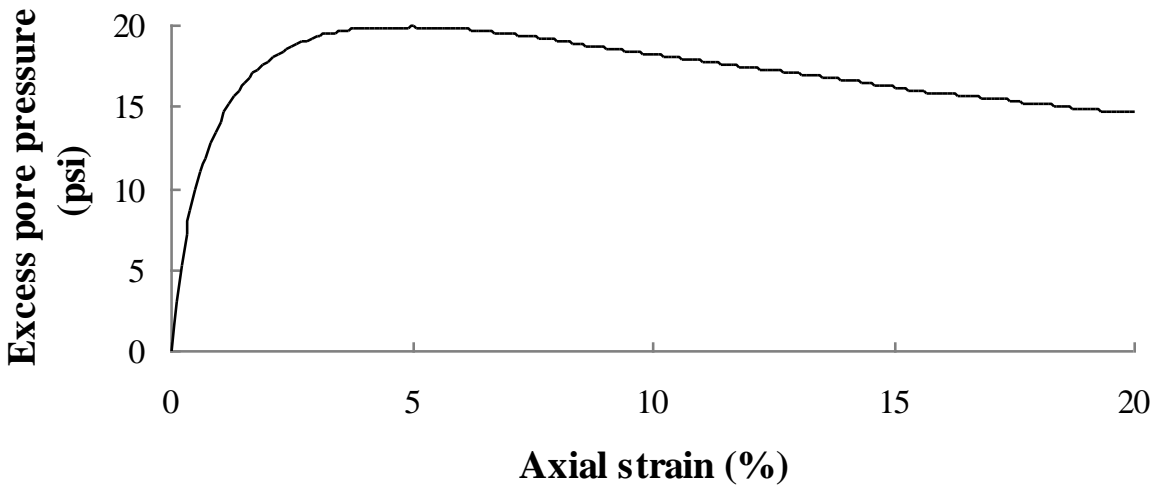

Figure 55 Excess pore pressure distribution for I-69 

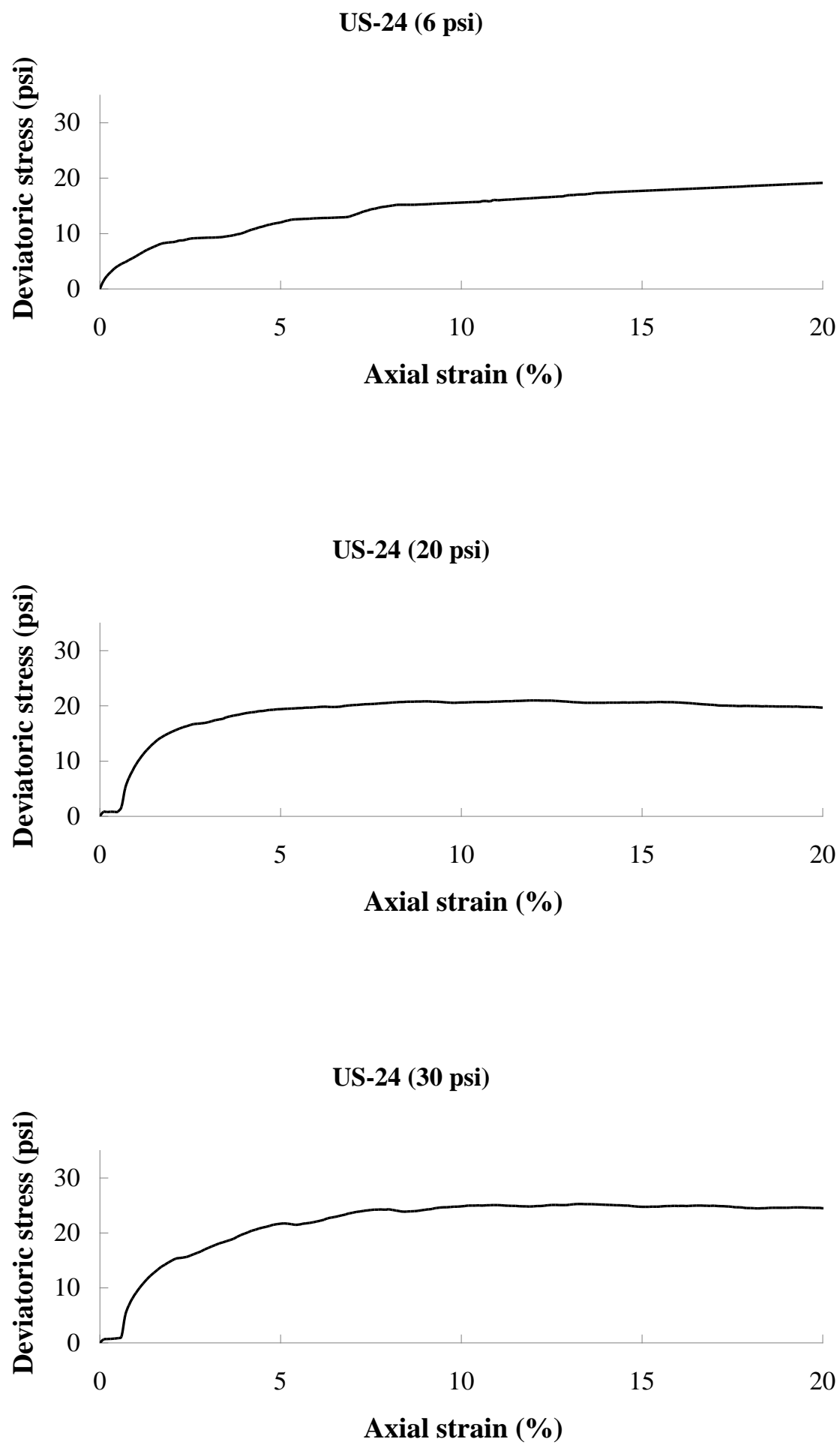

Figure 56 Stress-strain curve for US-24 


\section{US-24 (6 psi)}

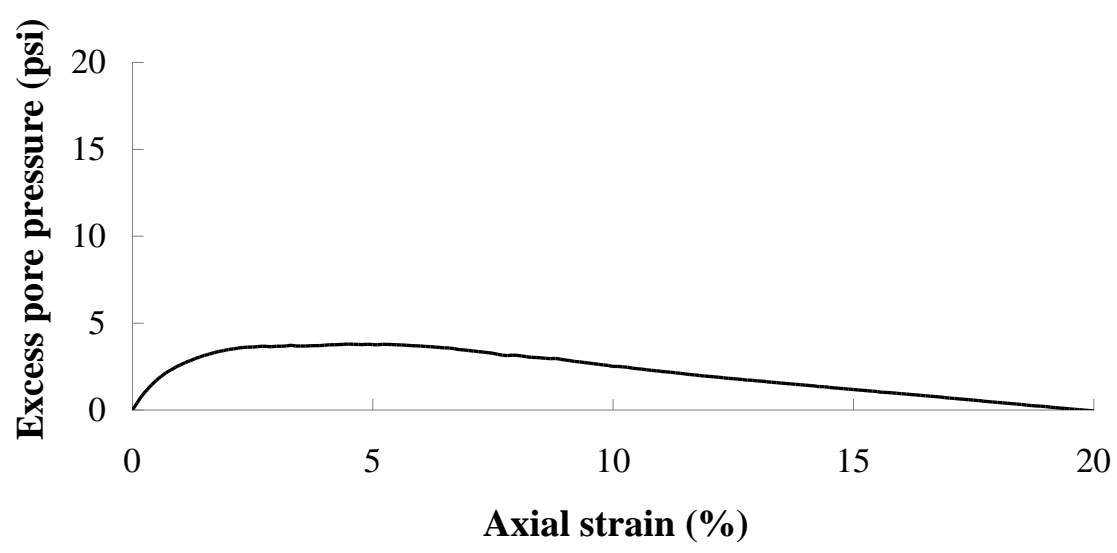

US-24 (20 psi)

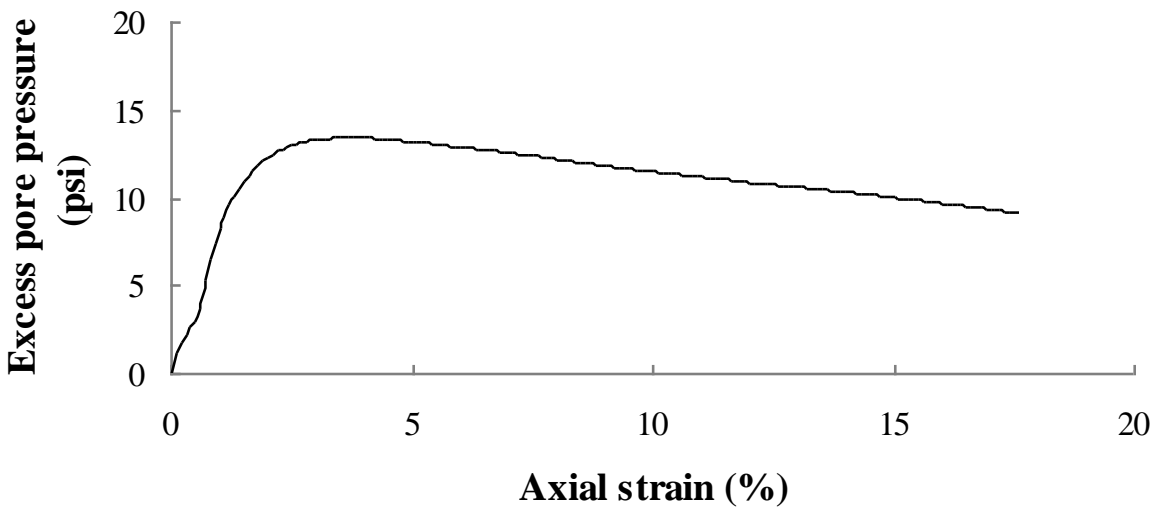

US-24 (30 psi)

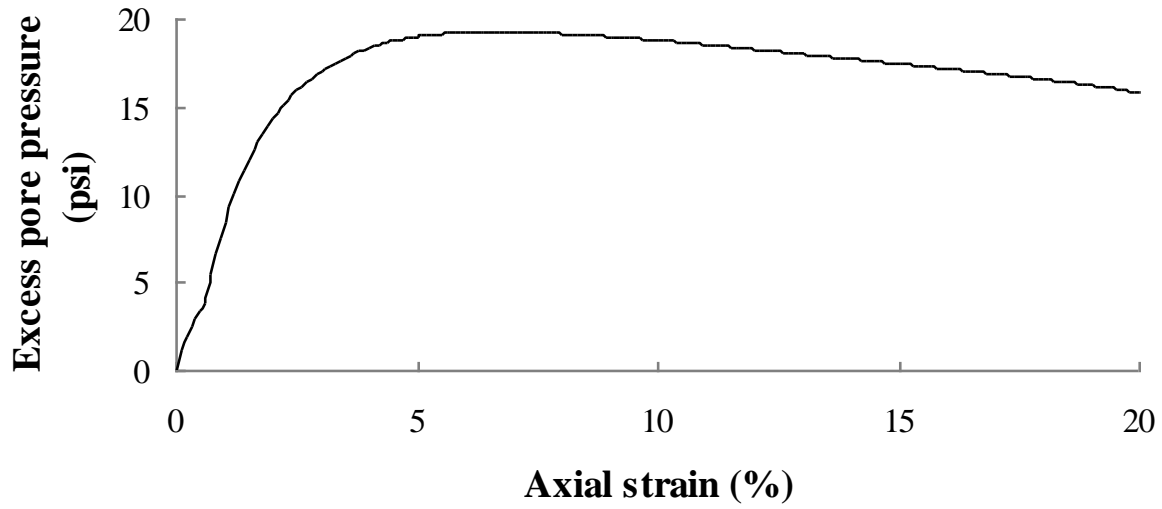

Figure 57 Excess pore pressure distribution for US-24 

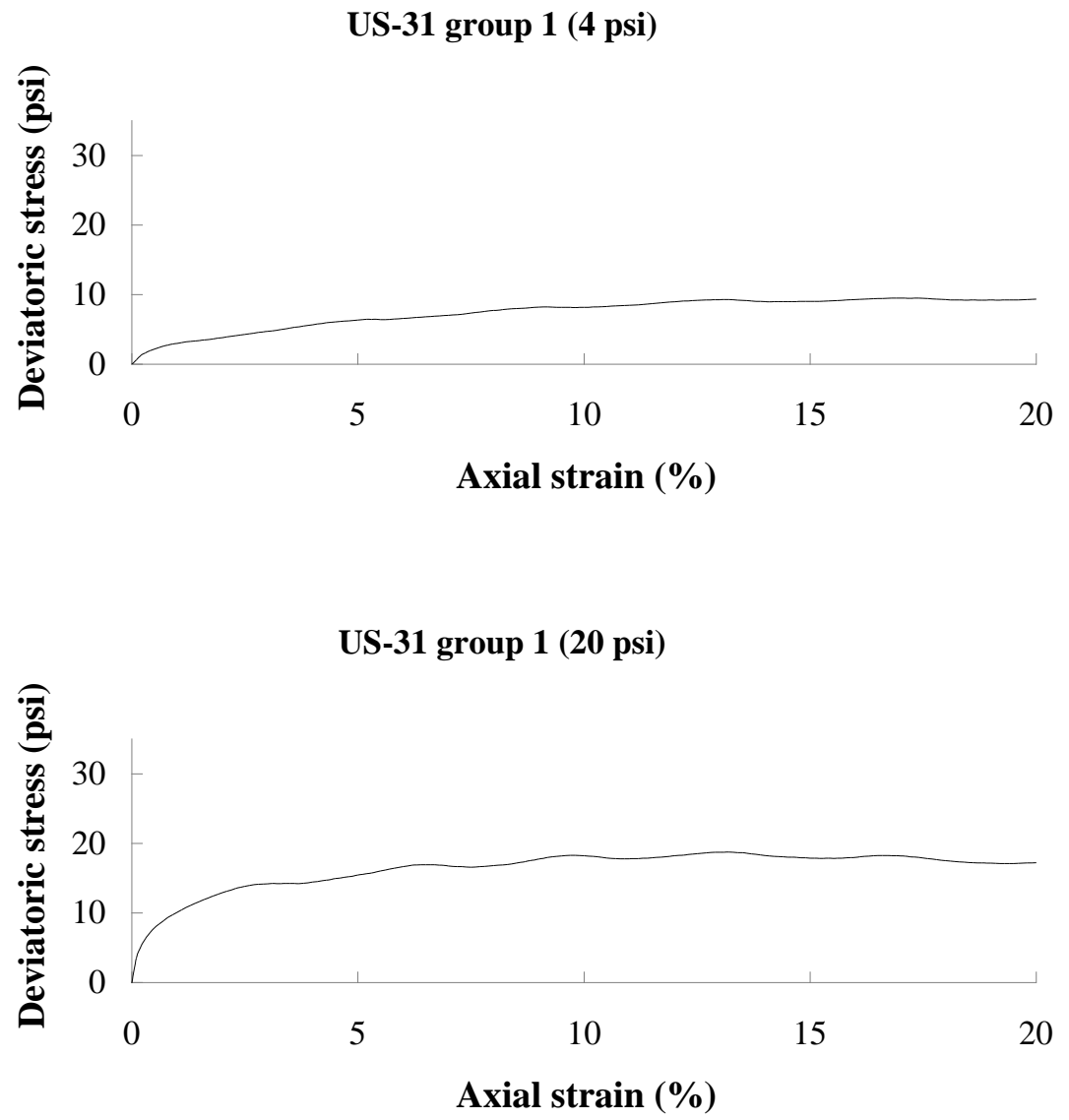

Figure 58 Stress-strain curve for RB-99(US-31)

US-31 group 1 (4 psi)

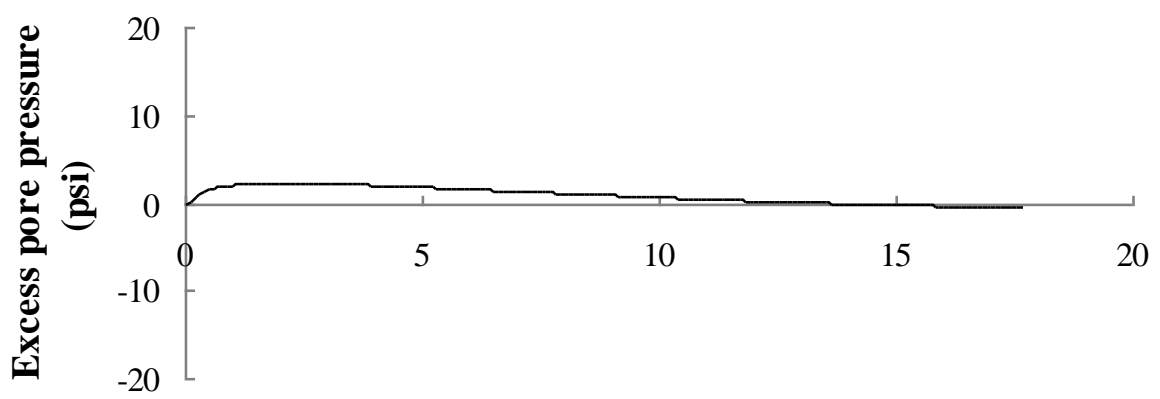

Axial strain (\%) 


\section{US-31 group 1 (20 psi)}

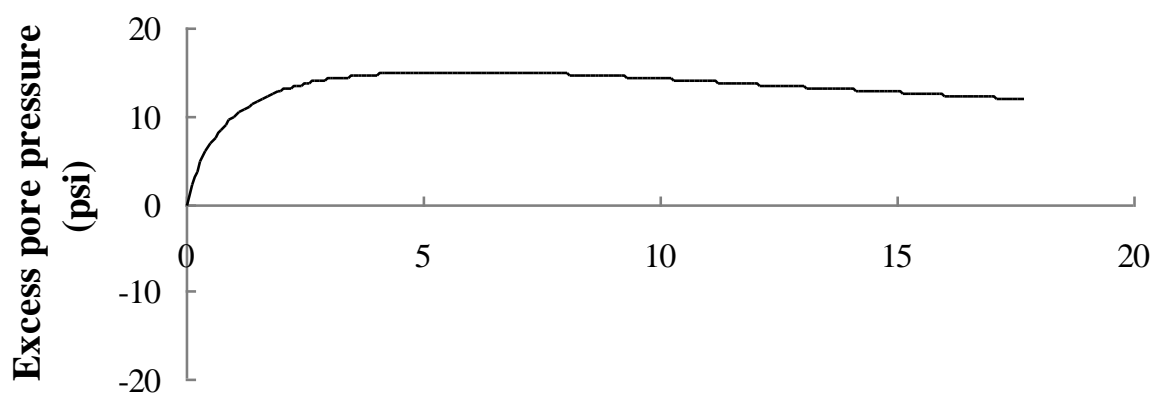

Axial strain (\%)

Figure 59 Excess pore pressure distribution for RB-99(US-31)
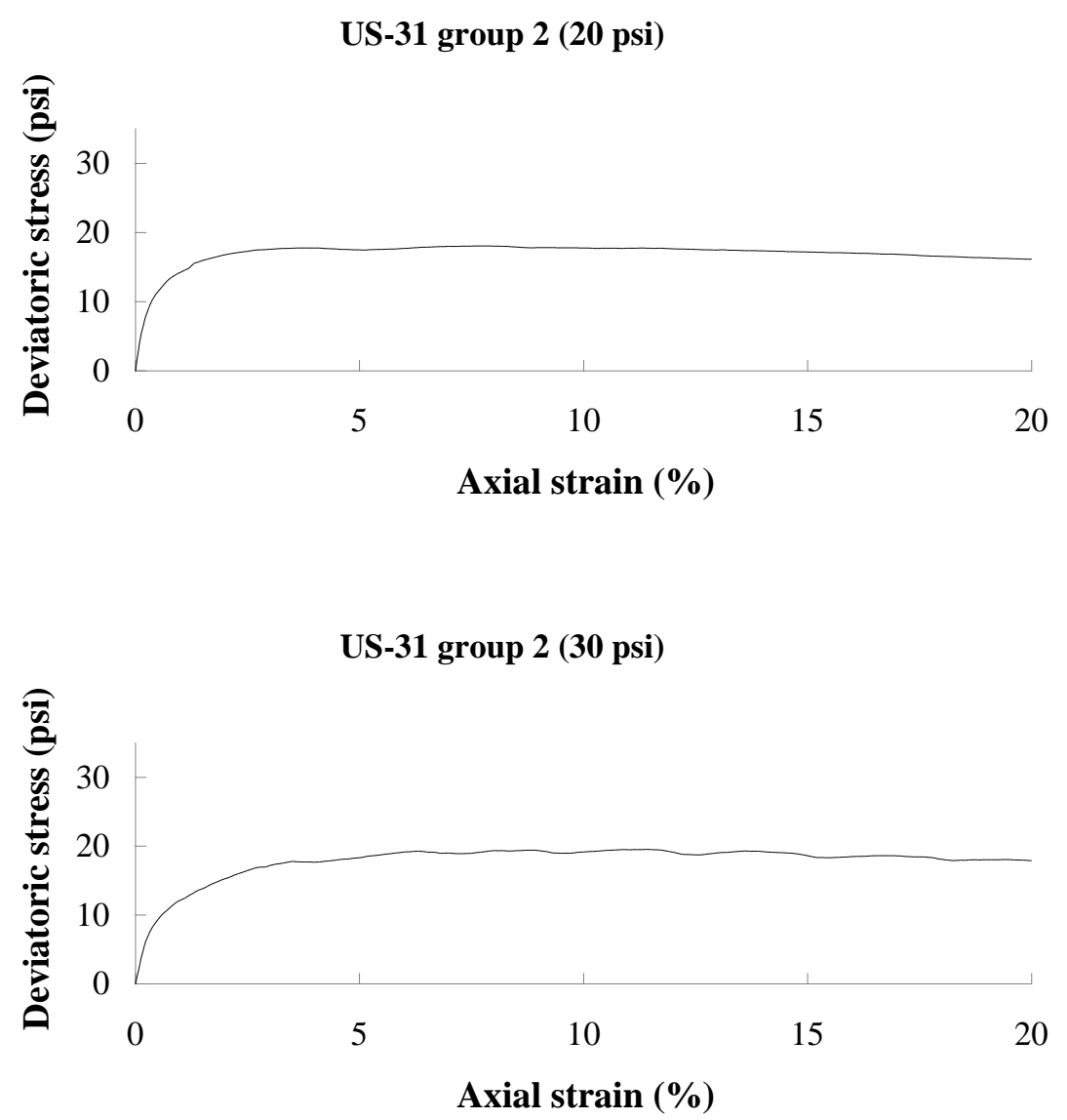

Figure 60 Stress-strain curve for RB-114(US-31) 


\section{US-31 group 2 (20 psi)}

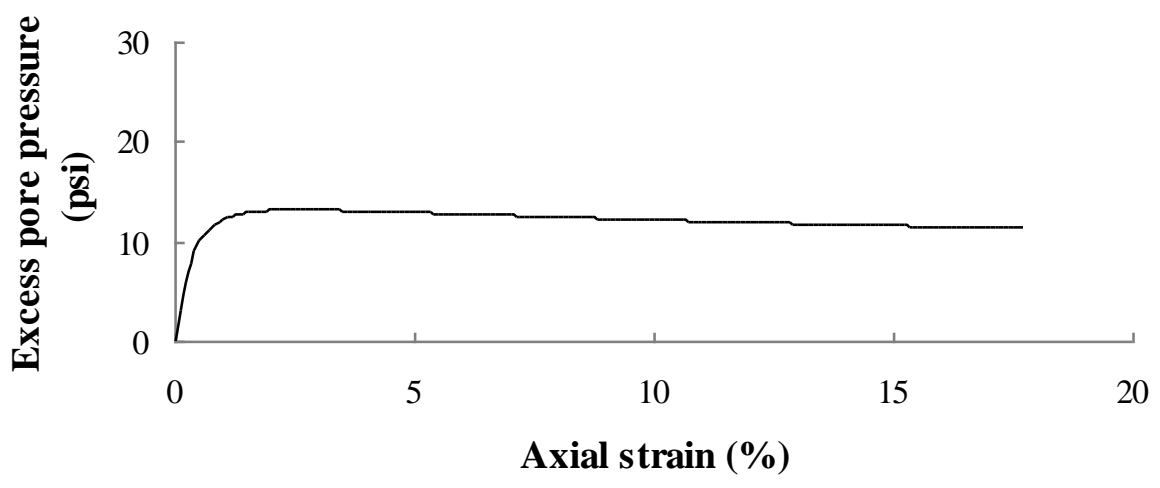

US-31 group 2 (30 psi)

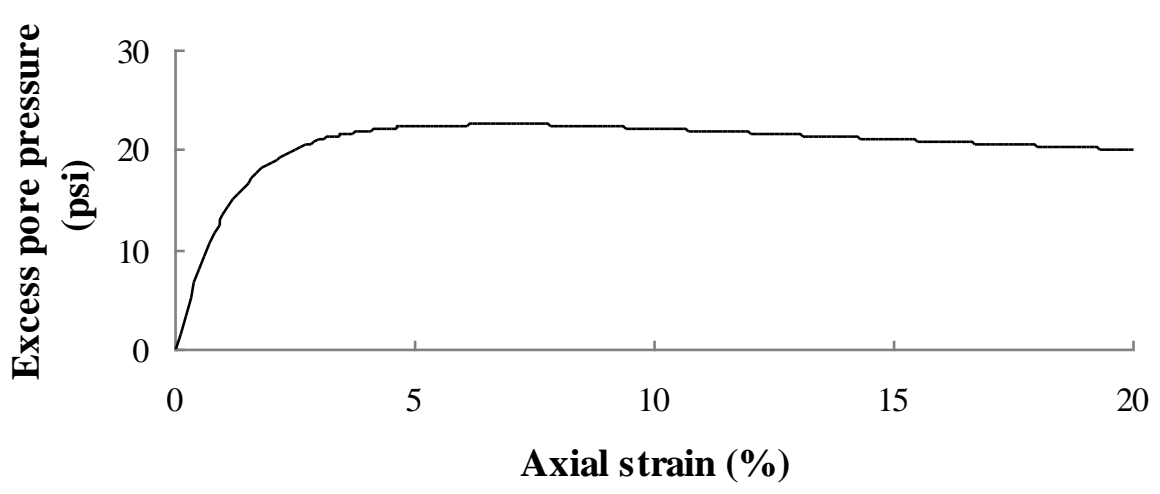

Figure 61 Excess pore pressure distribution for RB-114(US-31)

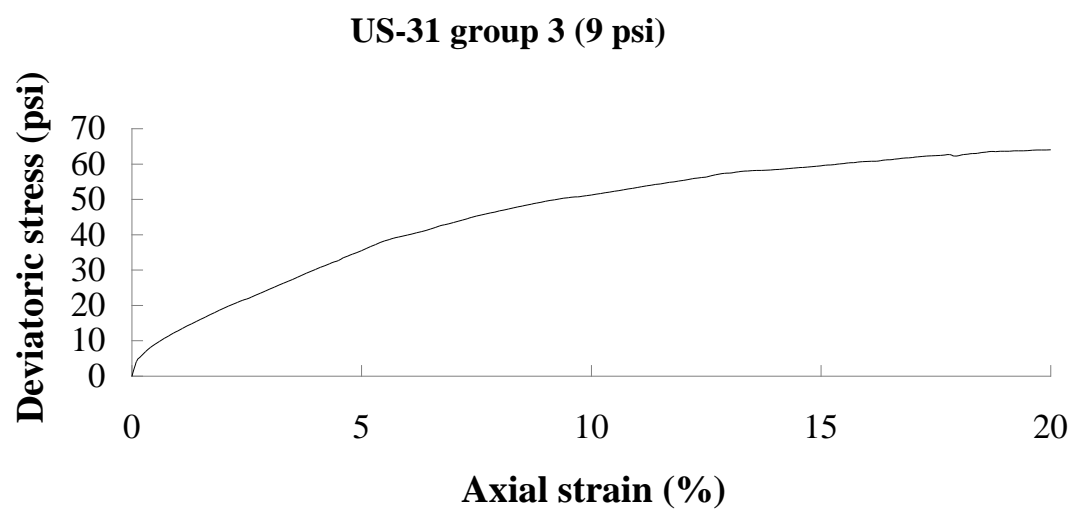

Figure 62Stress-strain curve for RB-31(US-31). 


\section{US-31 group 3 ( 9 psi)}

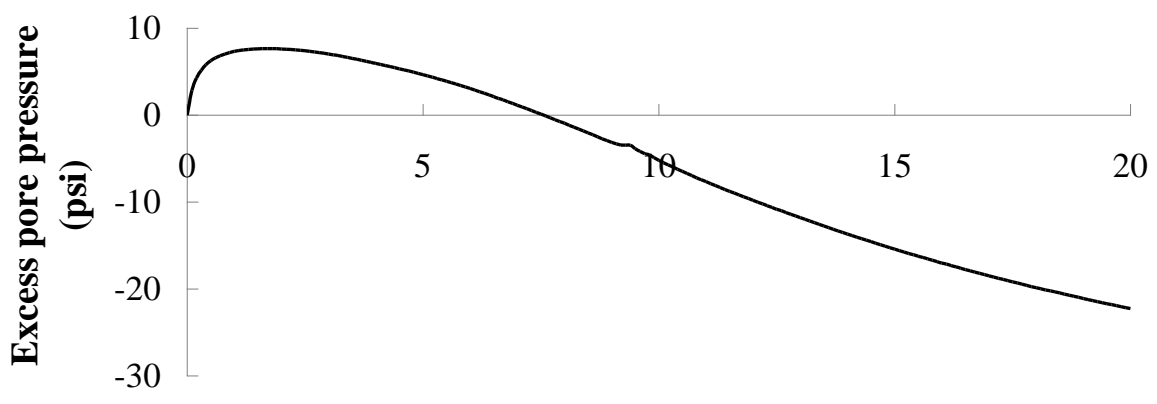

Axial strain (\%)

Figure 63 Excess pore pressure distribution for RB-31(US-31). 